Portland State University

PDXScholar

$1-1-2011$

\title{
Electronic Pillbox Logger for people with Parkinson's Disease
}

\author{
Beenish Zia \\ Portland State University
}

Follow this and additional works at: https://pdxscholar.library.pdx.edu/open_access_etds Let us know how access to this document benefits you.

\section{Recommended Citation}

Zia, Beenish, "Electronic Pillbox Logger for people with Parkinson's Disease" (2011). Dissertations and Theses. Paper 189.

https://doi.org/10.15760/etd.189

This Thesis is brought to you for free and open access. It has been accepted for inclusion in Dissertations and Theses by an authorized administrator of PDXScholar. Please contact us if we can make this document more accessible: pdxscholar@pdx.edu. 
Electronic Pillbox Logger for people with Parkinson's Disease

by

Beenish Zia

A thesis submitted in partial fulfillment of the requirements for the degree of

\author{
Master of Science \\ in \\ Electrical and Computer Engineering
}

Thesis Committee:

James McNames, Chair

Douglas V. Hall

Mark Faust

Portland State University

(C)2011 


\begin{abstract}
Parkinson' Disease (PD) is a motor disorder characterized by rigidity, tremor, and hypokinesia with secondary manifestations like defective posture and gait, mask like face and dementia. Over the years it may lead to inability to move, breath and ultimately patient may succumb to chest infection and embolism. Prevalence studies show that more than six million people around the world suffer from PD. At present, there is no cure for PD but there are effective treatments that can slow the progression of the disease and regulate its affects.
\end{abstract}

PD results from a deficiency of dopamine so most drugs that produce a salutary effect in PD either potentiate dopamine or work as dopamine agonists. Hence, to keep the symptoms of PD to a minimum it is very important that the medications be consumed regularly, so that the dopamine level is maintained in the body of the subject. Electronic pillbox logger is a device that has been designed to ensure this very much required medication adherence in PD subjects, which can also be used to measure the response to oral medication.

This work describes the design and implementation of an electronic pillbox logger for use by people suffering from Parkinson's disease (PD). The pillbox logger is designed to track medication adherence and prompt the user to take medication on time. It is pocketsized, portable, and compartmented. It has a variety of alarm systems to remind the user to take the correct dose of their medication at the correct time. Most importantly, it keeps an electronic log of the time of dosage consumption by detecting the presence/absence of 
pills in the pillbox. This overcomes major limitations of other pillboxes with a logging function that are often too large to carry, contain a single compartment, or only record the time the container was opened rather than the presence or absence of pills.

The proposed pillbox logger complements a wearable device under development for people with Parkinson's disease that continuously monitors impaired movement. The combination of the pillbox logger with the wearable sensor will permit clinicians to determine the response to oral therapies, which can be used to optimize therapy. People with PD consume similar pills throughout the day hence the pillbox logger has been designed to detect the presence/absence of pills in general in the pillbox rather than which specific pills are absent or present in the pillbox logger. This feature of the current design that the device records knowledge about pills in general in the pillbox logger and not about any specific pills is a major reason why the current design is specific to PD subjects only. However, though the current design of the pillbox logger is designed for people with Parkinson's Disease, the pillbox is suitable for other maladies in which the timing of the medication is critical.

The described pillbox logger was built and the design was validated after running a number of tests. The battery powered pillbox logger is able to accurately store the information about the actual presence/absence of pills in each compartment of the pillbox. It is capable of sending out reminder alarms at the right time of the day and can be connected to a host computer using a USB cable to read the stored information from it. The proper functional working of the pillbox logger after thorough testing proves that the design of pillbox logger was successful. 


\section{Dedication}

This thesis is dedicated to my mother and sister who have constantly supported me, guided me and have always been there for me. It is also dedicated to Dr. Abdul Qayum without whose generous donation to the PSU Foundation I would have never made it to Portland State University. 


\section{Acknowledgments}

It has been a great pleasure for me to do my thesis work at the Department of Electrical and Computer Engineering, Maseeh College of Engineering and Computer Science, Portland State University.

I wish to express my gratitude to all the people who were a part of this work in numerous ways. I would in particular like to thank my advisor Dr. James McNames, who gave me the opportunity to work on such an interesting topic and aided me to complete it with full understanding. Additional thanks are due to Andrew Greenberg and Tim Brandon for their tremendous help and to Joshua Booren for his assistance as well as to Dr. Douglas V. Hall and Prof. Mark Faust for serving on my thesis committee.

I am heartily thankful to everyone who has directly and indirectly contributed to my work. 


\section{CONTENTS}

Abstract

Dedication

Acknowledgements iv

List of Tables viii

$\begin{array}{ll}\text { List of Figures } & \text { ix }\end{array}$

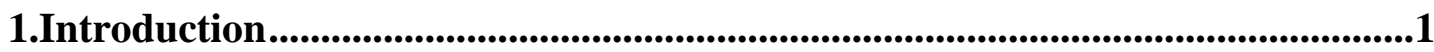

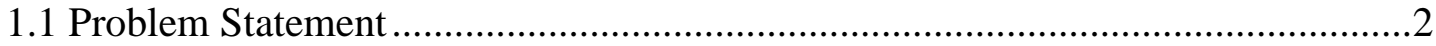

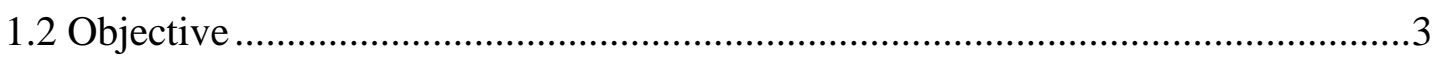

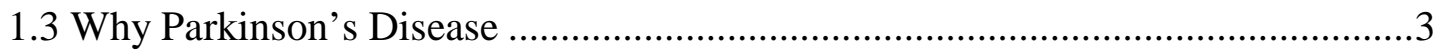

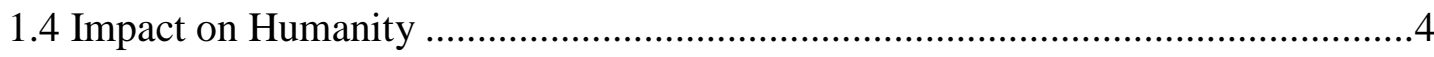

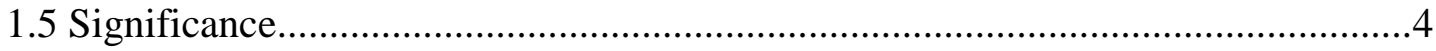

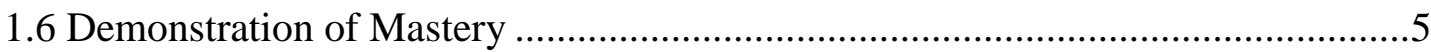

2. Existing Technologies and Literature Review...................................................6

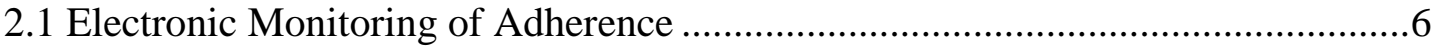

2.1.1 Medication Event Monitoring System (MEMS) ......................................

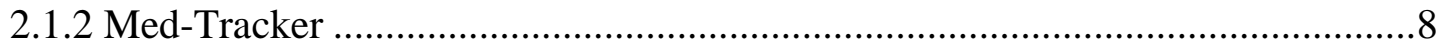

2.1.3 Eye drop medication monitor........................................................... 11

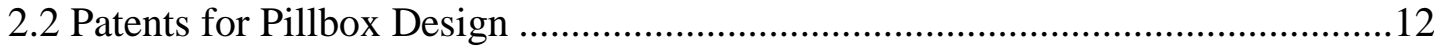

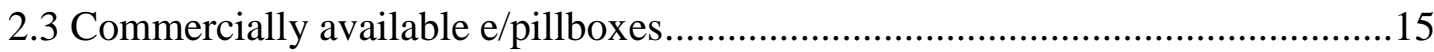

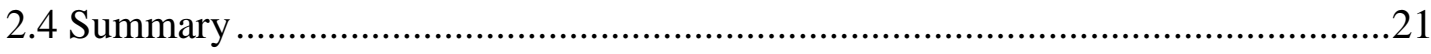




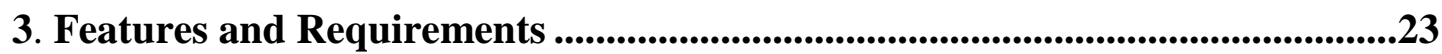

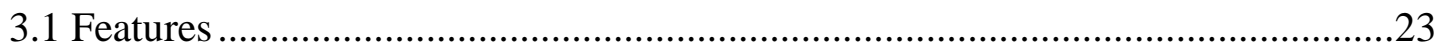

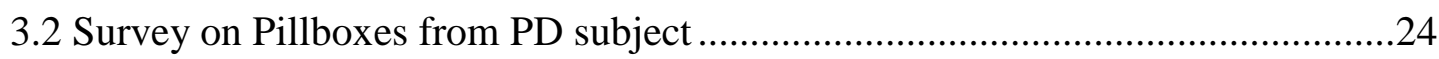

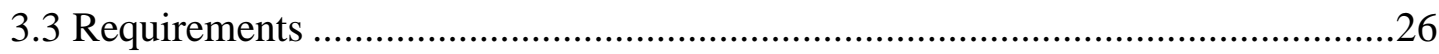

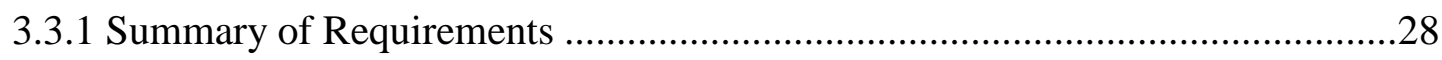

4. Design ......................................................................................................................................29

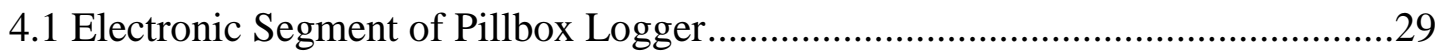

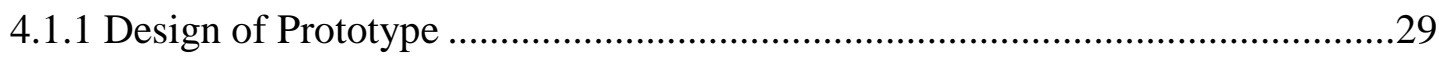

4.1.2 Design of Printed Circuit Board (PCB) …………..........................................50

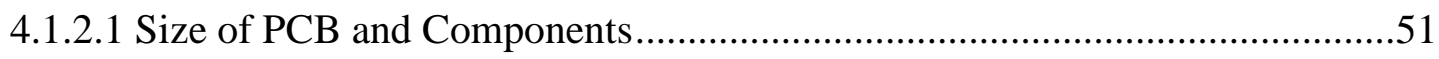

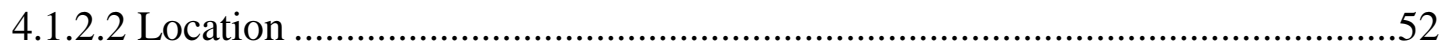

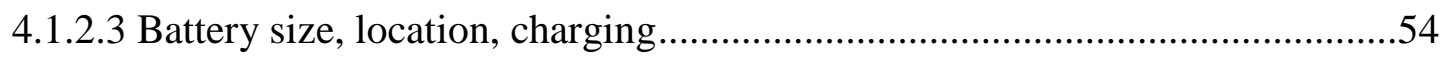

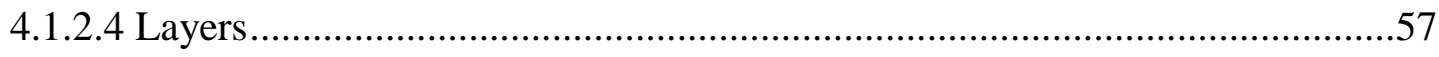

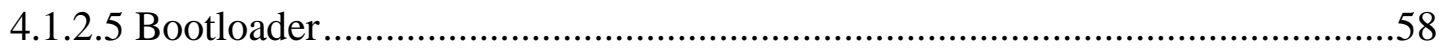

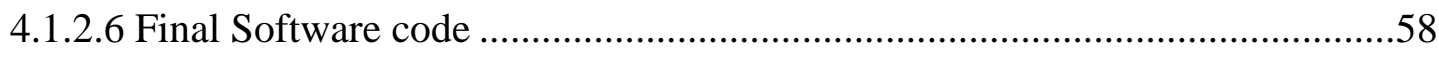

4.2 Mechanical Section.....................................................................................64

5. Validation and Verification..............................................................................................70

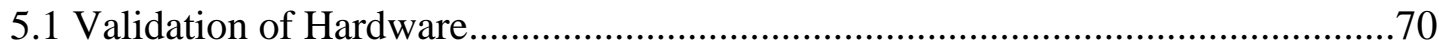

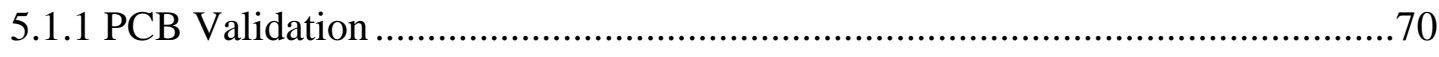

5.1.2 Validation of Mechanical model of pillbox logger............................................72

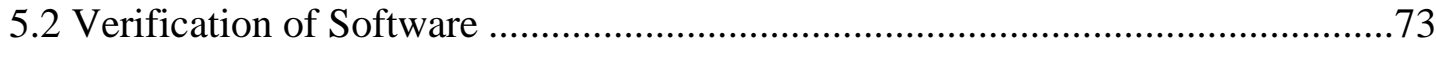

5.2.1 Bootloader Verification ……………..........................................................73

5.2.2 Pillbox logger Arduino Code verification .......................................................73 
5.3 Summary of Validation and Verification.

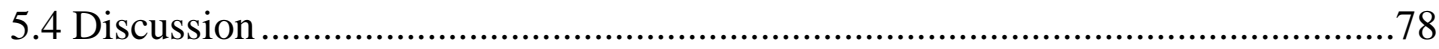

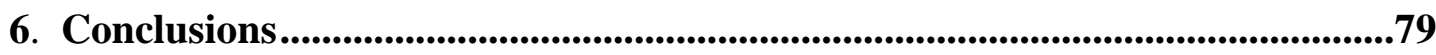

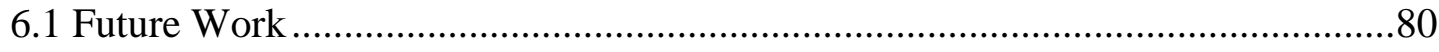

$\begin{array}{ll}\text { References } & 82\end{array}$

Appendix Components used on the PCB and their corresponding functions 88 


\section{List of Tables}

2.1 Table comparing some of the features of few of the existing pillboxes to that of the

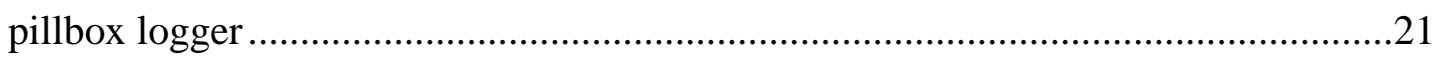

3.1 Survey results from PD subjects on pills and pillboxes....................................25

4.1 Score table for comparing different features between PIC and AVR microcontroller

5.1 Summary table for different validation and verification tests ............................77 


\section{List of Figures}

2.1 MEMS 2 monitor, with LCD display cap ................................................

2.2 7-day pill organizer used in Med-Tracker .................................................

2.3 The Med-Tracker device (Outside and internals of the device) .......................10

2.4 Side view of the Med-Tracker prototype ................................................... 11

2.5 Eye drop monitoring device and general eye drop bottle .............................12

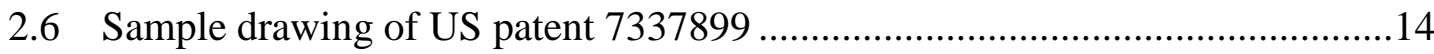

2.7 Example drawing for US patent D517799, pillbox with insert ......................14

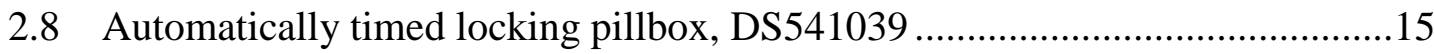

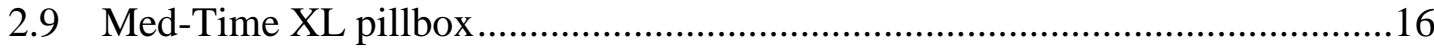

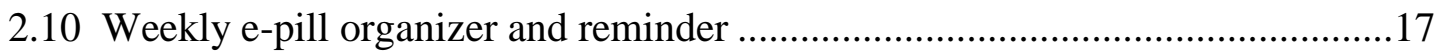

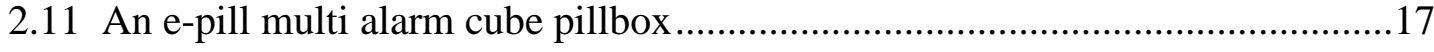

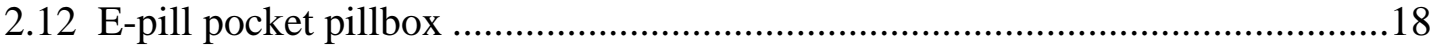

2.13 E-pill weekly medication reminder and organizer......................................19

2.14 Locked monitored automatic pill dispenser ...............................................19

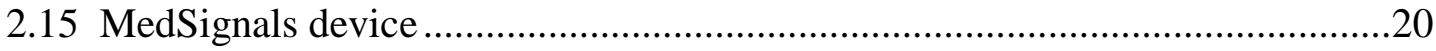

2.16 Pillbox logger compared with a MedTracker device and two other commercially

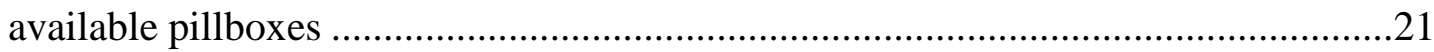

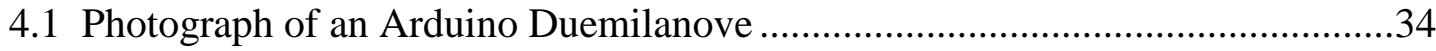


4.2 Momentary switch that was used in prototype, 50 gf momentary switch used for final design, compared to a dime and another momentary switch ....................................35

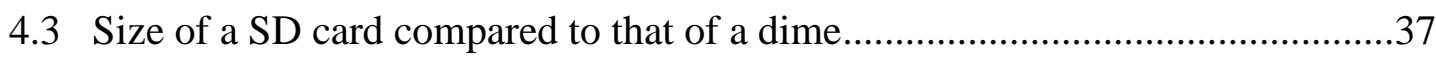

4.4 Prototype board for connecting SD card to Arduino board .............................38

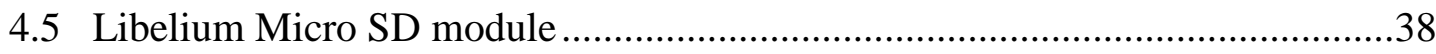

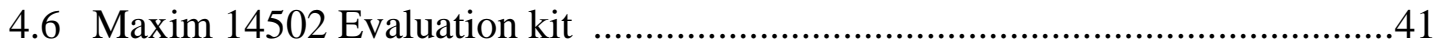

4.7 Arduino Pro- development board for AVR ...............................................43

4.8 Maxim 14502 EV board, Arduino Pro board and SD card module before connecting .44

4.9 Flowchart representing the sequential flow of operations in the electronic section

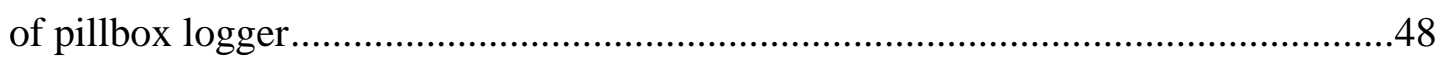

4.10 Prototype of the electronic section of the proposed pillbox logger with all

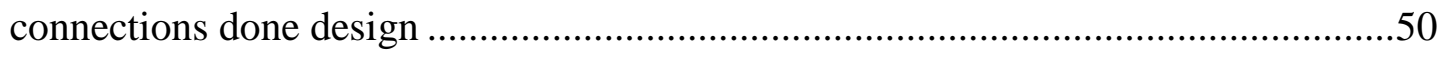

4.11 Dimensions of the bottom side of PCB with switches, vibration connector and USB connector using Solid Works .54

4.12 USB battery charging circuitry using Max 1555 and Max 8881 provided by the

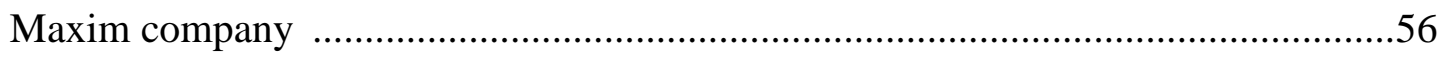

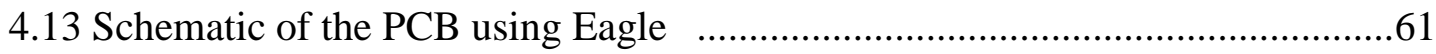

4.14 Eagle layout of the PCB (without copper pour) for pillbox logger, with only top and bottom layers turned on 61

4.15 Eagle layout of the PCB (with copper pour) for pillbox logger, with all four layers turned on .62

4.16 Top View of the final Printed Circuit Board .62 
4.17 Bottom View of the final Printed Circuit Board ............................................63

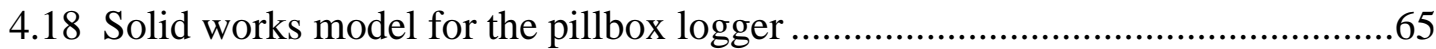

4.19 Solid works model for the pillbox logger with location of switches and USB

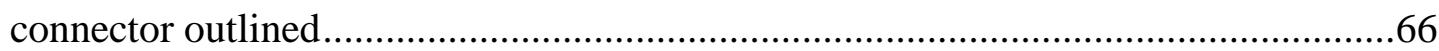

4.20 Solid Works model of the pillbox logger viewed from different angles ..........67

4.21 Top View of the final plastic model of the pillbox logger............................68

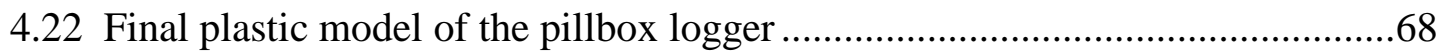

4.23 Side View of the final plastic model of the pillbox logger and the PCB..........69 


\section{Chapter 1}

\section{INTRODUCTION}

Parkinson's Disease (PD) is a progressive brain disorder which affects more than six million people worldwide and approximately one million in the USA and Canada [46]. Unfortunately at present, there is no cure for PD, but there are some very effective treatments including levodopa drug therapy and physical therapy, other drug therapies and surgery to manage its symptoms. There is also a search for treatments that can slow the progression of the disease. In order to treat the symptoms of PD effectively it is very important that medications be consumed regularly in a consistent way.

A device that can help remind subjects of medication intake time and keep a log of their daily medication intake would help clinicians optimize PD treatment. One such device gaining importance these days is an electronic pillbox. An electronic pillbox is a medication container designed to ensure medical adherence and reduce treatment failure. Treatment failure is a term usually used to describe the condition when a subject's body fails to respond correctly to prescribed medication or treatment. One major reason of treatment failure is uneven medication adherence.

The response to drugs cannot be measured very accurately because the pharmacokinetics of every individual varies; some need lesser doses and others higher. The Biomedical Signal Processing Laboratory, Portland State University (PSU) is developing wearable technologies that can directly measure the response to oral medication. However, in order to be to practice personalized medicine used in a clinical setting, clinicians must know the precise times at which people take their medications. 
Hence, the primary aim of this thesis was to design an electronic pillbox logger that permits careful tracking of medication timing. In people with PD the symptoms often appear after variable duration of time following a missed dose. The best way is to set time for reminder subsequent to thorough evaluation by clinician who sets up a dosing schedule which could then be programmed into the pillbox logger. This has the advantage of allowing close monitoring of subjects' medication consumption.

The electronic pillbox logger described in this thesis is a pocket sized, compartmented medication container designed to remind subjects to take their medication at the scheduled time. It also keeps an electronic record of presence and absence of pills in the pillbox, thus providing an indirect logging system of dosage consumption by the subject. This record will offer information that could be used for modifying the medications based on the subject's actual response to treatment.

\subsection{Problem Statement}

Pillboxes have been used by subjects suffering from different diseases for more than three decades. A commonly used pillbox is a small rectangular container with seven compartments containing the daily doses for each day of the week. Pillboxes are often used because they are inexpensive and are helpful in organizing the daily doses of medication in a simple way and can be used by subjects independent of the disease they suffer. However, such simple pillboxes have many drawbacks:

- Most commercially available pillboxes do not keep a log of when the pills were actually taken. 
- Many of the available pillboxes do not have an inbuilt system to remind the user to take the pills at right time. They are usually for just organizing the pills. Most of the advanced pillboxes that do have some kind of alarm system are expensive, bulky and have only a loud audio alarm, which may be annoying to people living with the user.

- The pillboxes are usually big, sometimes even of the size of a dinner plate. This makes it difficult for users to carry the pillbox around while doing daily activities, as is necessary for conditions that require precise timing and multiple doses scheduled throughout the day.

\subsection{Objective}

The objective of this work was to design and build a portable pillbox logger that can set off a reminder at scheduled intervals and record the actual dosage times. The pillbox logger has been designed to be pocket sized, have a variety of modes for alerting subjects (including vibration and audio), have low cost and present a user friendly interface. A unique feature incorporated in this design is a log of daily pill intake, which will allow clinicians to easily monitor response to therapy, make alterations as required, and give the ability to indicate treatment failure.

\subsection{Why Parkinson's Disease?}

There were two major reasons for choosing to build a pillbox logger especially designed for the needs of people with Parkinson's. Firstly, those suffering from PD take similar pills throughout the day. This means the device will have to monitor only pill intake rather than which specific pill the subject took. Secondly, wearable sensors for 
monitoring motion of PD subjects during their daily activities are being developed. Hence there is a need for a pillbox logger to serve as a necessary element to measuring the response to therapy in a more efficient and accurate way than is possible with subject logs.

\subsection{Impact on Humanity}

PD is a progressive and an extremely debilitating medical disorder. There is no cure. All therapies are directed at providing symptomatic relief and extending the quality of life. Our aim is to prolong this period by introducing a design that offers a systematic and controlled administration of drug in the body

Another symptom that characterizes PD is dementia. Unfortunately, none of the available medications improve dementia. However, a pillbox logger that can prompt the subject to take medication and record when medication was taken will help caregivers, subjects, and doctors monitor medication intake and more easily take corrective action when medications are taken at the wrong times.

\subsection{Significance}

The significance of such a device includes providing medical adherence, ensuring a continued and sustained response to treatment and simultaneously improving the physical quality of life in subjects with PD and other conditions that require frequent treatment. The pillbox logger will help doctors to increase or decrease the number of daily doses based on the medication response, recorded pill intake data, and treatment failures. Current devices can be used to prompt subjects, but knowledge of the actual medication 
times rely solely on subject's memory. The designed device could also be used in research and development of new drugs by using the data collected over a period on how regular pill intake in conjunction with wearable sensors during the daily activities affects the symptoms of PD subjects.

\subsection{Demonstration of Mastery}

This thesis is intended to demonstrate mastery of knowledge in the field of Electrical and Computer Engineering. This demonstration includes the completion of a literature survey to assess the current state of art in a given discipline (Chapter 2); a systematic creation of requirements and features for the design (Chapter 3); building of a prototype and final device in co-operation with inter-disciplinary colleagues, (Chapter 4); and thorough verification and validation of both the hardware and software section of device (Chapter $5)$. 


\section{Chapter 2}

\section{EXISTING TECHNOLOGIES AND LITERATURE REVIEW}

A number of pill organizers and electronic pillboxes (e-pillboxes) have been described in the literature or commercially produced which are similar to the electronic pillbox logger described in this thesis. This chapter describes some of these existing e-pillbox designs. This includes the few patents that have been filed, pillboxes commercially available, and academic research work in related field. An understanding of previous work by other researchers highlights the advantages of the proposed pillbox logger design. Also, the information gathered from previous work was used in developing the requirements and features of the pillbox logger described in this thesis.

\subsection{Electronic Monitoring of Adherence}

Improper medication adherence is one of the prime reasons of prolonged illness and cause of no response to prescribed medication also known as treatment failure [1]. In the work done by a group of researchers from Harvard School of Public Health, Massachusetts School of Medicine and the Lown Cardiovascular Center, 76\% discrepancy was found between what medicines subjects were prescribed and what medicines they actually consumed [4]. In another study a group of researchers reviewed 76 studies that used standard electronic monitoring to study relation between dose regime and medication compliance [2]. They concluded that medication compliance is inversely proportional to number of doses per day. They suggested that this inadequate compliance 
with prescribed medication regime may be one reason for poor control of medical disorders.

Hence, it is important to have devices that can help subjects stick to their daily doses of medication and help clinicians treat disease more effectively. Thus proper medication adherence is important for subjects and researchers.

A number of electronic medication adherence monitoring devices exist. Electronic monitoring units vary in design from standard pill containers with a microprocessor chip embedded in the cap to medication organizers with compartments for individual doses to monitored eye drop bottles. Most of these devices monitor medication dosing using special containers that store dosing information on electronically erasable programmable read only memory (EEPROM) of the microcontroller. Some of the devices that have been used by researchers in adherence studies are mentioned in the following section.

2.1.1 Medication Event Monitoring System (MEMS): Developed by the Aardex group, Switzerland, MEMS was designed for electronically monitoring drug dose regime in subjects [18]. In general all the MEMS devices developed by Aardex group have a small microcircuit in drug packages. The term event in MEMS refers to the action that occurs to remove the drug from the package.

All the MEMS monitor devices use a typical medicine bottle fitted with a specially designed closure (cap) which contains the microcircuitry. The microcircuitry records whenever an event of opening the closure of the package occurs along with the date and time of opening. A reader is then used to transfer the dosing history data from the MEMS micro-circuitry wirelessly to a computer running Microsoft Windows. Some of the 
models of MEMS devices have a display screen on the cap of the bottle which displays the number of doses taken in a 24 hour period and the time passed since the last dose. MEMS devices have the capability of recording up to 3800 different time stamped events in a non-volatile EEPROM memory [18].

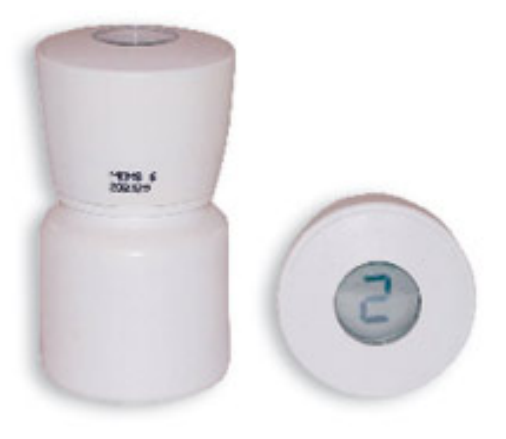

Fig.2.1: MEMS 6 monitor, with LCD display cap (Image taken from Aardex website [18]). MEMS have been used in several research studies focused on response to treatment based medication adherence [1] [2].

There are several drawbacks to the MEMS device. The opening and closing of the package is an indirect measure of medication intake, which raises the question of whether the prescribed dose was actually taken. Second, the MEMS lack a reminder system to remind the user to take the medication. Third, the cap of MEMS is difficult to open with arthritic hands [1][44][45]. Fourth, since MEMS is just a medicine bottle it lacks any provision for organizing medications into daily doses, as generally used by the elderly and when multiple drugs are taken. Fifth, the pills make a rattling sound by hitting against the wall of the bottle.

2.1.2 Med-Tracker: This pillbox was developed by a group of researchers from Oregon Health Science University (OHSU) and Intel Corporation, Oregon. Med-Tracker allows 
continuous monitoring of medication adherence [1]. The developers of the Med-Tracker instrumented a commonly available seven-day pill organizer, in order to make the device as familiar to the user as possible, rather than designing the pillbox themselves.

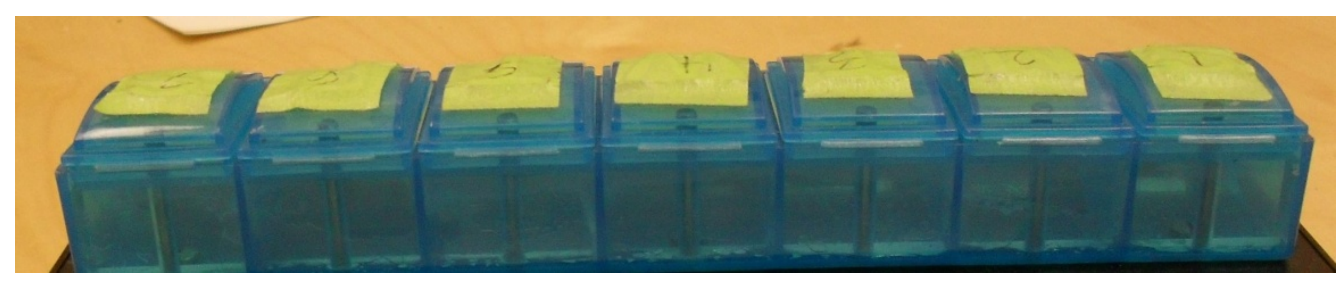

Fig. 2.2: 7-day pill organizer used in Med-Tracker (Image by Beenish Zia)

Med-Tracker has been designed to record the time each lid of the 7-day pill organizer is opened or closed. To the bottom of the 7-day pill organizer a box is firmly attached that contains all the electronic circuitry. The lid of each of the 7 compartments is connected to a plunger, which is, in turn, linked to a switch. Whenever the user opens a compartment lid on the pill organizer, the plunger releases a switch inside the device, sending signals to a microcontroller indicating that the lid was opened. Once every second the status of the lid is checked and any change is recorded along with the time of change in a circular RAM buffer of a 18LF252 Peripheral Interface Controller (PIC) microcontroller. Each event takes 4 bytes of storage space and Med-Tracker memory can store upto 256 distinct events. The Med-Tracker uses Bluetooth to wirelessly send its recorded data to the main computer. The Bluetooth link is controlled by the PIC controller on the board, which wakes up every two hours to send data and battery voltage over the Bluetooth link [1]. 

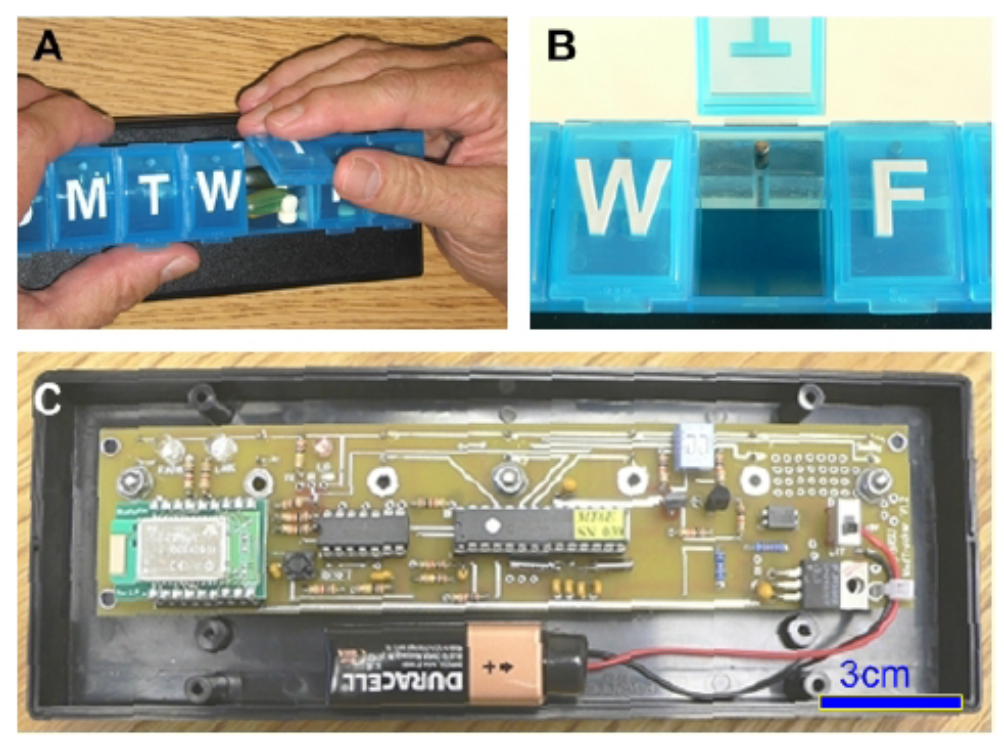

Fig. 2.3: The Med-Tracker Device [1]. A: Outside of the device. B: Close up of the plunger that activates the switch to record the activity; C: internals (Image taken from [1])

Though the Med-Tracker device overcomes several drawbacks of its predecessors [1], it still has room for improvement. One of the disadvantages of the Med-Tracker is its size. Although it is portable, it is bulky and not compact enough to slip in one's trouser pocket. Secondly, it uses a plunger based switch to record medication adherence detecting whenever the status of compartment lid on pillbox changes. This method does not give any information whether opening the lid meant the pills where taken out of the compartment or it was by mistake or if the lid was opened to check if pills were in the compartment or not. Thus, there is no exact information recorded about presence or absence of pills in the pillbox. Thirdly, since the Med-Tracker uses Bluetooth to send recorded data to main computer, the user of pillbox has to be in wireless range for the data to be recorded continuously. Fourthly, the Med-Tracker has not been commercialized and is not commercially available. Fifthly, the Med-Tracker has no alarm 
system in it to remind the user to take pills. Finally, like the MEMS the pills make a rattling sound by hitting against the walls of the container.

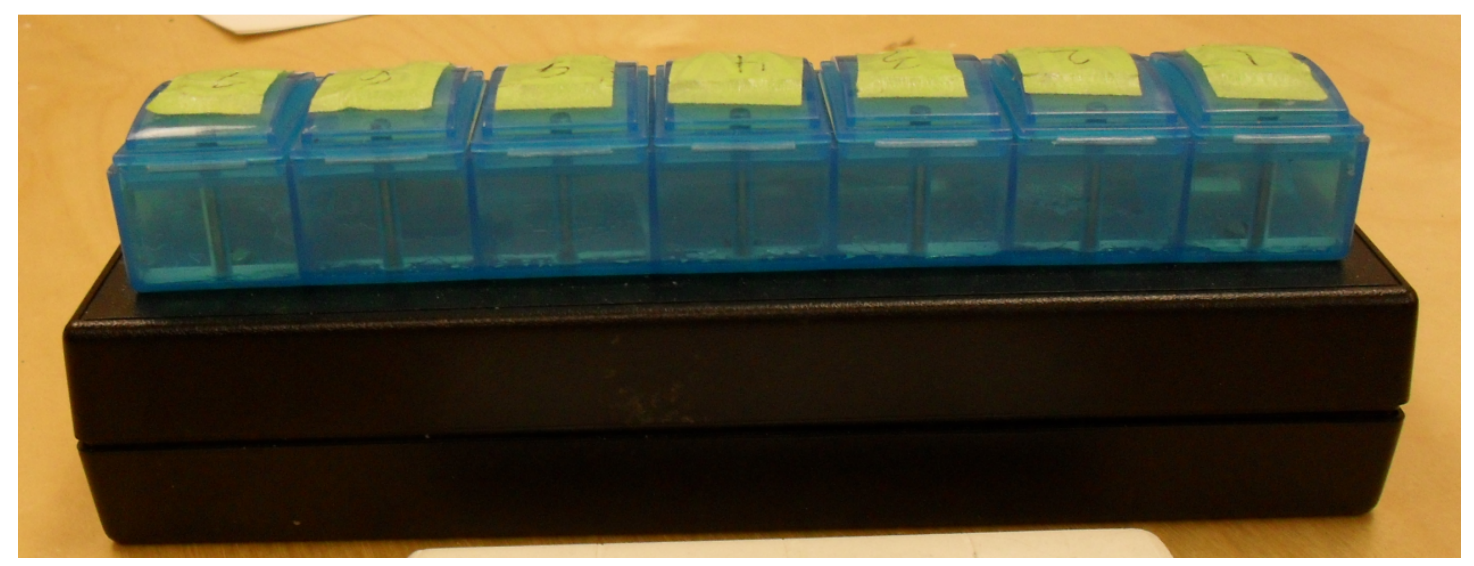

Fig. 2.4: Side view of the Med-Tracker prototype (Image by Beenish Zia)

2.1.3 Eye drop medication monitor: This device was developed by researchers at Department of Ophthalmology, University of Cologne, Cologne, Germany and was made for academic research purposes only [7][2]. The developers used the device to study the specificity and sensitivity of a microprocessor controlled monitoring device used in self administered eye drop medications.

The monitoring system includes an 8-bit microcontroller for data acquisition and storage and sensors for measuring applied pressure to the bottle, temperature and vertical position. The apparatus consists of three parts, the first part being a typical eye drop container. The second part is a flexible thin pressure sensor that measures the pressure or force applied on squeezing the bottle. The third part, which is attached under the eye drop bottle, holds the microcircuitry, battery and other electronics [7]. 


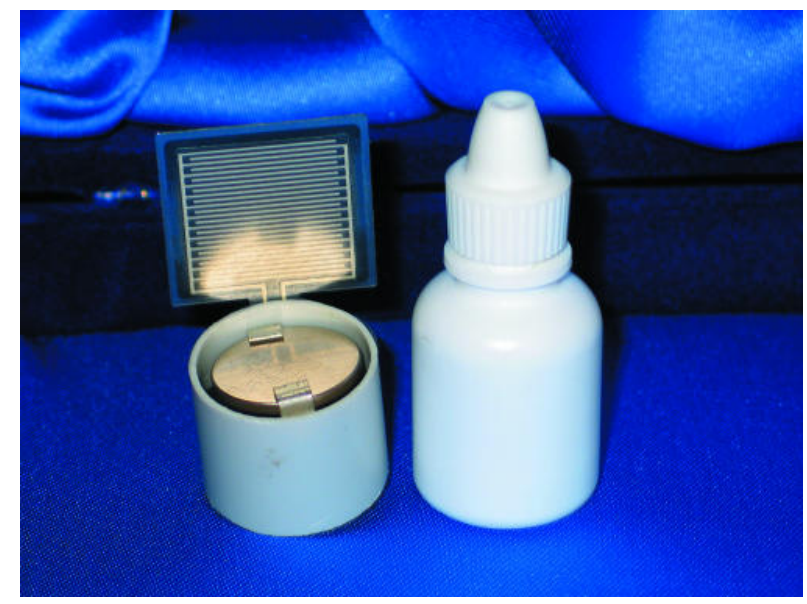

Fig. 2.5: Eye drop monitoring device and a general eye drop bottle (Image taken from [7])

The event of eye drop application is detected by a change in vertical position indicated by a tilt sensor and the change in voltage indicated by the pressure sensor. After detection of an eye drop application the data for time, date, and temperature are saved in an EEPROM chip. Collected data is transferred to a computer system using a three wire interface cable. The computer system program reads data out from EEPROM and provides setting of monitoring device clock and deletion of all data.

This device is not a pillbox like the one described in this thesis. However, it details the importance of medication adherence monitoring in ophthalmological treatment. Like the MEMS and the Med-Tracker this device keeps record of only the events that occur to take the dose and lacks a system for reminding the user to take the medication.

\subsection{Patents for pillbox design}

Pillboxes have been used by subjects suffering from different diseases for more than three decades. There have been several modifications made in the design of such pillboxes to make them more portable, user friendly and more accurate for clinical trials. 
This section describes some of the patents that have been filed after 1970 on various pillbox designs.

a. US3817372 Patent filed in Sept. 1971: This is one of the earliest patents filed in relation to pillboxes [13]. It describes a rectangular design for pillbox, which has a pair of row cavities transversely arranged. The upper row has compartments for holding pills and the bottom row is made in to a single compartment. A sliding door is placed on each of the row and on sliding the door one compartment is exposed at a time. This system lacks any electronic segment and was designed focusing on pill dispensing in an organized way.

b. US4084695 Patent filed in September 1976: This design contains plastic box with transparent lid [10]. The box is divided into multiple compartments and each compartment is attached to a central plastic support with a small plastic attachment. This attachment can be broken and each of the compartments can be accessed for dispensing medicine.

c. 5020037 Patent filed in May 1991: This is one of the earlier patents that includes an alarm and memory system. The patent describes a portable, one compartment pillbox which has an alarm system for reminding the patient to take the medication. Opening the lid of the compartment cancels the alarm and this alarm cancellation is recorded in the memory of the controller [9]. It has a display that provides visual indication of the record and has three push buttons on it for time and alarm adjustment.

d. US7337899 Patent, filed in Sept. 2004: This patent describes design of a portable one compartment pillbox that can be attached to the back of a portable electronic device 
(PED) like a cell phone [14]. It is small, simple container to hold pills, with no electronic section included in it.

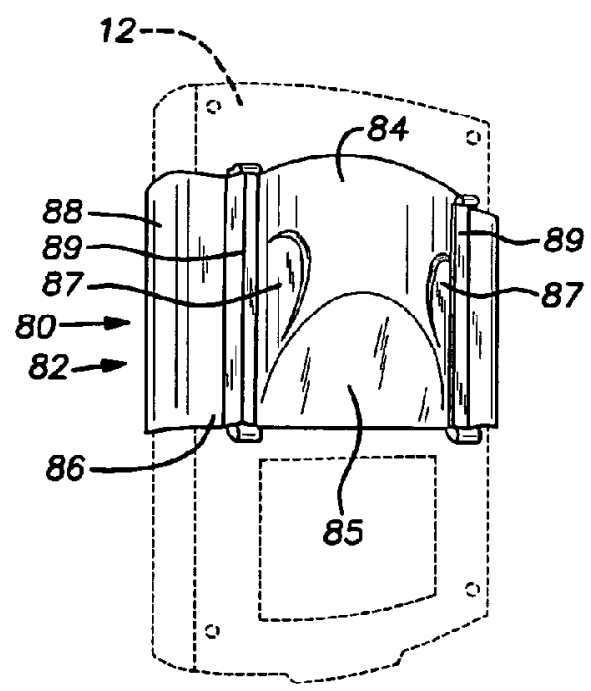

Fig.2.6: Sample drawing of US patent 7337899 (Image taken from [14])

e. USD517799 Patent filed in February 2005: This describes design of a pillbox with insert [11]. It lacks any form of electronic complexity, is small, portable and for general pill holding.

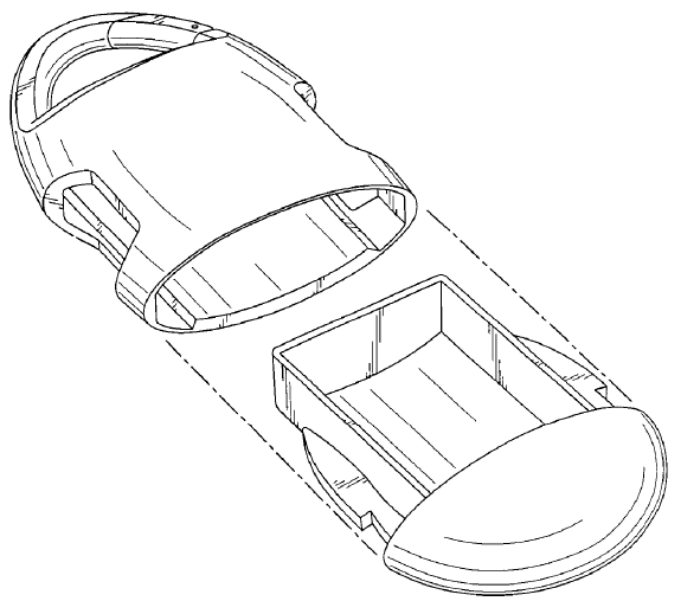

Fig.2.7: Example drawing for US patent D517799, pillbox with insert (Image taken from [11]) 
f. Patent DS541039 filed in August 2005: This patent describes a 7-day pillbox. The primary feature included in this design is automatically timed locking for pillbox [12].

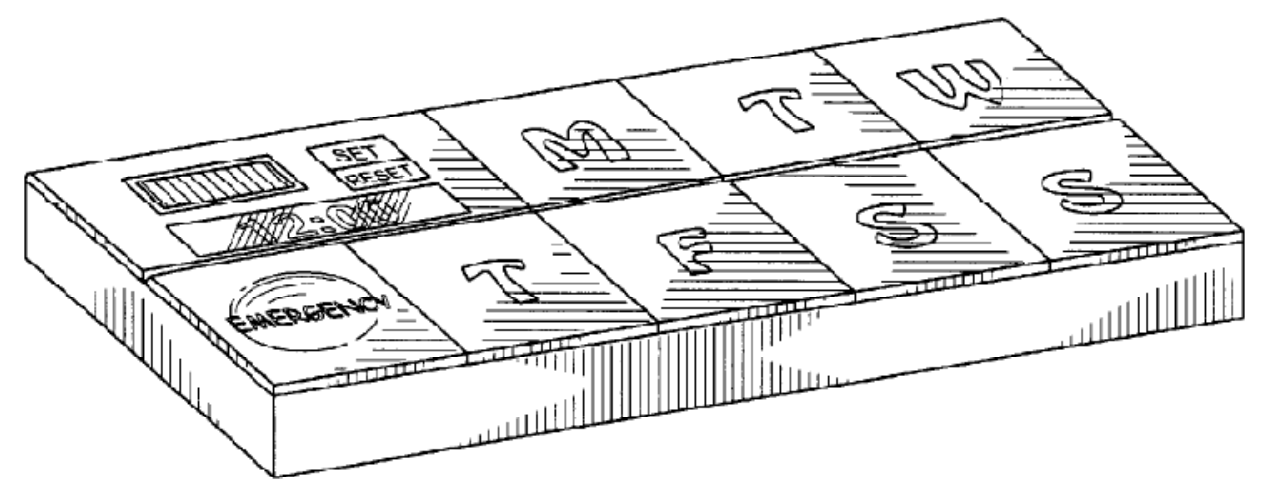

Fig 2.8: Automatically timed locking pillbox, DS541039 (Image taken from [12])

Most of the US patents of pillboxes mentioned above have no electronic section however the analysis of these different pillboxes helped in developing the requirements and design of the pillbox logger described in this thesis.

\subsection{Commercially available e/pillboxes}

This section gives details of a few of the e-pillboxes/dispensers available on market today. While some of them are general pill organizers with no electronics section in them, there are many with some kind of audio/vibration alarms in them. Generally, if the pillbox has some kind of advance electronics system in it, like remote event monitoring or last seven days history of pill dispensing then it is too big and costly for our application to monitor daily intake of multiple doses. Conversely, generally if a commercially available pillbox is small and portable, then it does not have any electronics. A major disadvantage with most of the commercially available pillboxes is 
that they do not have any mechanism to suppress the sound that pills make by hitting against the walls of the container.

a. New E-pill Med-time XL: Med-Time XL made in Sweden (marketed as Careousel in Europe) is one the most well known pillboxes available on market [21]. It is a device for dispensing medicine, reminding the user when medicine should be taken, and making the correct dose available.

It is a nice design for automatic medication dispensing with inbuilt alarm system. It has the provision to dispense twenty eight times a day and needs to be refilled every fourteen days.

One major disadvantage is that the Med-time XL is the size of about two dinner plates, which makes it bulky and not very portable.

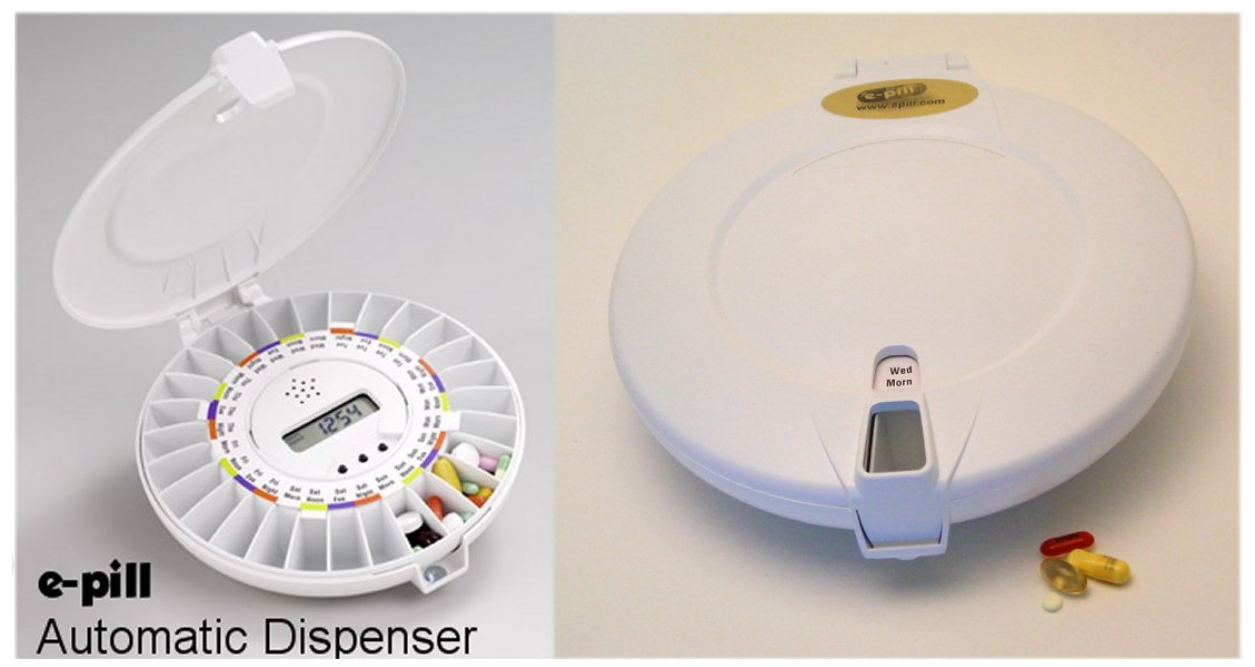

Fig. 2.9: Med-time XL pillbox (Image taken from epill website [21])

b. Weekly e-pill Pillbox, Sound only: This device helps organize daily pills and has a loud audio alarm to remind the patient to take pills [21]. It has a provision of setting 
alarm thirty seven different times per day. The daily organizer has four compartments for pills and the size of the whole device is $61 / 4 " \times 17 / 8$ " x 13/16", which is a little big to be easily carried around.

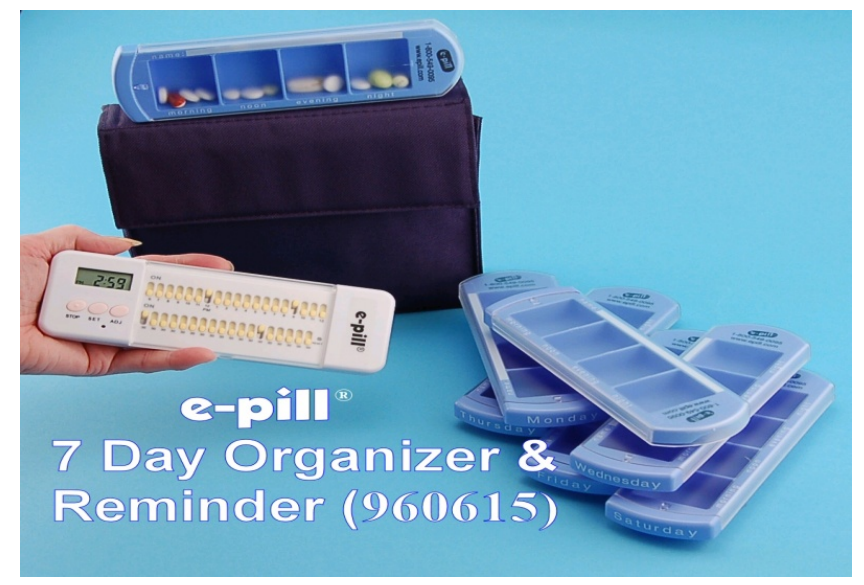

Fig. 2.10: Weekly e-pill organizer \& reminder (Image taken from epill website [21])

c. e-pill Multi-Alarm Cube Pillbox: The e-pill multi-alarm cube is a bottle-like pill container. It has five cubes, four of which are for keeping pills and one is for the pill timer. The four cubes for storing pills are easily detachable. The pill timer is an alarm system that can remind a user twenty four different times a day [21]. Each cube is $2 \frac{1 / 2}{2} \mathrm{x}$ $1 ”$

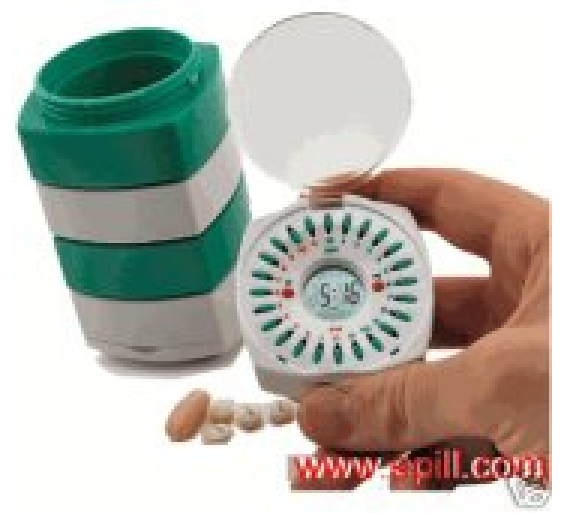

Fig. 2.11 An e-pill multi alarm cube pillbox (Image taken from epill website [21]) 
d. e-pill Pocket Pillbox: This is a compact pocket size pillbox for daily use [21]. It has four compartments at the back of the box to hold medication. It has both audio and vibration alarm systems and can be set for four times a day. The size of the pillbox is 2 $3 / 4 " \times 2 \frac{1}{2} " \times 7 / 8$ " and it has capacity for eight aspirin sized tablets per compartment.

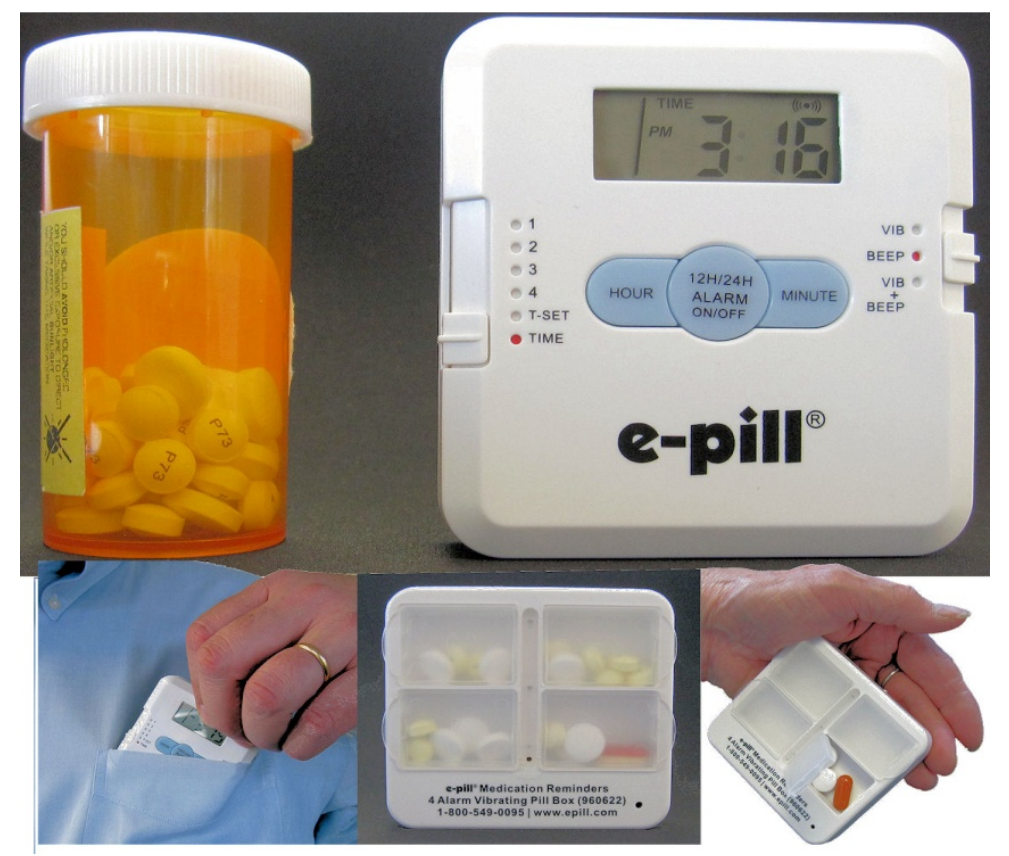

Fig.2.12 e-pill Pillbox Pocket (Image taken from epill website [21])

e. e-Pill weekly medication reminder and organizer: This has seven distinct pill containers each having four compartments [21]. Each of the seven pill containers can be attached to an alarm system box, which has the capability of reminding six times a day. The alarm system box has a visual display that can display the number of missed pills. This is one of those very few pillboxes which maintain pill dispensing history. It keeps a $\log$ of the last seven days of pill dispensing. The history feature shows the pills missed and pills dispensed during a day. Total size of the weekly organizer is $4 \frac{1 / 4}{4}$ x $3 \frac{1 / 4}{4}$ x 1 " with a capacity of eighteen aspirin-sized tablets fitting in each daily container. 

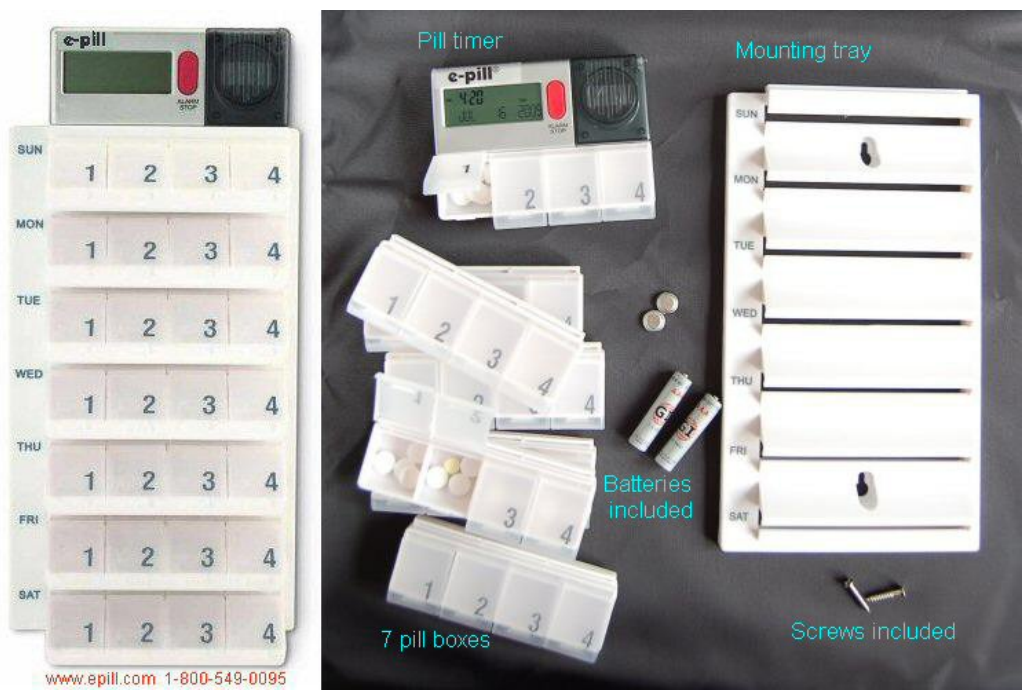

Fig.2.13 E-pill weekly medication reminder and organizer (Image taken from epill website [21])

f. Locked Monitored Automatic Pill Dispenser: This is a fully automatic medication dispenser [21]. It can dispense pills up to six times a day and has a loud audio and blinking light alarm system. An important feature included in this e-pillbox is remote event monitoring which alerts the caregiver if the pills have been missed. If meds are not taken, this e-pill will call the user/caregiver after sounding the alarm for sixty minutes. However, it is bulky in size with a diameter of $8 \frac{1 / 2}{2}$ x $2 \frac{1}{2}$ " in thickness.

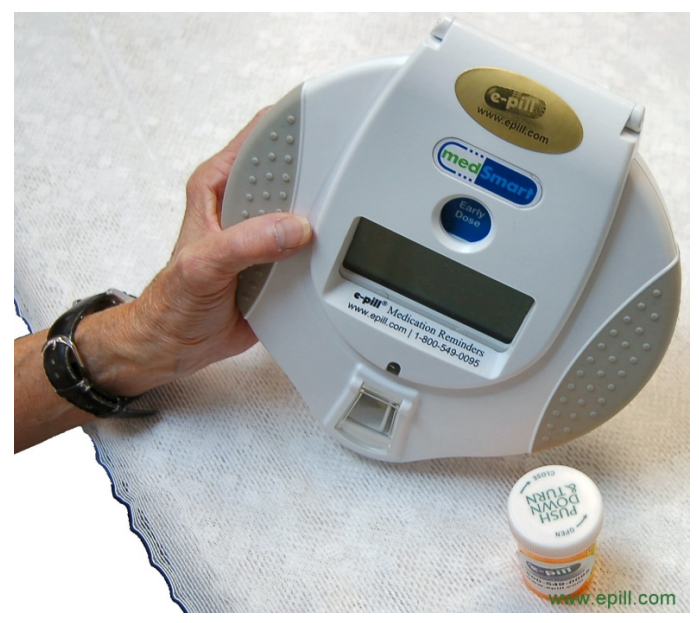

Fig.2.14 Locked Monitored Automatic Pill dispenser (Image from epill website [21]) 
g. MedSignals: This is one of the advanced pillboxes that have an alarm and memory system [19]. The pillbox has four barrel shaped compartments to hold pills, a display that indicates how many pills to take and any instructions if needed. It has an audio alarm system which beeps when it is time to take a pill and is augmented by an LED that flashes the number of pills the user has to take. The memory in the pillbox keeps a record when the lid of the compartment was opened. The box comes with a cradle which is connected to a phone line. When the pillbox is docked on the cradle, the cradle recharges the batteries as well as transfers the information stored in the memory of pillbox to the main computer system through the phone line. It has various other features like Braille numbers, voice announcements and language choice.

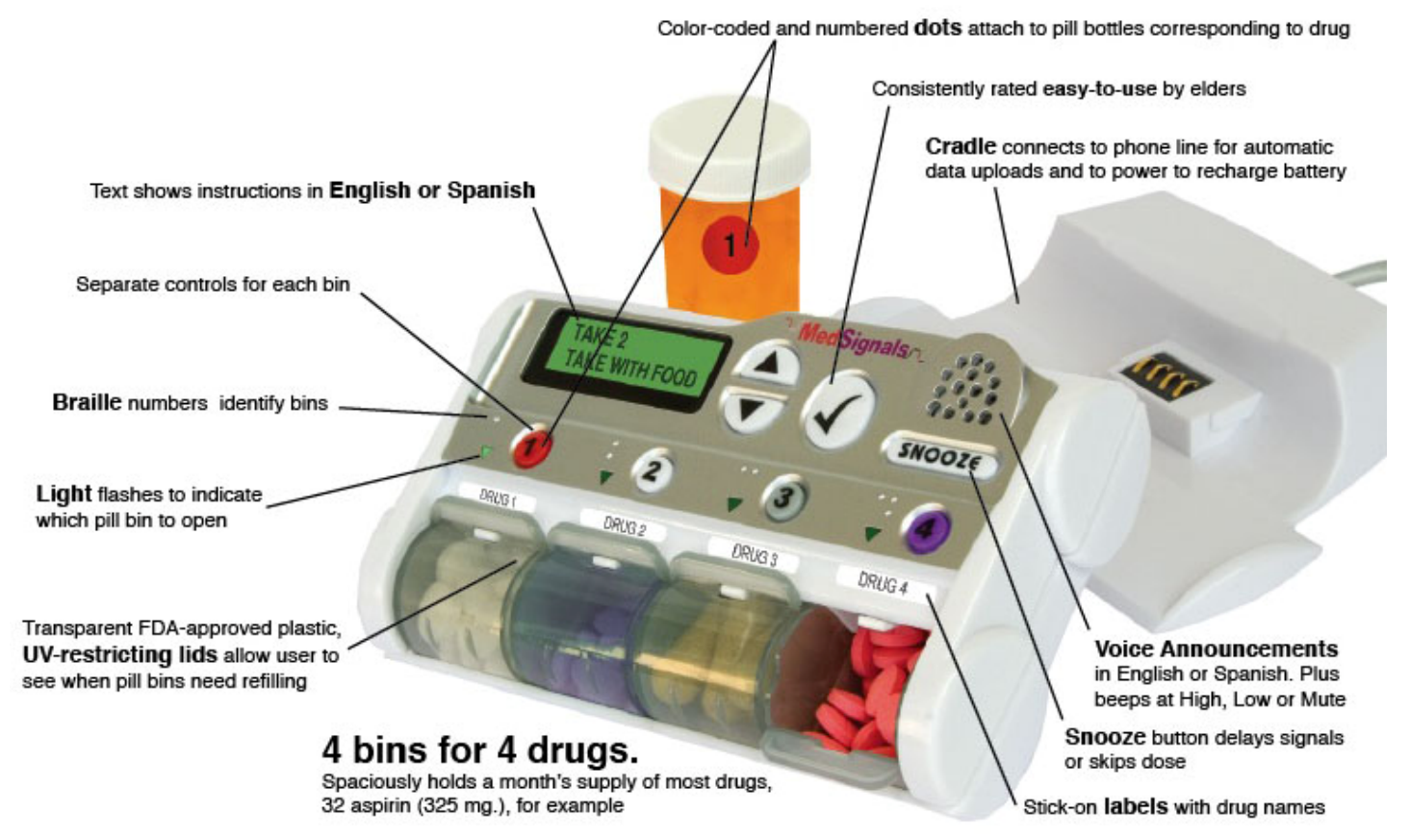

Fig. 2.15: MedSignals device (Image take from MedSignals website [19])

However, a number of users have reported MedSignals device to be cumbersome. It requires a subscription model which most people find not agreeable. It is also flimsy and 
difficult to open for people with impaired dexterity like people suffering from PD. The device is bulky and not portable.

\subsection{Summary}

Table 2.1 summarizes the literature review section by comparing four pillboxes mentioned in the literature review that are most closely related to the electronic pillbox logger. The table briefly reflects the advantages of the described pillbox logger over the existing designs.

\begin{tabular}{|c|c|c|c|c|c|}
\hline Feature & MedSignals & $\begin{array}{c}\text { e-pill } \\
\text { Weekly } \\
\text { Reminder }\end{array}$ & MedTracker & MEMS & $\begin{array}{l}\text { Pillbox } \\
\text { Logger }\end{array}$ \\
\hline $\begin{array}{l}\text { Portable/pocket- } \\
\text { size }\end{array}$ & & & & $\sqrt{ }$ & $\sqrt{ }$ \\
\hline Audio alarm & $\sqrt{ }$ & $\sqrt{ }$ & & & $\sqrt{ }$ \\
\hline Vibration alarm & & & & & $\sqrt{ }$ \\
\hline Pill intake log & $\sqrt{ }$ & $\sqrt{ }$ & $\sqrt{ }$ & $\sqrt{ }$ & $\sqrt{ }$ \\
\hline $\begin{array}{l}\text { Pill detection in } \\
\text { pillbox }\end{array}$ & & & & & $\sqrt{ }$ \\
\hline Pill organizer & $\sqrt{ }$ & $\sqrt{ }$ & $\sqrt{ }$ & & $\sqrt{ }$ \\
\hline Ease of opening & & $\sqrt{ }$ & & & $\sqrt{ }$ \\
\hline Rattling sound & $\sqrt{ }$ & $\sqrt{ }$ & $\sqrt{ }$ & $\sqrt{ }$ & \\
\hline $\begin{array}{l}\text { Easy data } \\
\text { transmission }\end{array}$ & & & & & $\sqrt{ }$ \\
\hline
\end{tabular}

Table 2.1: Table comparing some features of few of the existing pillboxes to that of pillbox logger 


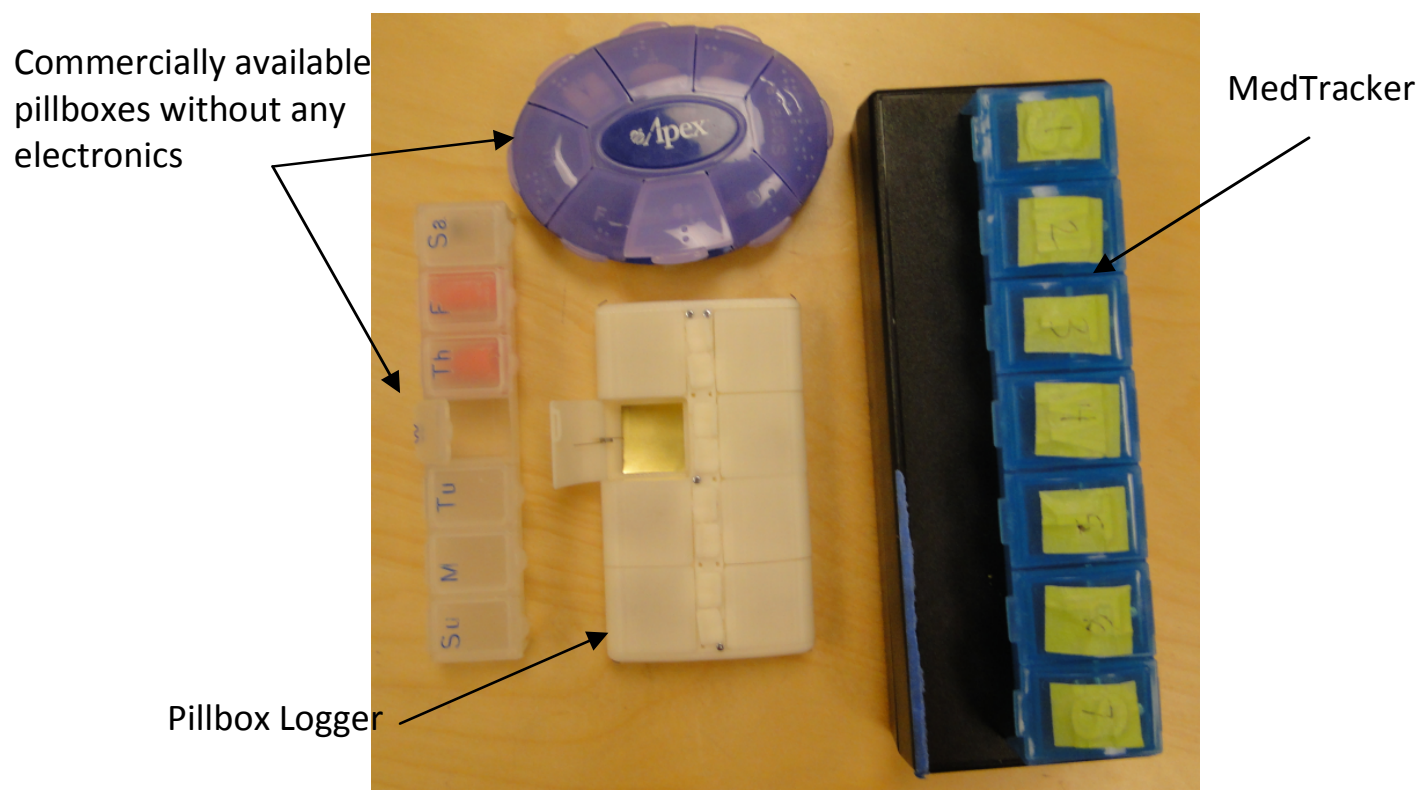

Fig.2.16: Pillbox Logger compared with a MedTracker device and two other commercially available pillboxes (Image by Beenish Zia) 


\section{Chapter 3}

\section{FEATURES AND REQUIREMENTS}

\subsection{Features}

There were three key features that were required in the pillbox logger design and were lacking in the existing designs.

- Pocket-size and portable: The pillbox logger was required to be of a size and shape that could comfortably fit in one's pocket or purse. This ensured that users would be able to carry the pillbox logger while doing their daily activities. Such a design would permit careful tracking of medication and help in therapy optimization.

- Variety of reminder options: The pillbox logger must have options for reminding the users to take their medication at the correct time. It must have a vibrator reminder and an audio alarm. Depending on the end-user's choice, one or both of these reminder systems may be set in the pillbox logger. A number of users find an audio reminding system to be annoying. A vibration reminder would be convenient to them. On the other hand a large number of PD subjects are over sixty years old, and in many cases they would not be able to easily sense the vibration of the reminder because of their aging sensory neurons. Hence, for such subjects, an audio reminder system would be beneficial.

- Record of pill intake: The pillbox logger must have an easy means of keeping track of when pills were actually taken. Unlike some of the existing designs [1] [21] where the opening of the pillbox compartment was used as an indicator to track pill intake, the described pillbox logger was required to use the actual presence or absence of 
pills in the pillbox as an indication for pill intake. The method of detecting whether the compartments of pillbox logger are empty or full is a more accurate way of tracking pill intake by subjects. Simply detecting opening or closing of lids of the compartments of pillbox has been found to be inaccurate since a number of times users open the compartments by mistake without actually taking any pills out of it.

These three chief features were used as a foundation to develop other features of the pillbox logger.

\subsection{Survey on Pillboxes from PD Subjects}

A brief survey about currently used pillboxes by PD subjects was done to augment developing the requirements of the pillbox logger. The survey was organized in collaboration with doctors and clinicians at the Oregon Health Science University (OHSU) who deal with PD subjects. A solid plastic model of the proposed pillbox logger was made that was pocket size and was thick enough to hold general PD pills like Levodopa and Carbidopa.

A set of questions to be asked from the PD subjects was prepared. Dr. John Nutt and Lisa Mann from OHSU helped set up the meeting with PD subjects who were willing to participate in the survey. The survey was held in the Center for Health and Healing (CHH), Portland, Oregon and eight PD subjects and a few clinicians participated in the survey. The plastic model of the proposed pillbox logger was shown to the PD subjects and the clinicians and comments on the new design and the existing pillboxes were recorded. 


\begin{tabular}{|c|c|c|c|c|c|c|}
\hline $\begin{array}{l}\text { Su } \\
\text { bj- } \\
\text { ect } \\
\text { No. }\end{array}$ & $\begin{array}{l}\text { How many } \\
\text { times a day } \\
\text { do you take } \\
\text { medication? }\end{array}$ & $\begin{array}{c}\text { Where } \\
\text { do you } \\
\text { carry } \\
\text { your } \\
\text { pillbox? }\end{array}$ & $\begin{array}{l}\text { What do you } \\
\text { use to remind } \\
\text { you when it's } \\
\text { time to take } \\
\text { your } \\
\text { medication? } \\
\end{array}$ & $\begin{array}{c}\text { What about } \\
\text { your current } \\
\text { pillbox made } \\
\text { you decide to } \\
\text { use it? }\end{array}$ & $\begin{array}{l}\text { What don't } \\
\text { you like } \\
\text { about their } \\
\text { current } \\
\text { pillbox? }\end{array}$ & $\begin{array}{c}\text { What } \\
\text { would } \\
\text { your ideal } \\
\text { pillbox } \\
\text { include? }\end{array}$ \\
\hline 1 & 4 & front box & $\begin{array}{l}\text { body } \\
\text { reminds(tremors } \\
\text {, loss of control } \\
\text { increases)/ } \\
\text { routine/watch }\end{array}$ & $\begin{array}{l}\text { pillbox has } \\
\text { break off } \\
\text { compartments }\end{array}$ & $\begin{array}{l}\text { Somewhat } \\
\text { bulky. }\end{array}$ & $\begin{array}{l}\text { Built in } \\
\text { reminder. }\end{array}$ \\
\hline 2 & 3 & purse & routine & $\begin{array}{l}\text { Picture (got it at } \\
\text { Disney world) } \\
\text { good size and } \\
\text { number of } \\
\text { compartments } \\
\text { for daily use. }\end{array}$ & $\begin{array}{c}\text { at home uses } \\
\text { shot glasses, } \\
\text { would like } \\
\text { travel } \\
\text { container to } \\
\text { hold several } \\
\text { days worth }\end{array}$ & $\begin{array}{l}\text { hold whole } \\
\text { days and } \\
\text { easy to get } \\
\text { into }\end{array}$ \\
\hline 3 & $\begin{array}{l}2 \text { - morning } \\
\text { and night }\end{array}$ & & & & & \\
\hline 4 & $\begin{array}{c}6 \text { - every } 4 \\
\text { hours }\end{array}$ & $\begin{array}{l}\text { suit coat } \\
\text { pocket }\end{array}$ & $\begin{array}{l}\text { doesn't have } \\
\text { anything which } \\
\text { is a problem }\end{array}$ & & $\begin{array}{l}\text { has the ideal } \\
\text { answer }\end{array}$ & alarm \\
\hline 5 & $\begin{array}{l}4 \mathrm{x}-\mathrm{PD} \\
\text { only once }\end{array}$ & purse & $\begin{array}{l}\text { routine } \\
\text { especially } \\
\text { because } \\
\text { container is } \\
\text { translucent }\end{array}$ & $\begin{array}{l}\text { small fits in } \\
\text { purse likes extra } \\
\text { storage when } \\
\text { heart medicine } \\
\text { was similar but } \\
\text { needed to be } \\
\text { taken at } \\
\text { different time }\end{array}$ & & \\
\hline 6 & 4 & $\begin{array}{c}\text { pants } \\
\text { pocket or } \\
\text { car }\end{array}$ & mind & $\begin{array}{l}\text { available and } \\
\text { cheap }\end{array}$ & need alarm & $\begin{array}{l}\text { audio or } \\
\text { vibration }\end{array}$ \\
\hline 7 & 6 & $\begin{array}{c}\text { wife } \\
\text { carries in } \\
\text { purse or } \\
\text { carries in } \\
\text { pocket }\end{array}$ & memory & $\begin{array}{l}\text { available and } \\
\text { cheap }\end{array}$ & $\begin{array}{l}\text { durable, } \\
\text { current ones } \\
\text { falls apart. } \\
\text { wants it } \\
\text { yellow or } \\
\text { bright color }\end{array}$ & $\begin{array}{l}\text { alarm } \\
\text { would be } \\
\text { good }\end{array}$ \\
\hline 8 & 5 & $\begin{array}{l}\text { pants } \\
\text { pocket }\end{array}$ & $\begin{array}{l}\text { wife, used pill } \\
\text { reminder from } \\
\text { radio shack } \\
\text { about } 4 \text { " circle }\end{array}$ & $\begin{array}{c}\text { no timer, only } 4 \\
\text { sections }\end{array}$ & & alarm \\
\hline
\end{tabular}

Table 3.1: Survey result from PD patients on pills and pillboxes 
There were three major points that surfaced from the survey.

- Most of the PD subjects took pills six times a day, with rare, severe PD cases where subjects took pills eight times a day

- There was an overwhelming demand for an alarm/reminder system in a pocket sized pillbox.

- Many PD subjects took some non-PD pills also during the day, hence there was a requirement that the pillbox have extra compartment(s) for holding non-PD pills. A good feature to add in the pillbox would be to mark the compartment with nonPD pills in some way.

\subsection{Requirements}

There were seven prime requirements that were requisite in the pillbox logger design.

- Compact and portable

- User friendly

- Eight compartments, which are sufficient to hold enough pills throughout the entire day for most people with PD

- Audio and vibration alarm options

- A more accurate method than existing designs to detect pill intake

- Storage device to keep a time stamped log of daily pill intake

- Long battery life (at least 1 month)

The sizes and the number of medications that a PD subject takes per day on average were used to create the dimension requirements of the pillbox logger. Since the subjects 
take a combination of pills four-six times a day the pillbox logger must have at least six compartments. Also, some of the subjects mentioned that they usually take a few vitamin pills and would like to have an extra compartment for those. Hence, it was decided to have eight compartments in the pillbox logger. The requirement to have the compartments big enough to fit a few maximum sized PD pills comfortably in it and at the same time keep the total dimensions of the pillbox logger small enough to fit in a person's pocket easily were used to come up with the required dimensions of the pillbox logger.

The existing methods for keeping track of pill intake by using an indicator for detecting opening/closing of lid of pillbox has been reported as inaccurate. Hence, for the pillbox logger a more accurate method for monitoring pill intake was required. This method consists of detecting the actual presence/absence of pill(s) in each compartment of the pillbox logger. For detecting the physical presence of pill(s) either a visual sensors could be used or some pressure sensor. Visual sensors are usually bigger and bulkier compared to pressure sensor hence the pressure sensors were chosen over them. To have the total cost of the final device low, light throw switches were used instead of true pressure sensors.

A convenient method of detecting presence of pills in the container was to place one or more small light throw switches under the base of each compartment of the pillbox logger. A layer of foam $\approx 1 / 2 "$ in thickness would also be attached on the inside of the lids of the compartments. On closing the lid of a compartment, if pill(s) are present in the compartment then the foam would cause the pill(s) to exert pressure on the base of the compartment thus turning on the switches underneath. This turning on/off of the switches 
would be used as an indication for detecting the actual presence/absence of pill(s) in each compartment of the pillbox logger. This method is expected to provide more accurate data about physical presence of pills in the compartment providing a more accurate pill intake record.

The requirement for the device to be portable and compact led to other requirements like battery powered and small, thin, rechargeable batteries. The need for the medication $\log$ to be easily available for review on demand required that a commonly used way to read the storage device in pillbox logger read be included in the design.

\subsubsection{Summary of Requirements}

All of the requirements mentioned above were considered in the process of developing the pillbox logger. It is quite possible, however that not all of them could be realized in the short term. Furthermore, qualitative goals such as convenience, time limit and expenses were satisfied to varying degrees. The design goals and the requirement were prioritized based on the necessity of the requirement, easiness and time to include the feature in the design. 


\section{Chapter 4}

\section{DESIGN}

This chapter provides details on technical description and justification of the pillbox logger design. It includes a detailed description of the hardware design of the pillbox logger and the software.

The design of electronic section of pillbox logger is described in Section 4.1. This section explains construction of the prototype, layout of the printed circuit board (PCB) and the software. The mechanical section on outer box design is covered in Section 4.2.

\subsection{Electronic Segment of pillbox logger}

\subsubsection{Design of Prototype}

A prototype of the electronic segment of pillbox logger was created and built before designing the PCB. This was helpful in validating the design and selecting the major components. The prototype also gave a good idea about the approximate size, location and connection of different components that would be on the final PCB. The prototype was designed and built by interconnecting independent development boards and specific electrical components together in a bread board format.

The following sections summarize the design of the pillbox in a series of nine steps. Each section describes a significant step towards the completion of the overall design. 


\section{Step 1: Choose Host Microcontroller}

An important step in building a prototype was to choose a host microcontroller. Since the pillbox logger requirements included switch(es) under each of the eight compartments and a vibration motor, the microcontroller was required to have nine or more digital I/O (Input /Output) pins. The design required the microcontroller to be connected to a storage device so it was necessary that a few pins on microcontroller be available for communicating with the storage device. Apart from these, some pins on the microcontroller would be needed to connect a crystal, power supply, and other connections that are used for basic start up of the microcontroller. The requirement for a number of general input/ output pins on microcontroller resulted in deciding in favor of a microcontroller that was available in a package with 32 pins or more. Also it was essential that a good development board be available for the microcontroller. A good development board is useful in understanding the operation of microcontroller, in developing a prototype and for debugging.

There were two commonly used microcontrollers to make a choice from: Microchip PIC (Peripheral Interface Controller) family and the Atmel AVR family. Different aspects of both these microcontroller families were compared before making a choice on the host microcontroller for the pillbox logger prototype.

a. Package: For prototype a chip that is easy to work with was needed. This required that the package be a dual in line package (DIP). However, for the final PCB a thin quad flat with no lead (TQFN) package, which is a small surface mount device, would be required. Both PIC (Peripheral Interface Controller) and AVR come in these packages. 
b. Languages: Both microcontrollers can be programmed in Assembly and C. Both PIC and AVR have assemblers available for free from Microchip (MPLab) and Atmel (AVRTools) respectively, for Windows. For AVR, there is also a free Unix command line assembler, avra, which can be run under MacOS X or Linux. Likewise, PICs have an assembler called gpasm [43].

$\mathrm{C}$ is one of the best languages for microcontrollers. It is fast and has features of arrays, pointers, and functions. For PICs, the standard compilers are from HiTech and CCS (C Compiler System) for Windows. A free compiler for PIC is also available which can be downloaded from the Microchip website and can be used in the Microchip MPLAB IDE. The free version is, however, a student's version and all its features are enabled only for the first week. After that, the compiler can optimize the code only up to two levels. There is also SDCC (Small Device C Compiler) which is an open source, free compiler for C code which can target most, but not all PIC devices [43].

The compiler for AVR is based on a commonly used avr-gcc, a version of gcc (GNU Compiler Collection) for the AVR microcontroller. There are various positive points about an avr-gcc. Firstly, it is free and works for different platforms like Macs, Linux, and Windows. Secondly, it supports features like standard libraries, includes, linking, unions, structures, and pointers, which make it more compatible with C. Lastly, it uses the same optimizer as every other gcc and generates efficient code.

c. Software Integrated Development Environment (IDE): Both AVR studio and MPLab for PICs have similar features so both are equally good with respect to IDE. 
d. Beginner's Development Board: These development boards are aimed at people starting with microcontrollers for the first time. There are two broad options: Basic Stamp and Arduino.

BASIC Stamp is a development board from Parallax Inc. It is programmable in BASIC, has a PIC with a BASIC interpreter, EEPROM for storing instructions, RS232 converter.

A contender for BASIC Stamp in development boards is Arduino. Various versions of Arduino are available. They are programmable in Arduinase language, which is based on $\mathrm{C}$ with some macros, and use AVR as the main microcontroller. The Arduino board generally comes with direct USB (Universal Serial Bus) connections or some extension board for USB instead of RS232.

e. Price: There are various chip sets available for both PIC and AVR which vary in price. However for the project described in this thesis a microcontroller with at least 32 pins was needed. Since PIC, unlike AVR, does not come in a 32 pin package, prices for a 40 pin package and 32 pin package for both the microcontroller were compared. The 40-pin PIC18F452 cost was $\$ 10.35$ and the ATmega32 cost was $\$ 8.17$.

f. Online Support: Both PIC and AVR have substantial online support at PIClist.com and AVRfreaks.com. However, there are a greater number of online forums dedicated to Arduino than Basic Stamp. 


\begin{tabular}{|c|c|c|}
\hline Features & $\begin{array}{c}\text { AVR } \\
\text { (points out of 5) }\end{array}$ & $\begin{array}{c}\text { PIC } \\
\text { (points out of 5) }\end{array}$ \\
\hline Package & 5 & 4.5 \\
\hline Languages & 4 & 3 \\
\hline Software IDE & 4 & 4 \\
\hline $\begin{array}{c}\text { Development } \\
\text { board }\end{array}$ & 5 & 4 \\
\hline Price & 5 & 4 \\
\hline Online Support & 5 & 4 \\
\hline Experience & 2 & 0 \\
\hline Total & $30 / 35$ & $23.5 / 35$ \\
\hline
\end{tabular}

Table 4.1: Score table comparing different features between PIC and AVR microcontroller

All the required features of the two major microcontroller families are listed (Table 4.1) and both the microcontrollers were awarded points corresponding to each feature. After analyzing the total points in Table 4.1, it was clear that an Atmel AVR was a better choice for the pillbox logger design than a PIC.

The Arduino Duemilanove (2009), a development board for AVR, was used for starting the prototype design. The choice of Arduino Duemilanove was made because it is one of the most widely used AVR development boards. I also had previous experience with it. It has an ATmega328 as the host microcontroller in a 32 pin DIP package. There are six analog inputs and fourteen digital input/output pins, out of which six can be used as PWM output. The board has a $16 \mathrm{MHz}$ crystal oscillator and a USB connection to interact with a computer which powers up the board, if needed [26]. There is a reset 
button and a power jack for an external power connection. The board runs at a power supply of $5 \mathrm{~V}$. The Atmega328 on the Arduino board comes pre-burned with a bootloader that allows the developer to upload new code to it without the use of an external hardware programmer.

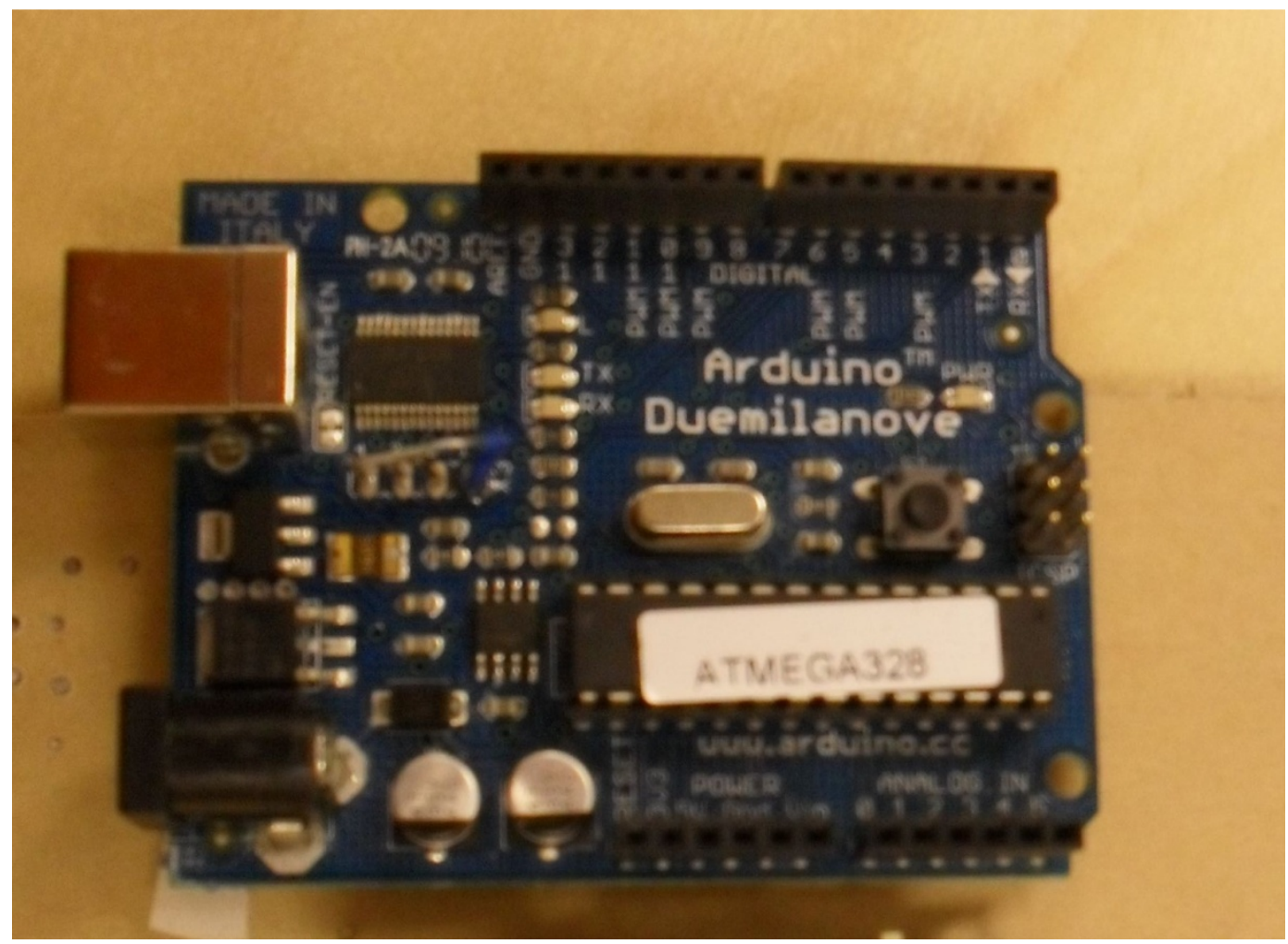

Fig. 4.1: Photograph of an Arduino Duemilanove (Image by Beenish Zia)

\section{Step 2: Select Switches}

The next step was to select switches to connect to the Arduino board and detect the state (On/Off) of the switches. The design of the pillbox logger required the presence of at least one switch at the bottom of each compartment. When the pills are present in a compartment, the pressure of pills when the lid of the compartment is closed should be enough to turn the switch on, thus sending a signal to microcontroller indicating that pills 
are present in the pillbox. This required the switches to indicate such an event and send a signal only when pressed and send no signal when released. Small push button switches, which are single throw, single pole switches also known as momentary switches, were chosen based on this requirement. Momentary switches turn on (closed) when pushed and turn off (open) when released.

Since the pressure of the pills was to be used to turn on the switches, it was required that the operating force of the switches be small. After a number of trials with actual pills pressing different momentary switches, a $50 \mathrm{gf}$ (gram force) operating force looked ideal for the design. A special category of momentary switches known as tactile switches were chosen. Since a 50 gf momentary switch was available only in an SMD (Surface Mount Device) package, a different momentary switch which came in a through hole package but with operating force of $100 \mathrm{gf}$ was chosen for prototype designing, since it could be easily placed in the bread board while prototyping. The $50 \mathrm{gf}$ momentary switches were used in the final PCB design.

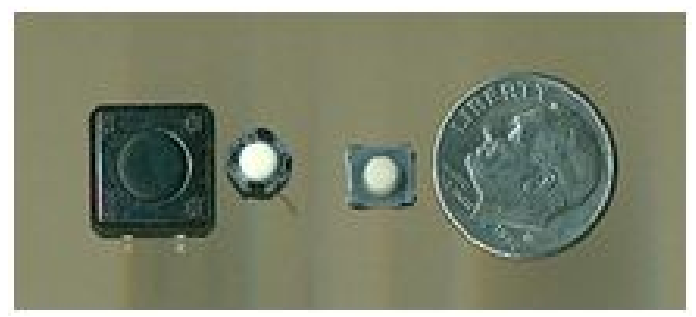

Fig. 4.2: 100gf Momentary switch that was used in prototype (extreme left), 50gf momentary switch used for final design (second from right) compared to a dime and another $80 \mathrm{gf}$ momentary switch that was tried before choosing the 50 gf switch (Image by Beenish Zia) 


\section{Step 3: Detect The State (ON/OFF) of the Switches}

For detecting the state of the switches (On/Off), the momentary switches were connected to the digital I/O pins of the Arduino board. The Arduino board was then loaded with a test code for detecting state of switches. The correct state of switches were tested by connecting light emitting diodes (LEDs) to each switch through a different $\mathrm{I} / \mathrm{O}$ pin on the Arduino board. When a switch was pressed an input signal was sent to microcontroller, which, in turn, sent an output signal causing the corresponding LED to glow.

\section{Step 4: Storage Device Selection}

The existing designs of pillboxes that have memory for storing the information about medication adherence of subjects have mostly used the EEPROM of microcontroller for that purpose [1][18][19]. That choice has resulted in smaller duration of information record ranging from seven days to few weeks. This has provided inconsistent intermittent information on medication intake by a subject. The storage device for the proposed pillbox logger should be able to store information continuously for at least a year, without being erased. A complete, continuous year's record of a subject's medication record would provide more consistent, reliable information to the doctor. A storage device with a large capacity would also help subjects avoid unnecessary trips to their doctor just to have their medication record transferred to the doctor's system before the memory of the device gets full.

Since the dimensions of the proposed portable pillbox logger were tight and not much space was available for a storage device, a small size but large capacity 2GB micro SD (Secure Digital) card appeared to be the best choice. The dimensions of a micro SD card are $\approx 11 \times 15 \times 1 \mathrm{~mm}$. The socket used to hold micro SD cards are generally a few 
millimeters more than the dimensions of the SD card but small enough to fit into the pillbox logger design easily.

For ease of use, we decided to store information on the SD card in a file in plain text format (.txt file). It was calculated that a single line of information which contains date, time followed by state of each compartment in 1/0 form, uses $~ 32$ bytes of memory space. This implied that $2 \mathrm{~GB}$ of storage space would allow $\sim 2^{26}$ different lines of recording without being erased, which would be sufficient to last a year.
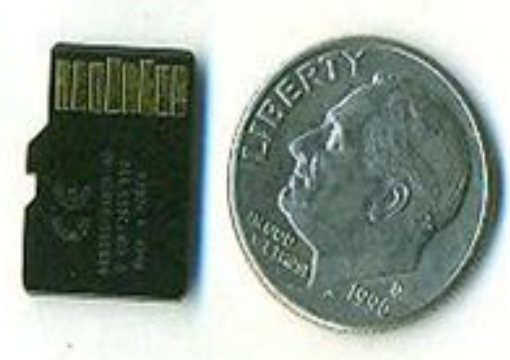

Fig. 4.3: Size of a micro SD card compared to that of a dime (Image by Beenish Zia)

\section{Step 5: Record the Switch State in Memory}

There were two major possibilities of externally connecting an SD card to the Arduino. One way as described in [29] was to use an SD card socket and externally wire its pins to the corresponding pins on Arduino. The second way is to use an Arduino board compatible SD card module manufactured by a European company called Libelium [31].

Though both options to connect the SD card to Arduino use the same basic principle for connection, the first option as shown in Fig. 4.5 needed to build a prototype board for connecting SD card to Arduino. The second option came in an application specific development board as shown in Fig. 4.6. The second option required less time and testing so it was chosen over the first one. 


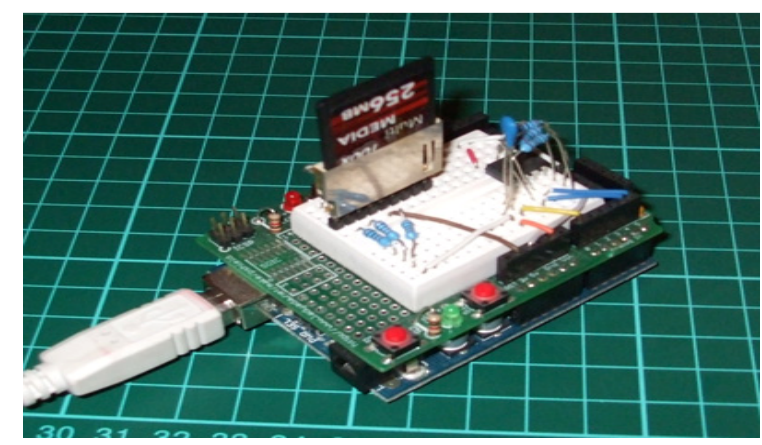

Fig. 4.4: Prototype board for connecting SD card to Arduino board.

(Image by agent_orange [29])

The Libelium Micro-SD module for Arduino as shown in Fig. 4.6 is a small board with micro SD card socket attached to it and all the necessary connections for powering up the SD card done. It has male header pins soldered which could be easily plugged into the female header pins on Arduino board. Arduino's rich library has built-in functions dedicated to SD cards. The pre-existing SD library was used in test code for reading/writing micro SD card.

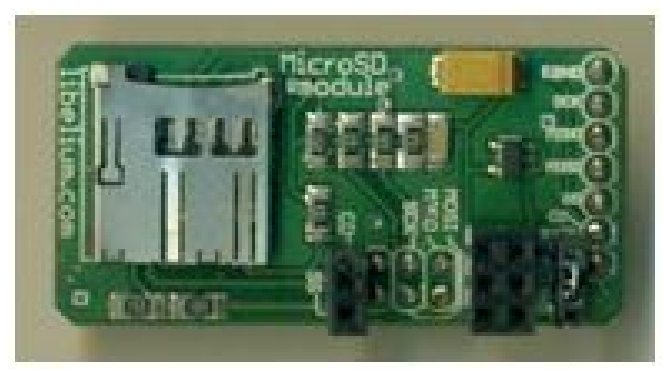

Fig. 4.5: Libelium Micro SD module (Image by Beenish Zia)

After the switches had been connected and the coded Arduino program had been tested thoroughly for proper reading/writing of the SD card, a specific format was vital to record the data received from switches. The prime concern was to store all the 
information in a way that used less space on storage device and was easily readable. Storing information in plain text (.txt) file was a simple solution to this concern. Since the key idea was to store all text information in as less memory space as possible, it was decided that the international standard (ISO 8601) [42] representation for date and time be used, followed by state of switches in $1 / 0$ form. Thus the final format that was followed for writing the state of the switches on SD card was mm/dd/yyyyhh:min:ss=>s1, s2, s3, s4 etc. where mm stands for month, dd for date, yyyy for year, hh for hours (24 hour format), min for minutes, and ss for seconds. s1, s2 etc. depict state of switches 1 to 6 in 1/0 formats. 0 signifies the presence of pills (switch pressed or closed), and 1 signifies absence of pills (switch not pressed or open). The state of switches are checked every five seconds and logged only when a change is detected in state of any one or more of the switches.

\section{Step 6: Reading the Memory through USB}

There were two main approaches that could be followed for reading the data stored in memory (micro SD card). Either the SD card could be removed from the pillbox and read by plugging it into an external SD card reader or a USB interface could be designed in the pillbox logger to read the SD card.

There were a few disadvantages to the first method. Having to unplug the micro SD card every time, which could be once or twice every month, to read the data is cumbersome. Not many users would like to plug out the tiny SD card from the pillbox and plug it into a SD card reader every time to read it. It would be a hassle for even the doctors to plug out micro SD cards from each subject's pillbox, read it, and then plug it back into the right pillbox. Hence, it was decided that having USB read of micro SD card 
would be more convenient and efficient. Windows, Linux, MacOS all the three major operating systems have ability to read memory using a USB port, hence use a USB to read the memory would make pillbox logger easy to use on any operating system.

However, since now the SD card would be inside the pillbox logger while it was being read, it was crucial to have some bypass chip that would allow either USB to read SD card or microcontroller to write to it.

The main solution to the problem of separating the read and write cycles was to find a micro-SD to USB converter chip. The design required that when a USB connection was detected the micro-controller be informed about it and stop writing to memory. Once the micro-controller had completed its writing, a handshake signal should be sent to the converter chip to allow the USB to read the memory.

There was only one chip that satisfied all the requirements: the Maxim 14502 high speed USB-SD card reader [38]. The Maxim 14502 chips have two distinct read and write modes for SD cards, a desirable feature for pillbox logger. The two operation modes of these chips are the pass through and the card read mode. In the pass through mode an externally connected micro-controller could write to the SD card. In the Cardread mode the SD card can be read using a USB port.

For the prototype, the Maxim 14502 evaluation kit was chosen over using individual Maxim (Max) 14502 chip by itself which comes in a $5 \mathrm{~mm}$ x $5 \mathrm{~mm}$ TQFN package. Because of lack of experience with the Max 14502 chip and difficulty of soldering a 40 pin TQFN package, the evaluation board for Max 14502 chip was used for the prototype. The Maxim 14502 EV (Evaluation) kit comes with a socket for a micro SD card, Maxim 14502 chip soldered onto it, various pin outs, three USB ports and various other plug in 
and plug outs, which made interfacing it with the Arduino board and understanding its operation easier.

The Maxim 14502 EV kit board had MAXQ2200 chip soldered onto the board, which was acting as the local host processor for all the operation. For the prototype, the MAXQ2200 was bypassed to use ATmega328 on Arduino board as the host processor instead.

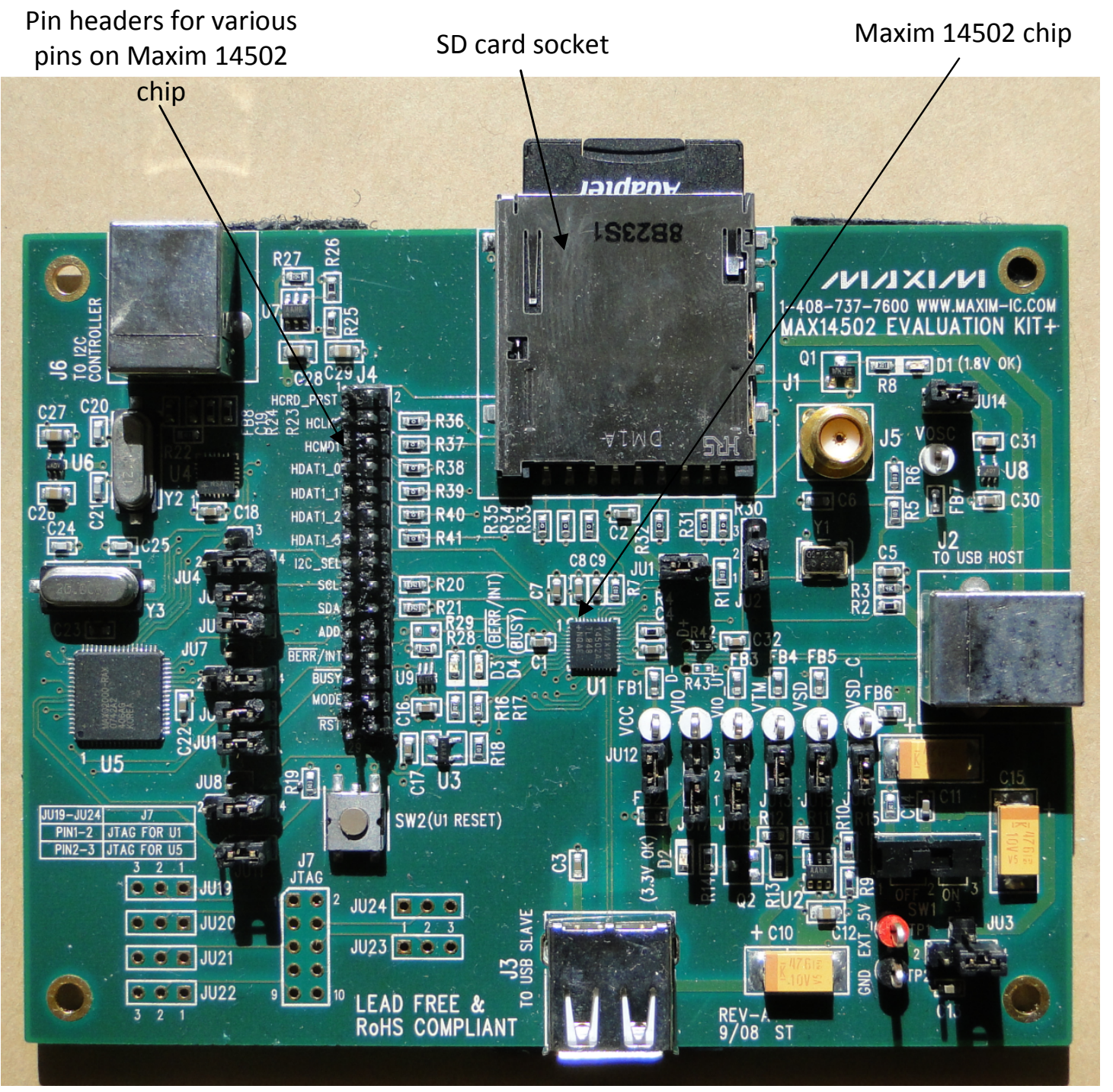

Fig. 4.6: Maxim 14502 Evaluation Kit (Image by Beenish Zia) 
A significant feature of the Maxim $14502 \mathrm{EV}$ board was that it had pin header outlets for all the pins needed to communicate to SD card using an external micro-controller and Maxim 14502 chip. This made connecting Arduino board and Maxim EV board using jumper wires easy. The SD card socket on Max EV board eliminated the need to use the Libelium SD card module for reading/writing the SD card.

However, the Maxim $14502 \mathrm{EV}$ board used a power supply of $3.3 \mathrm{~V}$ across all the components on the board. Unlike the Maxim EV board, the Arduino Duemilanove used a power supply of $5 \mathrm{~V}$. This mismatch between the power supplies resulted in failure to write to SD card during the pass through mode of Maxim 14502 chip by the AVR.

There were two solutions to the problem of non-uniform power across the AVR development board and the USB-SD card read evaluation board. Either a converter chip could be used to convert the $5 \mathrm{~V}$ coming out of Arduino Duemilanove board to $3.3 \mathrm{~V}$ or another model of Arduino board, which had almost same features as the Arduino Duemilanove, but was powered by $3.3 \mathrm{~V}$, could be used. The second option was chosen over the first because that gave uniform power supply over the whole prototype, was easier, ultimately would reduce production costs, and required less time.

The Arduino-Pro board which is sleeker than Arduino Duemilanove board, uses the ATmega 328, has an $8 \mathrm{MHz}$ crystal, and is powered by a $3.3 \mathrm{~V}$ power supply, was chosen as the development board for AVR [25]. It has almost the same features as Arduino Duemilanove and was the only available Arduino with ATmega 328 and $3.3 \mathrm{~V}$ power supply. The Arduino Pro board, however, did not have a USB port. An external Future Technology Devices International (FTDI) basic board was used to power it using a USB cable. 


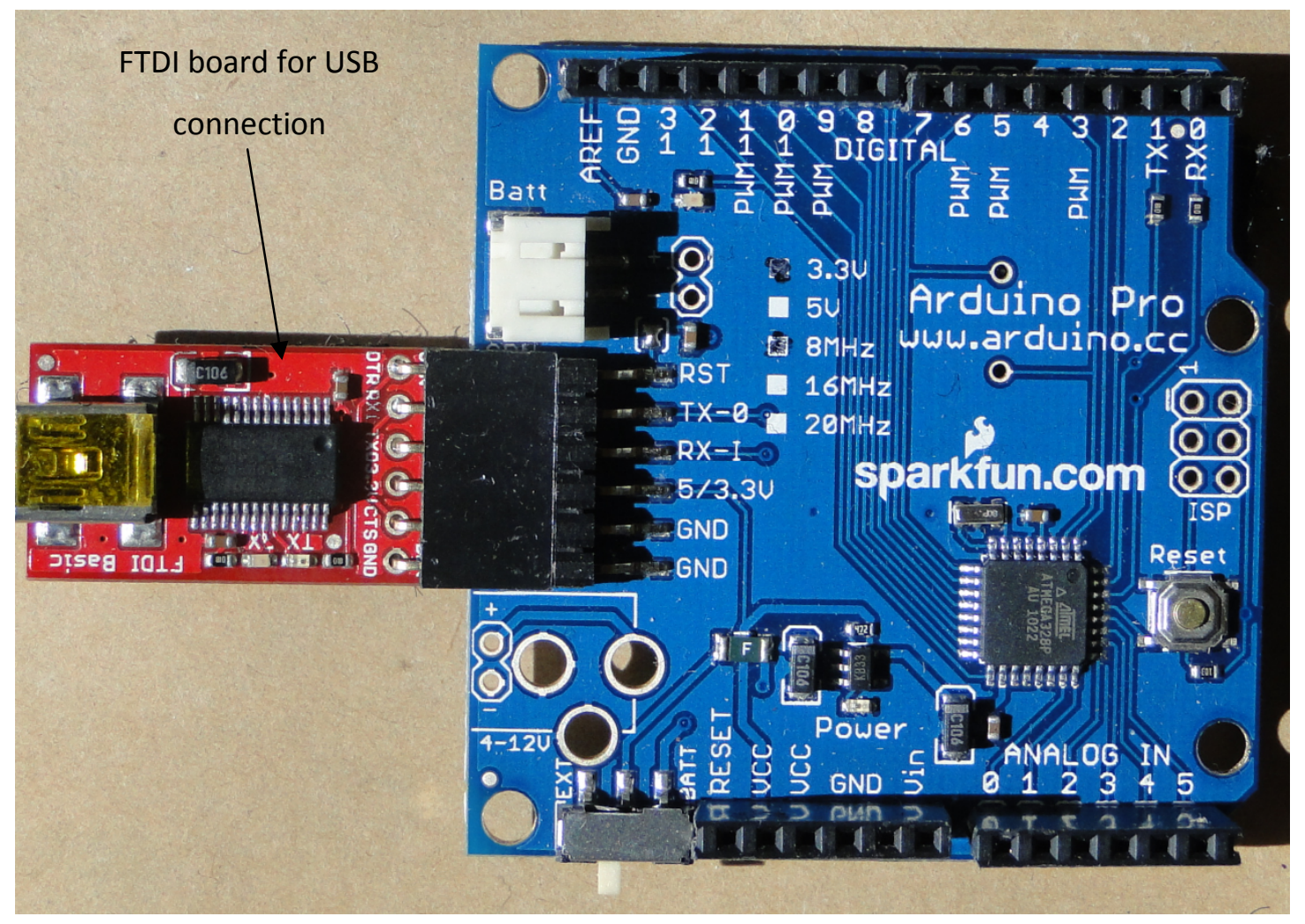

Fig. 4.7: Arduino Pro - development board for AVR (Image by Beenish Zia)

Memory read/write by use of Arduino Pro and Maxim EV board was thoroughly tested. When the mode pin of the Maxim 14502 chip was externally connected to ground (GND) the chip was in pass-through mode and the Arduino board was able to write to the SD card. When the mode pin was connected to $3.3 \mathrm{~V}$, the chip was in card-read mode and the SD card could be read using the USB port. For prototype testing a common USB port was used to power up the Max 14502 EV board through a computer, which, in turn, powered the Arduino Pro board. The same USB port was used to upload the Arduino code on ATmega 328 chip on Arduino board from a computer. This was the same USB port that was used to read the SD card in card-read mode. 


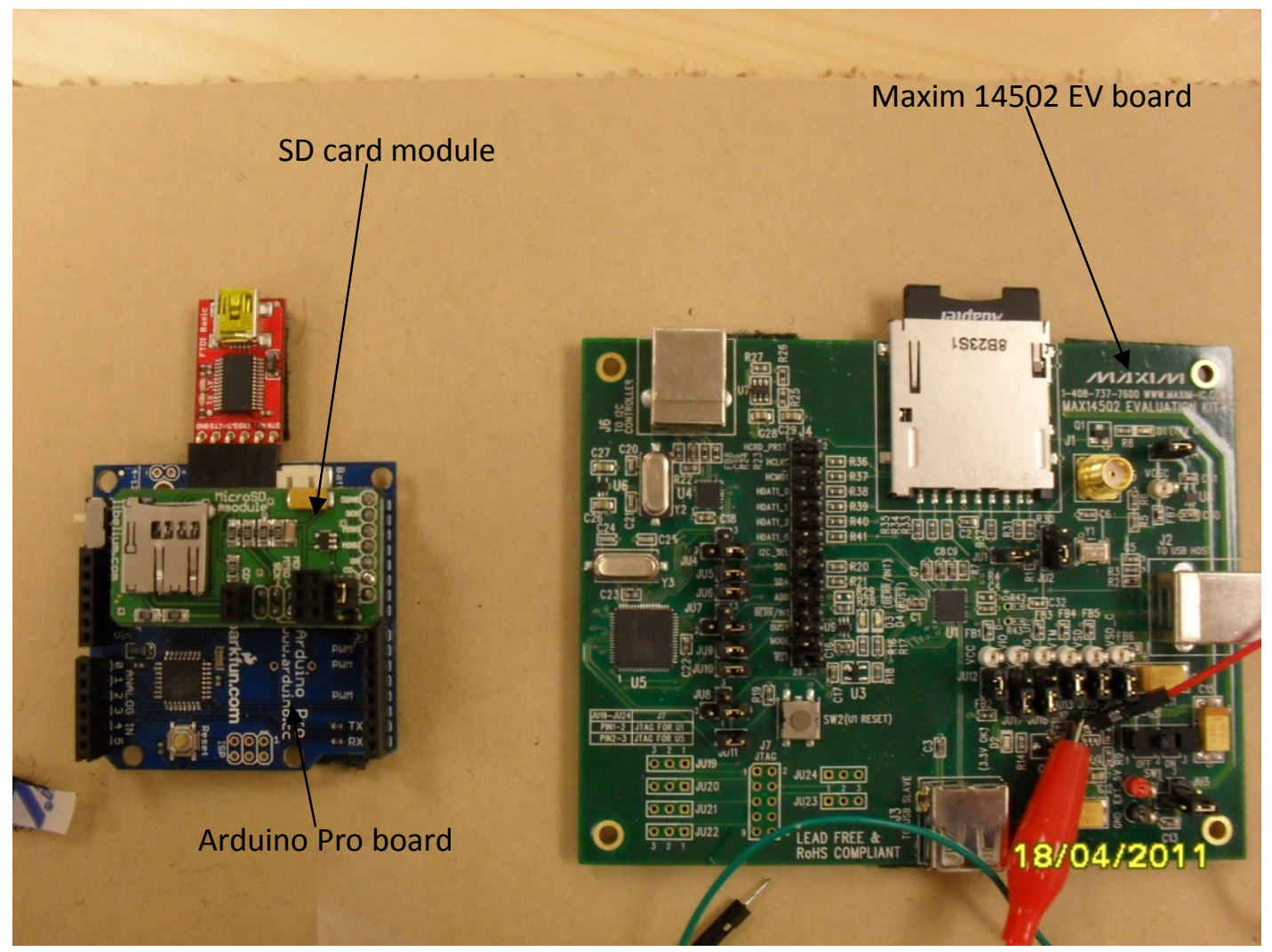

Fig. 4.8: Maxim 14502 EV board, Arduino Pro board and SD card module, before connecting. (Image by Beenish Zia)

\section{Step 7: Connect Vibration Motor}

The idea of having a vibration motor in the pillbox was to send a vibration alarm to remind the subject to take the pills. A vibration alarm was chosen over other forms of alarm system for two main reasons. First, the majority of the PD subjects who were interviewed stated that they would prefer a vibration alarm over audio alarm because they found audio alarms annoying to them and to people around them. Secondly, since the proposed pillbox logger has been designed to be portable, it is expected that most of the time the user would have the pillbox in his/her pocket or in their bag. Since, the pillbox logger would not be in direct sight for most of the day, having a visual alarm was not an 
important feature. Also, adding a visual alarm would consume additional battery power, which was not desirable for a battery powered device. An additional audio alarm using a magnetic speaker was, however, added. The pillbox logger was programmed to turn it on only if the user required it. By default the pillbox logger was programmed to turn on only the vibration alarm system. Audio alarm may be a required feature for elderly users of pillbox logger who might not be able to sense the vibration alarm.

The vibration motor that was chosen was a simple DC vibration motor, similar to ones used in cell-phones and pagers. There is an offset weight attached to the shaft of the motor that causes vibration when the motor spins. The tiny motor has two metal plates on its outer covering, one of which is connected to the positive end of power supply and other to ground.

The positive terminal of the vibration motor was connected to one of the Pulse Width Modulation (PWM) out pins on Arduino and the negative terminal was grounded. Arduino was then programmed to set the assigned pin high for few seconds and repeat this action after regular intervals of time until a specific time of day.

\section{Step 8: Initialize Date, Time, and The First Alarm Time}

One of the last steps in building a prototype for the pillbox was to initialize all the timing variables used in the prototype. Since, the subject's caretaker, doctor, or, in some cases, the subjects themselves would be setting the initial date, time, first alarm time, it was important to make the initialization operation simple and easy. There were three ways the initialization operation could be done. 
a. Real Time Clocking (RTC) system. Using RTC would mean that every time the pillbox logger was plugged into a computer it would set its time according to the computer time. However, this would involve writing complex code in Arduino language.

b. Buttons. Another option was to use a small display and reset buttons like digital watches to initialize time and first alarm start time. This too would involve complex code in Arduino along with adding extra hardware in form of reset buttons and display screen to the pillbox logger. Since the pillbox logger has been designed to be portable, adding a feature like this would result in adding some kind of lock feature along with it. The lock feature would prevent any unintentional pressing of time buttons on pillbox logger. Extra hardware in this form would require more time as well as increase the total weight of pillbox.

c. File-based Initialization. A third option was to have two files on the SD card: one file to initialize date and time and a second one to initialize the time for first alarm of the day. The code uploaded on AVR would read the files from SD card and initialize the time variables in the code. The code will then use the frequency of the crystal attached to the AVR to increment values of time variables every second. However, this initialization would be done by doctor/subject's caretaker/subject and they would have to follow a certain format in which they write the data on SD card.

Using the option (c) for initialization seemed easily achievable. It did not require any complex coding, adding extra hardware to the pillbox logger, and gave the user of pillbox a choice to initialize the time as per his/her choice. Once the device was initialized and turned on, it would stick to the initialized values unless it was changed. 
There are few drawbacks to this method of initialization. First, the user would have to initialize the date and time to some value before the actual initialized time and then remember to turn on the pillbox at the initialized time. If the subject forgets to turn on the device at the initialized time then there may be mismatch between the real time and the time recorded on SD card. However, it is expected that in most cases a clinician would initialize the pillbox before handing it to the subject. Second, the subject must enter the initial date and time on a specific SD card file and in a specific format. The format for date and time initialization uses the international standard format as mentioned under Step 4. Similarly the time for first alarm of the day would be initialized in a different specific file in the same ISO format for time, where the initialized value would be when the alarm would first ring. The code by default has settings of alarm remaining on for 5 seconds and the alarm going off regularly every 4 hours after the first alarm time, till 10 o'clock at night. These default values can be easily changed in the Arduino code or be programmed to be read from SD card. Lastly, though convenient and easily achievable for first generation pillbox logger design, a graphical user interface to program current time and sequence of alarm times would be more user friendly than editing text files written in a specific format.

\section{Step 9: Combine and Test all Features of the Prototype}

Getting the electronic section for a working prototype of the pillbox logger required combining all the above mentioned steps into a sequential flow process. The major step in accomplishing this task was to write a single code in Arduino, which would do all the operations in a regular flow as shown in Fig.4.9. 


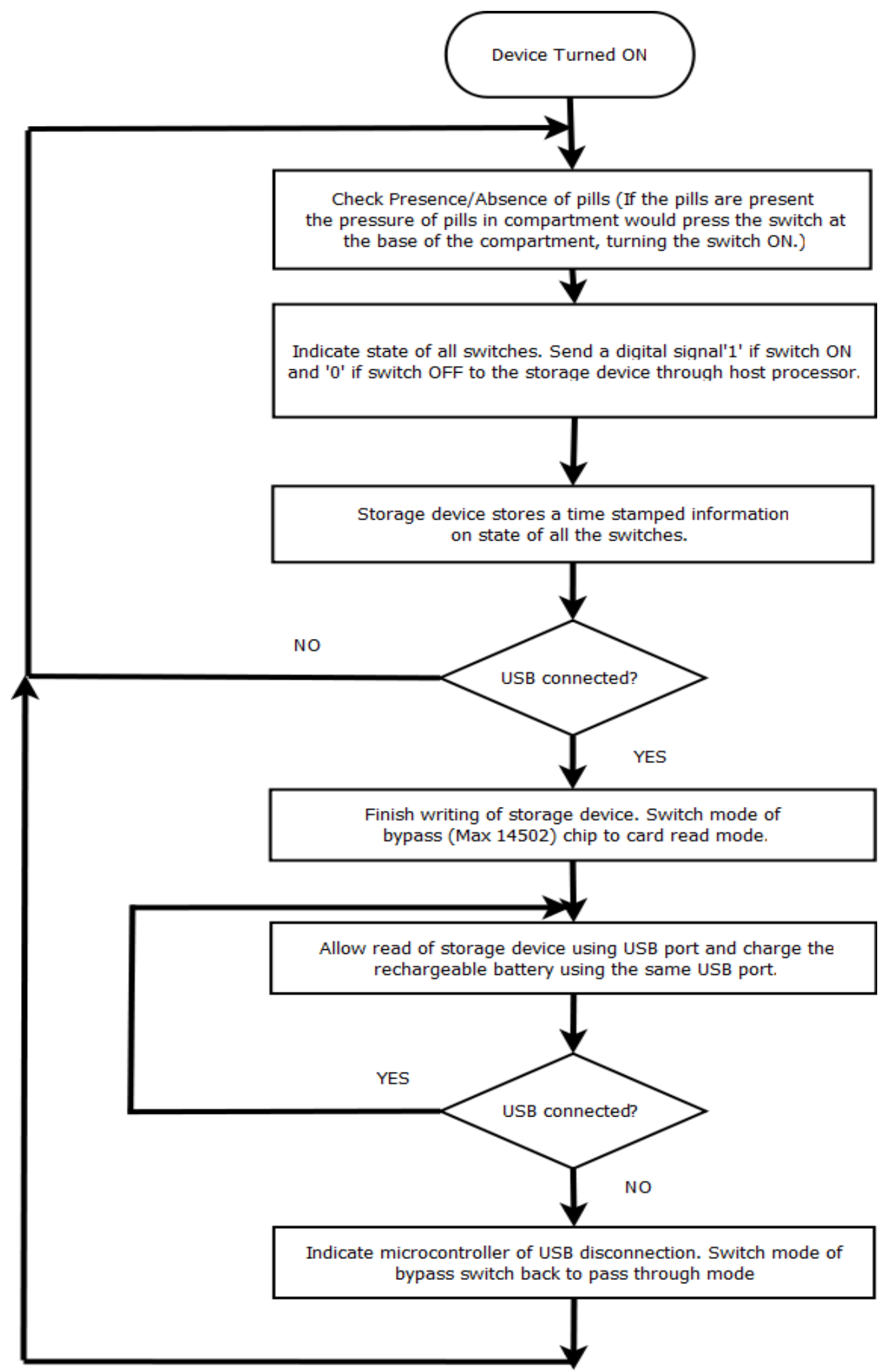

Fig.4.9: Flow chart representing the sequential flow of operations in the electronic section of the pillbox logger. 
The final code had three major sections. The first part did all of the initialization. It initialized the date and time, the first alarm time from SD card, and other variables from within the code. The second section consisted of a loop that checked the state of the six switches and recorded their state on the SD card along with date and time of check. It then checked whether it was time to vibrate alarm. If it was it would send signal to analog out pin of the Arduino. That signal would, in turn, vibrate the vibration motor attached to it for 5 seconds. The 5 second delay was then added to the time calculation block. This loop operation continues until the power is turned off.

The prototype was designed so that as long as the SD card was being written by Arduino, the Maxim14502 was in pass-through mode. To read the SD card, the Max 14502 chip needed to be reset and then changed to card read mode. For the two different modes of Max 14502 chip, there is a common mode pin, which was manually set high or low according to the mode desired. However, this was only for the prototype. For the final PCB the state of the mode pin on Maxim 14502 were controlled by the microcontroller as described in section 4.1.2.6. This could not be done for prototype because sufficient pin outs were not available in the Maxim EV board to make the required connections. 


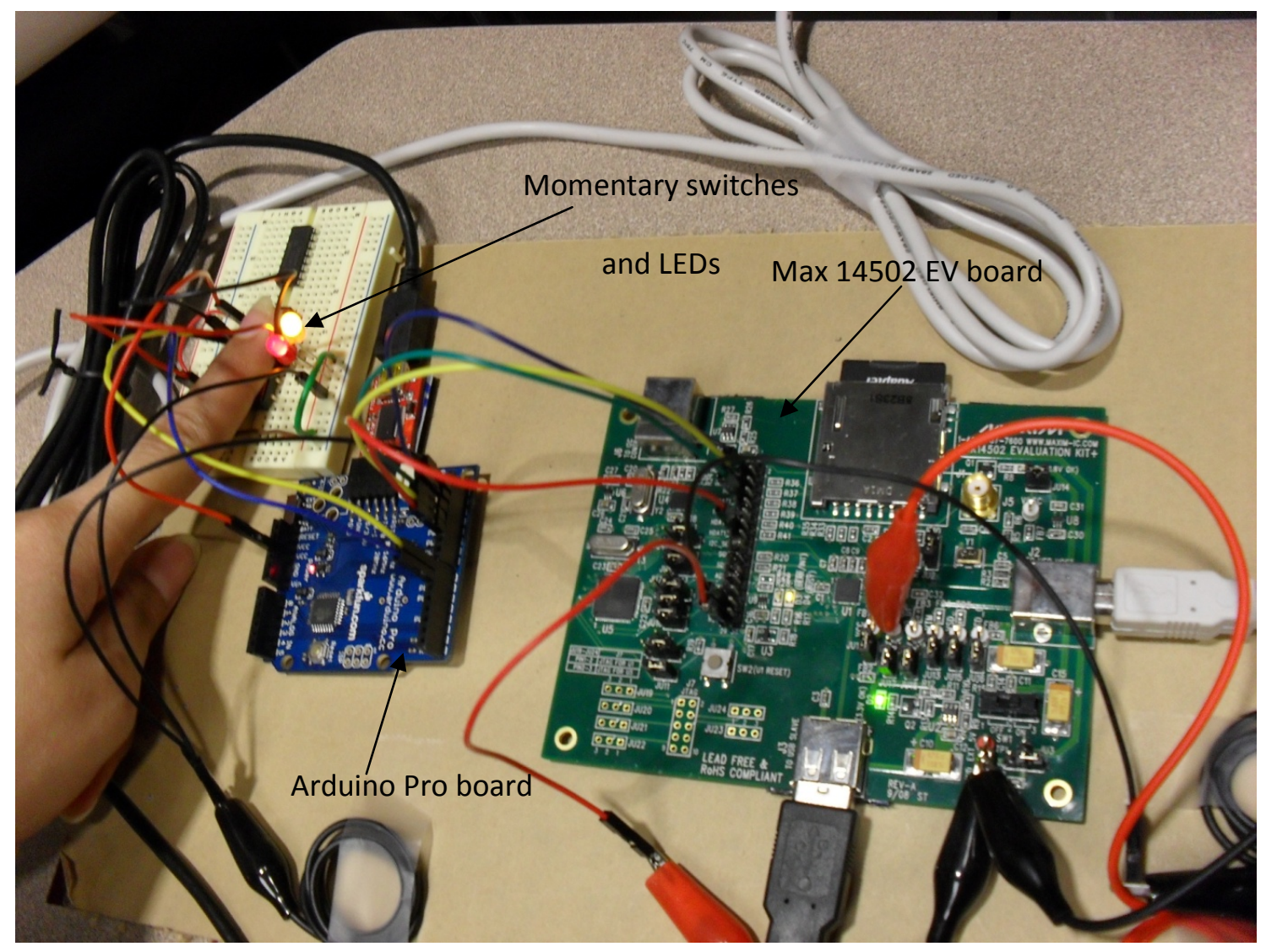

Fig. 4.10: Prototype of the electronic section of proposed pillbox logger, with all connections done (Image by Beenish Zia)

This step concluded the process of getting a working prototype for the electronic section. The prototype gave an idea about the basic electronic components and their connections, which proved helpful in laying out the printed circuit board (PCB).

\subsubsection{Design of Printed Circuit Board (PCB)}

The prototype supported the choice of components for the electronic section of pillbox logger. It also gave a thorough understanding of the connections between those components. For designing the $\mathrm{PCB}$, issues like component sizes, wire lengths, supply planes, layers, location of components, parasitic impedances, bootloading and battery charging were addressed. Cadsoft Eagle 5.11 was used to design the printed circuit board. 


\subsubsection{Size of PCB and Components}

PCB: A mechanical model of the pillbox logger illustrated that the pillbox logger would have two rows of four compartments. The size of each compartment would be $25.4 \mathrm{~mm} \mathrm{x}$ $25.4 \mathrm{~mm}$, and the two rows of compartments would be separated by a gap of $\approx 12 \mathrm{~mm}$. The base of the pillbox logger would be $\approx 113 \mathrm{~mm}$ x $66.5 \mathrm{~mm}$. Since switches were to be placed under the base of each compartment, this required the PCB to be at the base of the pillbox logger and have dimensions big enough to cover an area encompassing all the switches. This meant the PCB would need to be made a few millimeters smaller than the size of the base of the pillbox logger. The PCB dimensions were hence decided to be $106 \mathrm{~mm} \times 54 \mathrm{~mm}$. This insured that PCB covered all the switches, as well as easily fitted at the base of pill box. The thickness of PCBs in general is $0.0625 \mathrm{~mm}$. It was assumed that the PCB for the pillbox logger would be this thickness.

Components: For ease of portability the thickness of the pillbox was required to be as small as possible. The mechanical model of pillbox showed that the largest sized PD medication would fit easily in a compartment with a depth $\approx 16.05 \mathrm{~mm}$. A desirable feature of the PCB was to minimize added thickness to the already $16 \mathrm{~mm}$ deep pillbox logger. Hence all the components for PCB were chosen to be surface mount devices (SMD) in the smallest package available. Max 14502 and ATmega328 were chosen in TQFN (Thin Quad Flat with No lead) and TQFP (Thin Quad Flat Package) respectively, which are $5 \mathrm{~mm} \times 5 \mathrm{~mm} \times 0.88 \mathrm{~mm}$ since other packages were bigger and few millimeters thicker. Apart from the vibration motor, micro USB connector, and switches, all other components like resistors, capacitors, and LEDs, were less than $2 \mathrm{~mm}$ in height. The minimum sized vibration motor that was available in bulk was $\approx 6 \mathrm{~mm}$ tall. Similarly, 
the smallest size sturdy micro B series USB connector available was $\approx 3 \mathrm{~mm}$ tall. However, these two components were placed in the $12 \mathrm{~mm}$ gap between the two rows of compartments in a way such that they did not add any extra height to the pillbox logger. However, $\approx 1 \mathrm{~mm}$ extra thickness was added because of the switches on the bottom of the $\mathrm{PCB}$ and $\approx 2 \mathrm{~mm}$ at the top of the $\mathrm{PCB}$, because of other components. Hence, the electronic section added $\approx 3 \mathrm{~mm}$ of extra thickness to the pillbox logger. Compared to the thickness of the mechanical model, this was a small addition and did not add any significant increase in height of pillbox logger.

\subsubsection{Location}

The next important issue in designing the PCB was to determine the location of all components. The exact location of the momentary switches on PCB was most important. Since the base of each compartment would have switches for detecting the presence/absence of pills in the compartment, it was crucial to determine the exact location and number of switches required for that purpose. Having a single switch at the center of each compartment would not guarantee detection of pills in the worst case when a single small size pill may be lying in one of the corners of the compartment. Hence, this required that at least four switches be placed under the base of each compartment, with one switch near each of the four corners of every compartment.

A set of four switches were placed under each compartment which assured detection of pill/s even in the worst case. The mechanical design of the pillbox logger showed that each compartment base would be $25.4 \mathrm{~mm} \times 25.4 \mathrm{~mm}$ in size with rounded edges. Hence, four switches were placed at each corner under each compartment with $6 \mathrm{~mm}$ spacing between two switches in a compartment and 7.30mm spacing between switches in 
consecutive compartments. The four switches were connected in parallel so at least one of the four switches under each compartment was on (pressed) when the compartment was detected to be having pill(s).

To save some pins on the microcontroller the set of eight switches (with four parallel connected switches in each set) were connected to the host controller (Atmega328) using an $8 x 1$ mux/demux (multiplexer/de-multiplexer) on the PCB. The $8 \times 1$ mux/demux has three select line, eight input lines, one enable pin and one output line. The output pin and the select pins of the mux were connected to the host controller. The eight input lines were connected to the set of eight switches under each compartment. The host controller selects each input line in a sequence and writes to the SD card the detected state $(1 / 0)$ that it receives from the output line of the mux. Unlike the prototype, the PCB uses this method for detecting and then recording the state of each compartment (empty/full) of the pillbox logger. This change in switch connection and compartment state detection using an $8 \times 1$ mux/demux resulted in modification of software code also which is discussed in section 4.1.2.6

Like the vibration motor, the micro USB connector was placed on bottom of the board positioned under the $12 \mathrm{~mm}$ gap between the two rows of compartment in pillbox logger, since it was a taller component. This requirement led to determining the exact location of pads on PCB for connecting these two components.

The switches needed to touch the base of each compartment to detect the presence/absence of pills in the pillbox. Hence the switches along with the vibration motor and the USB connector were placed on the bottom layer of the PCB. The rest of the components were placed on the top layer of the PCB. 
The exact location of other components like the AVR, Max 14502 chip, resistors, capacitors, LEDs, and MOSFETs were established based on factors like shortest routing path, least parasitic impedances, and ease of placement.

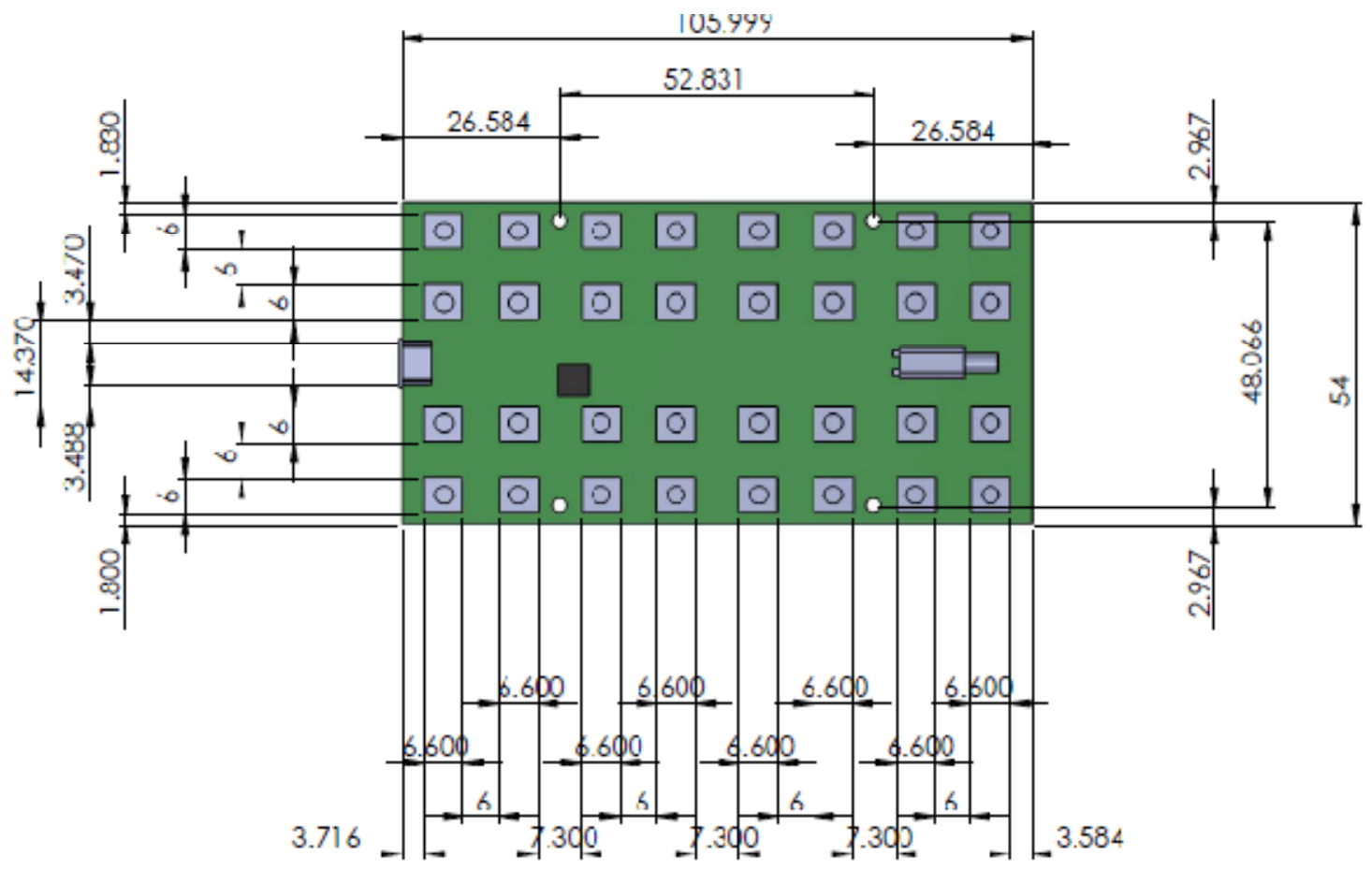

Fig. 4.11: Dimensions of the bottom side of PCB with switches, vibration motor and USB connector from Solid works (Image by Joshua Booren)

\subsubsection{Battery size, location and charging}

An important feature that was not taken care of in the prototype design was battery connection. The prototype was powered by an external power supply so it was missing a very crucial part of final design. All the components on the prototype board were powered by a power supply in the range of $3.3 \mathrm{~V}-2.5 \mathrm{~V}$, hence a battery power supplying a $3.3 \mathrm{~V}-2.5 \mathrm{~V}$ was required. The batteries also needed to be small, thin, and light so that 
they could be easily placed in pillbox without increasing dimensions of pillbox. Two rechargeable $3.7 \mathrm{~V}$ Li-ion polymer batteries with $40 \mathrm{mAh}$ and $0.85 \mathrm{~mm}$ thickness appeared to be ideal [48]. Since the batteries were less than $1 \mathrm{~mm}$, the pads for battery connections could be easily placed at the top layer of the PCB. An advantage to having components like battery, micro SD card located on top of PCB was that they can be easily replaced when needed without having to take the whole board out of the pillbox logger.

\section{Recharging the batteries}

The same USB used to read the micro SD card is used to recharge the batteries. This avoids adding another connector to the pillbox design for just recharging the batteries. It would also save space and time in including an extra USB connector to pillbox logger.

However, to do that chips would be needed that would allow battery recharging, voltage regulation, and would send a signal out to AVR that could be used to detect the USB connection as well as indicate if the battery was discharged. The USB detection would lead to proper turn off of the SD write operation by AVR and get the SD card ready for USB read operation.

One of the many options provided by Maxim for battery charging using the USB port while also providing voltage regulation and external device read was a circuit using a combination of the Max 1555 chip and the Max 8881 chip [39]. Out of all the alternatives provided by Maxim, there were several reasons for choosing this option. Firstly, the circuit will charge the battery whenever the pillbox logger is docked to a USB port. At the same time, the system load would be connected to the battery through a simple linear regulator (Max 8881) which is capable of supplying up to 200mA. So as long as the 
average load current is less than charging current, the battery will charge. Secondly, one characteristic of Max 1555 that was required by the USB specification is that current should never be allowed to flow back to a power input from either the battery or another power input. In conventional chargers, this can be guaranteed with input diodes, but the small difference between the minimum USB voltage and the required lithium battery voltage makes even the Schottky diodes inappropriate. For this reason all reverse current paths had been blocked within the Max 1555. Thirdly, the circuit was simplest of all the choices available.

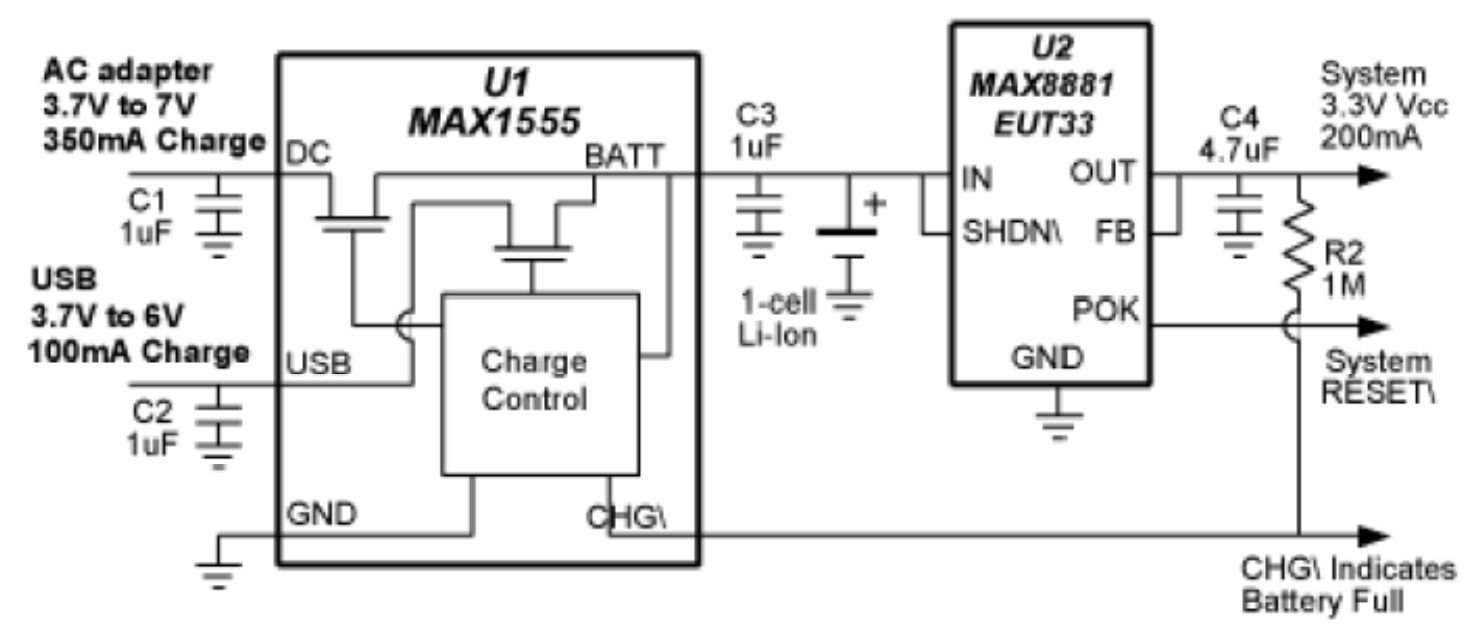

Fig. 4.12: USB battery charging circuitry using Max 1555 and Max 8881 provided by the Maxim Company. (Image taken from information sheet provided by Maxim [39])

However, there are limitations to this circuit which may make it inappropriate for certain USB devices, but not for the pillbox logger. The most obvious is its relatively low charge current $(100 \mathrm{~mA})$, which translates to long charge time, if the Li-ion battery capacity is more than a few hundred mA-hours. The rechargeable Li-ion batteries that would be used in pillbox logger are expected to have $80(\max ) \mathrm{mAh}$ in total. This means 
it may take around 2 hours to completely charge the batteries, which is not a problem for the pillbox logger. However, the anticipated battery life between charges is only $\approx 8$ hours for the current design of the prototype of the pillbox logger. But this short period of battery life is mainly because it does not include any power saving features both under hardware and software sections, as the device is still under testing. To commercialize the product in future power saving features would be added to increase the battery life between charges to at least a couple of days.

\subsubsection{Layers}

The PCB was designed using a four layer board instead of the conventional two layer board. There were two major reasons for choosing a four layer board over a two layer board. Firstly, using a 4 layer board made the task of laying out the PCB easier and faster. All power and ground connections were available just using a via. Traces on layer three could be run whenever desired, which helped in avoiding continuous jumping back and forth between layers, which would be necessary with only two layers. This saved an enormous amount of time. Secondly, four layers provide a very low impedance path for power, which reduces noise in the system. This noise shows up in analog circuitry and gets radiated out as electromagnetic interference (EMI). Four layer boards, if done carefully, reduce EMI significantly. Though the PCB for pillbox logger does not have

much analog circuitry, this may be helpful for future generations of pillbox logger where analog circuitry may be added. 


\subsubsection{Bootloader}

The bootloader is a set of software programs that are burned onto the AVR so that Arduino code can be uploaded to it without the use of external hardware programmers. The Arduino Pro board used for prototyping came with a bootloader pre-burned on the Atmega328. However, for the final PCB it was required to burn the Atmega328 with a bootloader. To do this, pin headers for connecting an in circuit serial programming (ICSP) cable were soldered to the PCB. An AVR-ISP (In System Programmer) was used to burn Arduino Pro version bootloader on to the Atmega328. The bootloader files were downloaded from the Arduino website [49]. Burning the AVR with bootloader facilitated in uploading the Arduino sketches (code) on to AVR using a FTDI board to the pillbox logger PCB.

\subsubsection{Final Software code}

The final step after designing and building the PCB and after burning the bootloader was to upload a software code on the AVR that would perform all the required operations. Like the prototype, the Arduino software was used to program and upload the final code on the PCB. The final program was based on the algorithm shown below.

\section{Algorithm:}

1. Include the inbuilt Arduino SD card library

2. Define all the pins on the Atmega 328 that are to be used for read and write

3. Initialize all the variables that are to be used in the code. For example the variables for time calculation

4. Create a setup function, which would be executed only once whenever the AVR is reset. In the setup function do the following operations 
a. Check if the SD card is present or not. If SD card is not detected send an error message on the serial monitor

b. Check if the SD card is selected by checking the status of the chip select line pin connected to the AVR from the SD card socket.

c. If the SD card is selected, initialized the SD card else send an error message on serial monitor that card could not be initialized

d. Once the card is initialized open the date file and initialize the date and time variables based on the values read from the date file

e. Close the date file

f. Open the alarm file and initialize the alarm time variables from the values read from the alarm file. Close the alarm file after reading

g. Initialize all the output pins on the AVR

h. End the set up function

5. Create a loop function that keeps operating as long as the AVR is powered on 6. Inside the loop function do the following operations

a. Check if the USB is connected or not

b. If USB is not connected then

i. Set the mode of Maxim chip to Pass through mode

ii. Disable the crystal oscillator connected to Maxim chip for power saving

iii. Power cycle the SD card if it was previously in USB transfer mode

iv. Initialize SD card and change the transfer mode to SPI mode if previously the card was in USB transfer mode 
v. Select each set of switch and save its state in a string

vi. Open the datalog file and record the state of all the eight sets of switches on to the SD card in a time stamped format, whenever a change in state of the switches is detected. Then close the file

vii. Check if it is time to set the alarm on. If it is then vibrate the motor for ten seconds

c. If USB is connected

i. Change the mode of Maxim chip to Card read mode

ii. Enable the crystal oscillator connected to the Maxim chip

iii. Power cycle the SD card if the SD card was previously in SPI transfer mode

iv. Change the transfer mode to USB mode

v. Allow the USB to read the SD card

d. Update the date and time values

e. End of the loop function

The Arduino code based on the above described algorithm was uploaded on the AVR for getting a working PCB. Several debugging comments were added in it initially and the serial monitor in the Arduino software was primarily used for debugging the code. The software was equally important as the hardware in getting a successfully operating pillbox logger. 


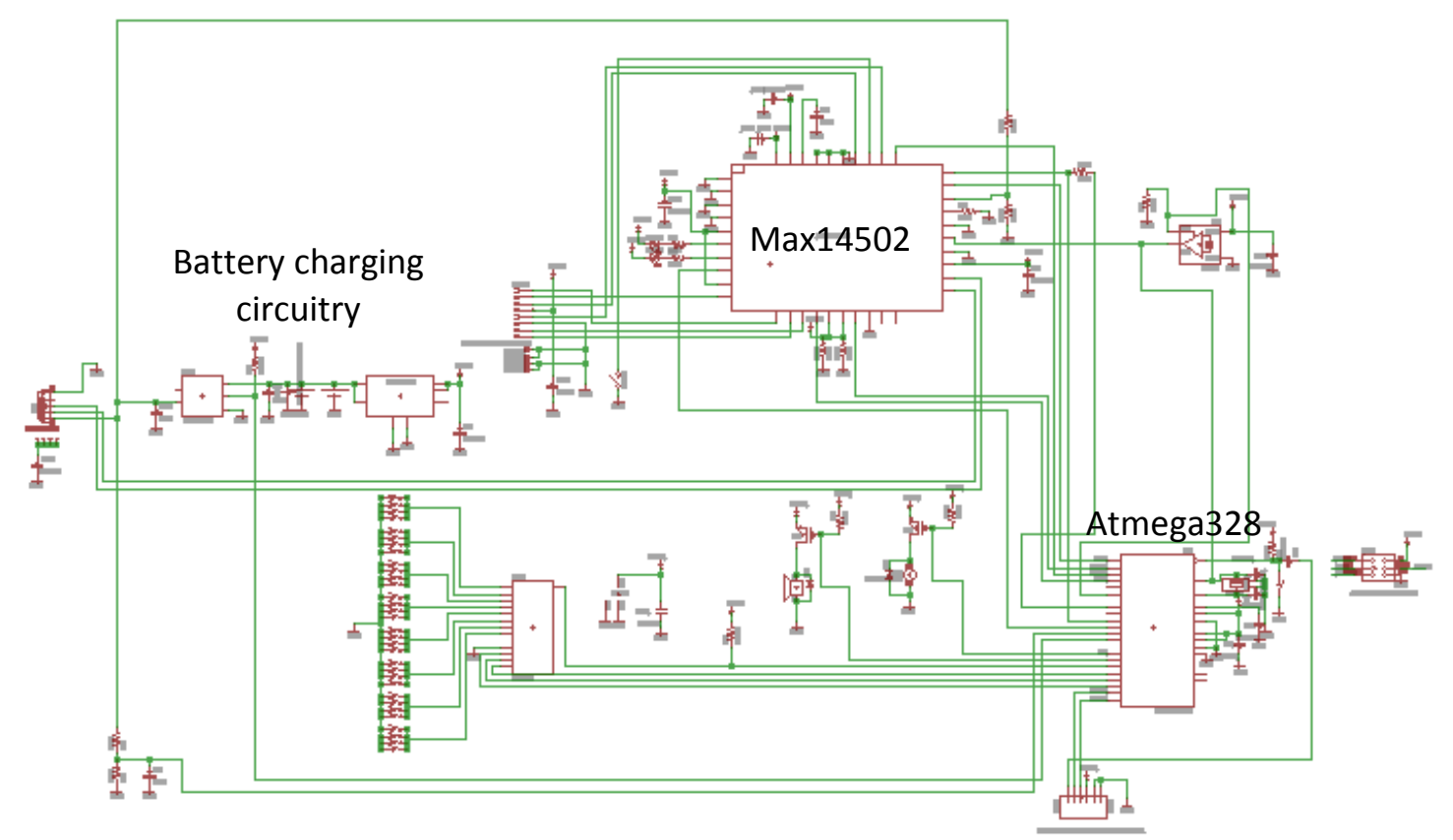

Fig. 4.13 Schematic of the Printed Circuit Board (PCB) drawn using Eagle Cad (Image by Beenish Zia)

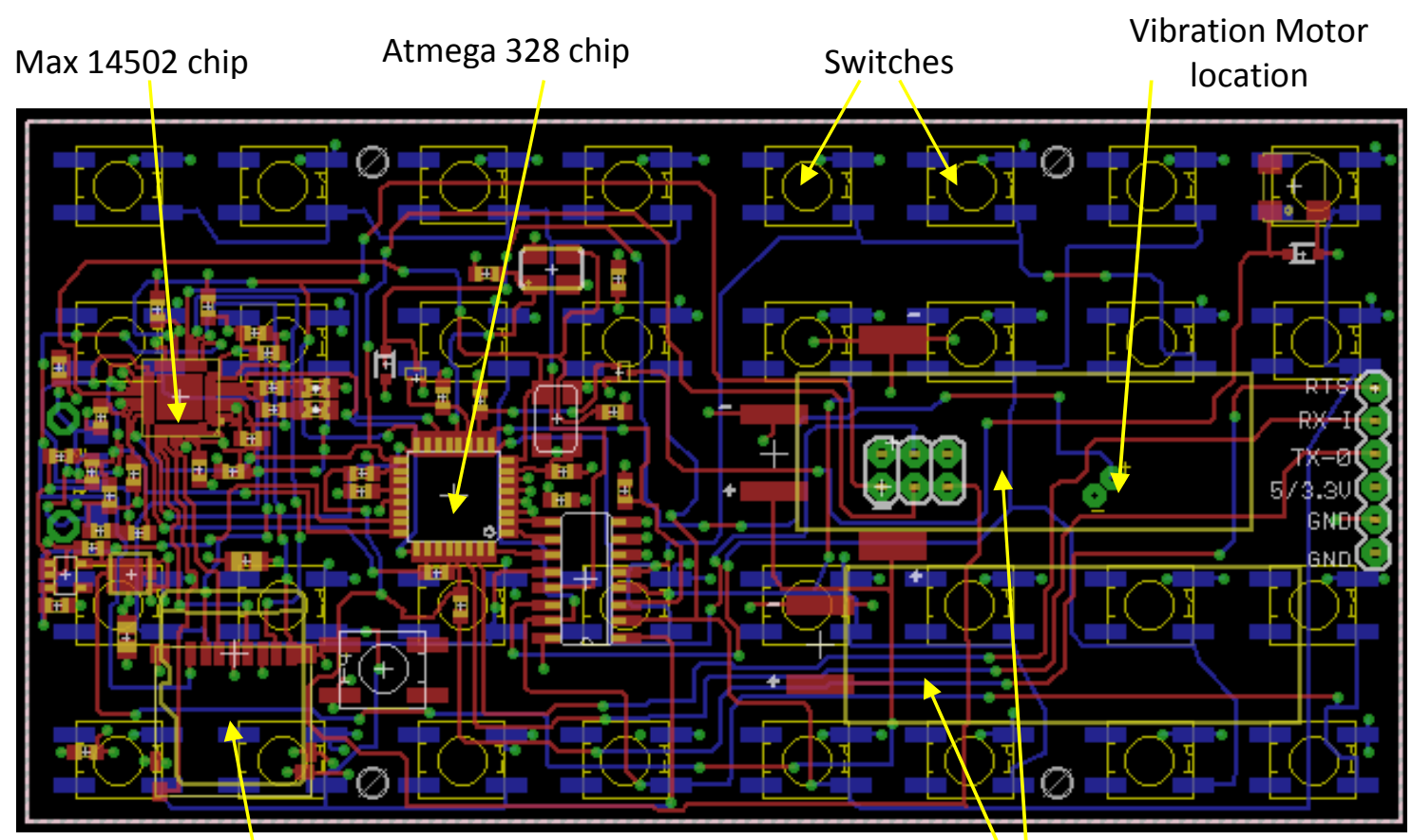

Micro SD card socket

Battery locations

Fig. 4.14: Eagle Layout of the PCB (without copper pour) for pillbox logger, with only top and bottom layers turned on (Image by Beenish Zia) 


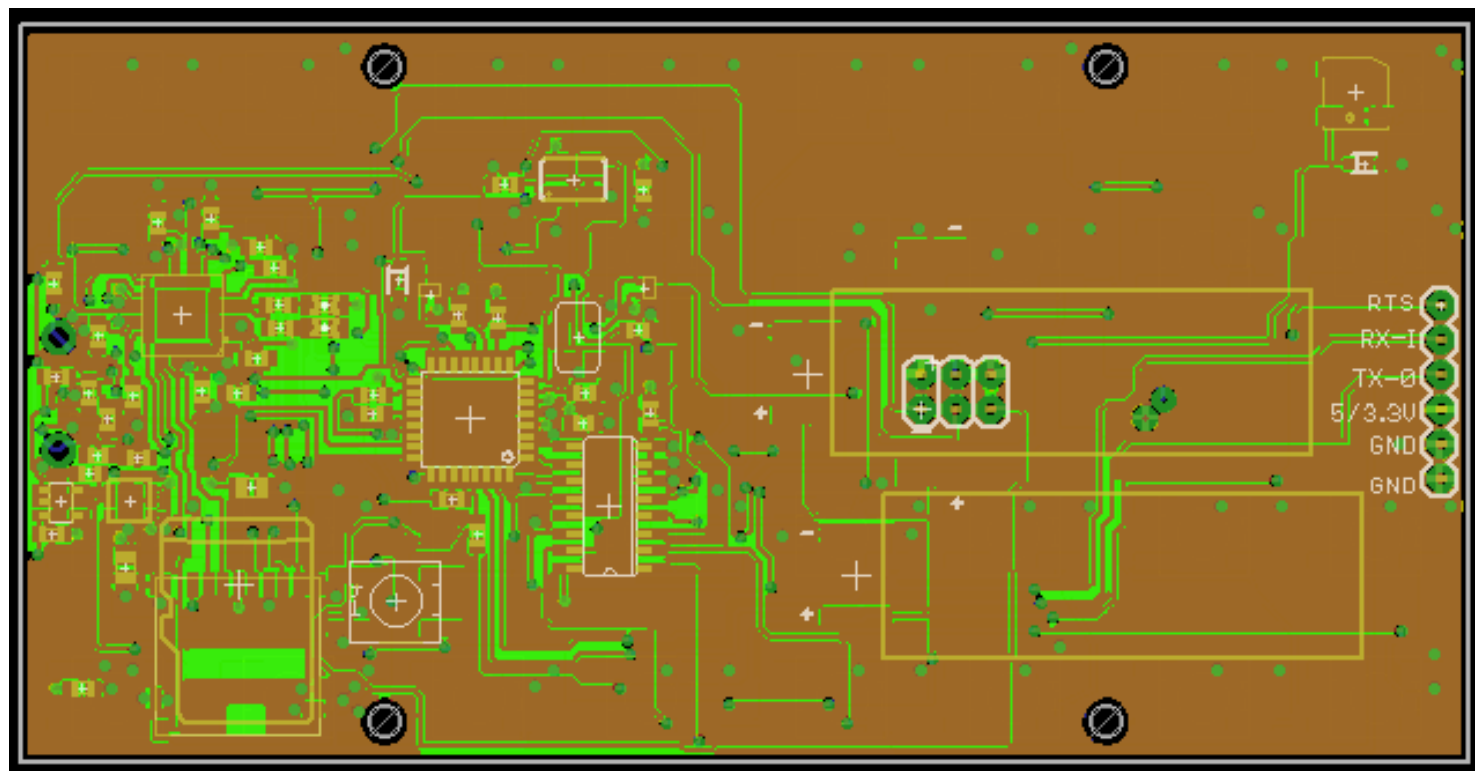

Fig. 4.15: Eagle Layout of the PCB (with copper pour) for pillbox logger, with all four layers turned on (Image by Beenish Zia)

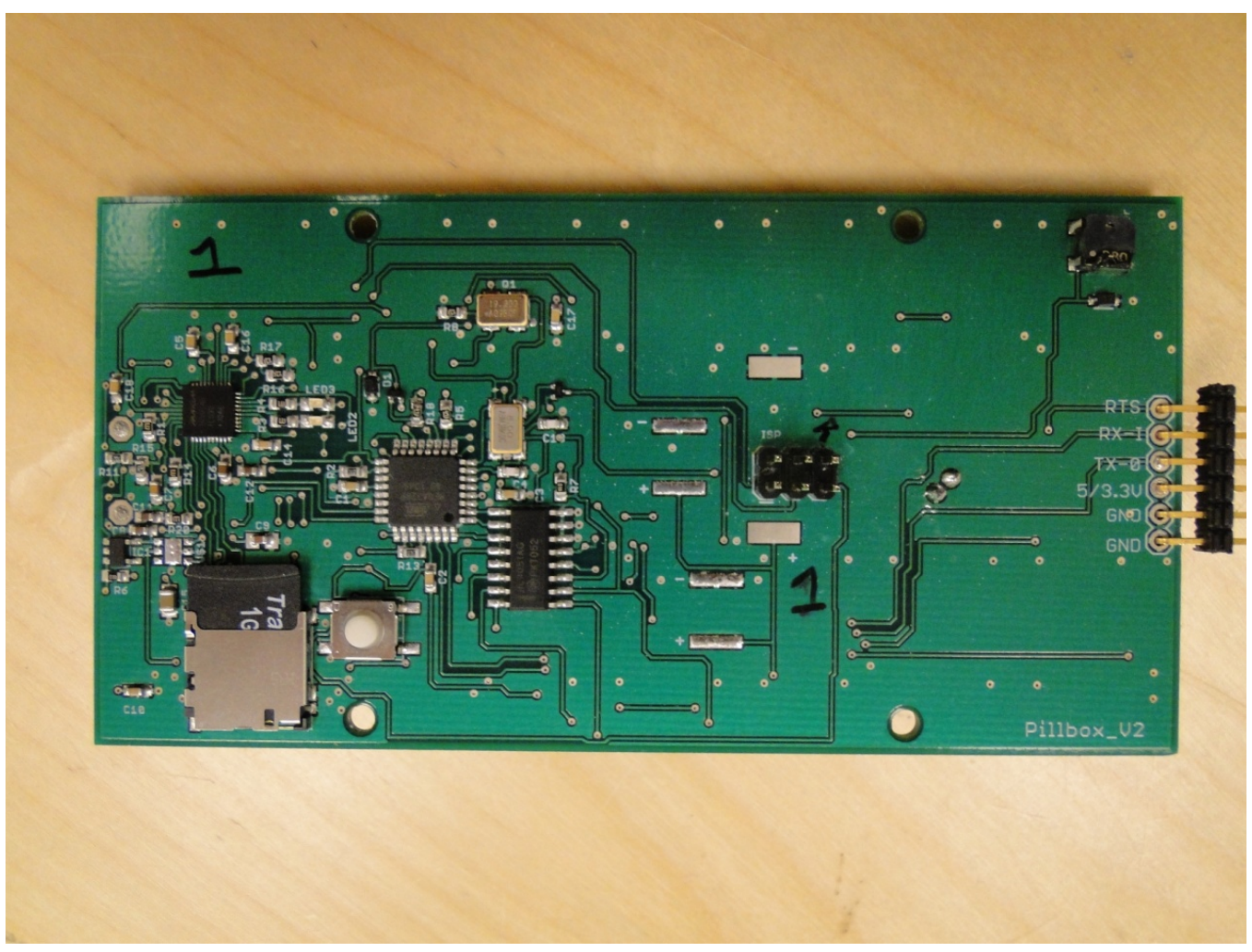

Fig. 4.16: Top view of the final Printer Circuit board (Image by Beenish Zia) 


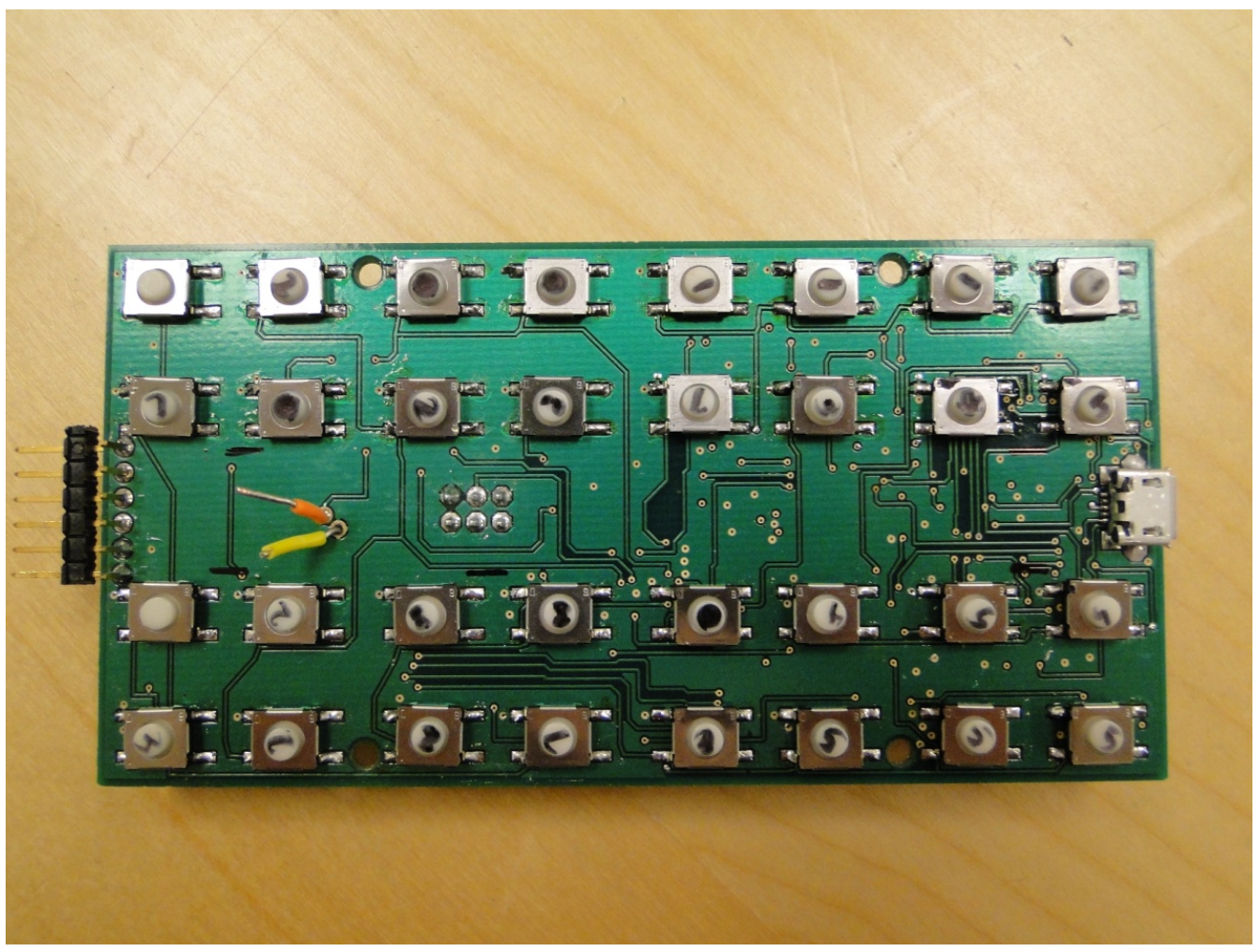

Fig. 4.17: Bottom view of the final Printer Circuit board (Image by Beenish Zia) 


\subsection{Mechanical Section}

One of the prime requirements of the pillbox logger was to be small and portable. This meant the size of the pillbox logger be designed in way that it holds the daily medications of a patient comfortably and is small enough to fit in a pocket or purse.

A brief survey of medication and medication containers from PD subjects showed that on average a PD subject takes a combination of pills 4-6 times daily. In rare cases this may be 8 times a day. A few subjects also took some non-PD related pills daily like vitamins.

The most common medications for PD are two drugs: carbidopa and levodopa commonly sold together as Sinemet. Carbidopa is usually a yellow a biconvex oval shaped pill, which comes in $25 / 100 \mathrm{mg}$ tablets. The dimensions of carbidopa are generally $7.1 \mathrm{~mm} \times 12.7 \mathrm{~mm}$ [48]. Levodopa is typically a dappled blue biconvex oval shaped pill, which come in 25/250 mg tablets. The general dimensions for levodopa are 7.9mm x $15.1 \mathrm{~mm}$ [48]. There are few other medications for PD, but mostly smaller than the size of Sinemet. Medications are mostly less than $4 \mathrm{~mm}$ thickness.

Since a PD subject, on average, takes 2-3 pills at a time 4-6 times a day, this required the compartment to be big enough to hold three large pills. After a number of trials with actual pills, it was concluded that a compartment of $25.4 \mathrm{~mm}$ x $25.4 \mathrm{~mm}$ x $16 \mathrm{~mm}$ would be appropriate to hold a combination of PD pills comfortably. This also gives room for the users to insert their finger in the compartment and take the pill out easily, without having to turn the pillbox over to take out the pills. A pillbox with eight such compartments appeared to be a good design choice since on average a PD patient took 
PD pills 4-6 times a day and few non-PD related pills 1-2 times a day. Rarely, some subjects took PD pills 8 times a day. Having eight compartments in pillbox logger covered majority of the cases for pill intake.

In view of the fact that each compartment was $25.4 \mathrm{~mm} \times 25.4 \mathrm{~mm}$ and eight such compartments were required in a way that the pillbox would fit in a pocket easily, it was decided that two rows of four such compartments back to back would be the best choice. In that case the maximum dimensions of the pillbox logger came out to be $\approx 113 \mathrm{~mm} \mathrm{x}$ $66.5 \mathrm{~mm} \times 23.6 \mathrm{~mm}$ including dimensions of material for building pillbox logger, electronic section and locking mechanism.

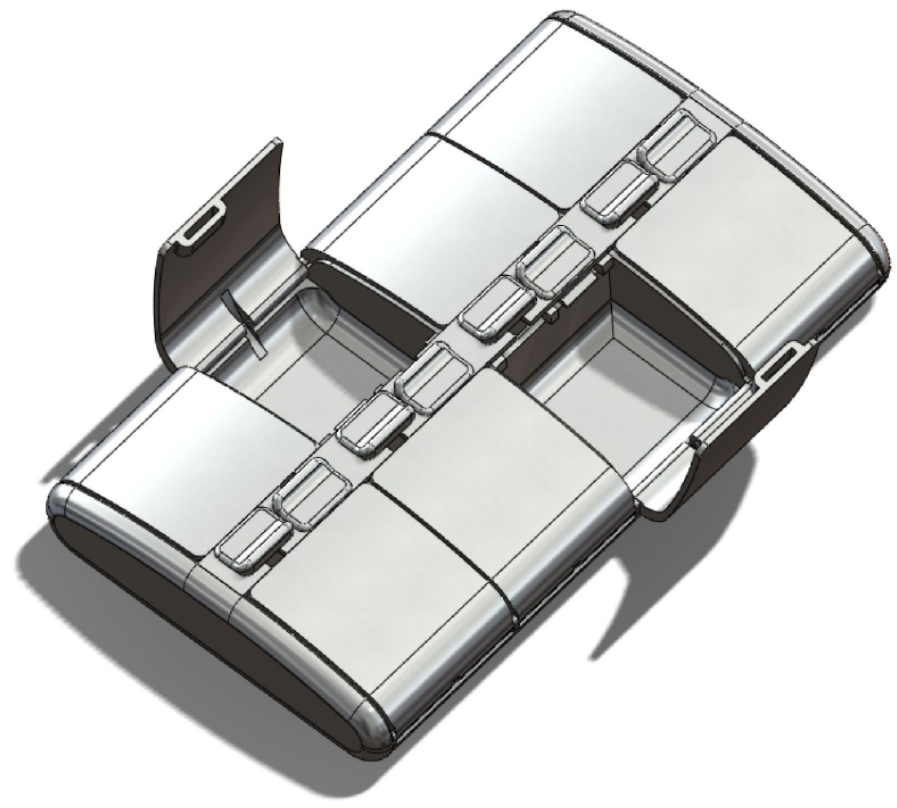

Fig. 4.18: Solid works model for pillbox logger (Image provided by Joshua Booren)

According to the electronic segment there would be four switches at the base of each compartment for detecting the presence/absence of pills in the compartment. This required a thin plate like structure at the base of each compartment which would help in 
uniformly distributing the pressure of pills to the base of compartment and aiding in turning all the switches on/off.

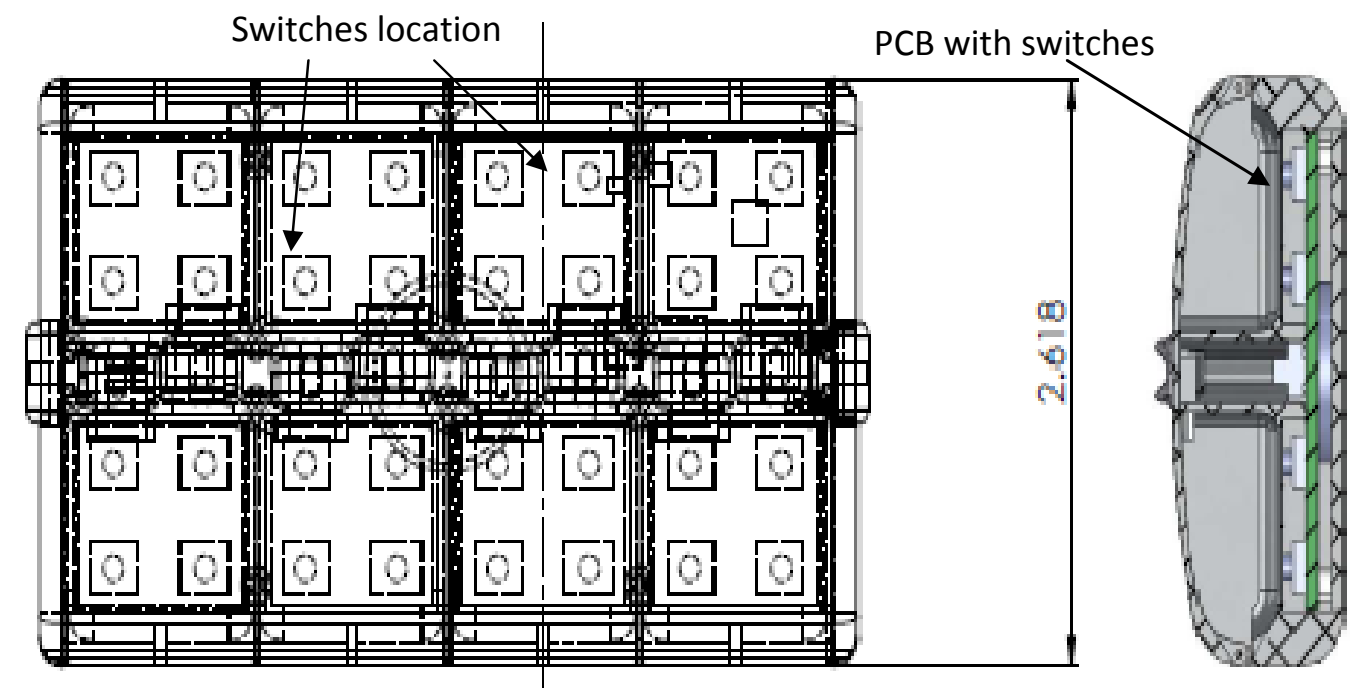

Fig. 4.19 Solid works model of the pillbox logger with the location for switches and USB connector outlined (Image provided by Joshua Booren)

A locking mechanism was added in the middle section of the pillbox logger to avoid opening of the pillbox by mistake, while in a users pocket or purse. It was also decided that a thin layer of food grade foam [51] would be added to the inner side of lids of all the compartments. The foam would insure that when lid of a compartment was closed there was just enough pressure to turn switches on because of presence of pills, without breaking the pills. However, in absence of pills the foam thickness was not thick enough to press the plate at the base of compartment and turn the switches on. Addition of foam would also aid in reducing the rattling noise that pills may make by hitting against the walls of the pillbox logger.

Students version of Solid Works software was used to come up with the mechanical drawings of the pillbox logger. Since the students version of the software does not 
support simulation testing environment tools, the Solid Works model of the pillbox logger with exact dimensions were sent to a local company for plastic prototyping [50].

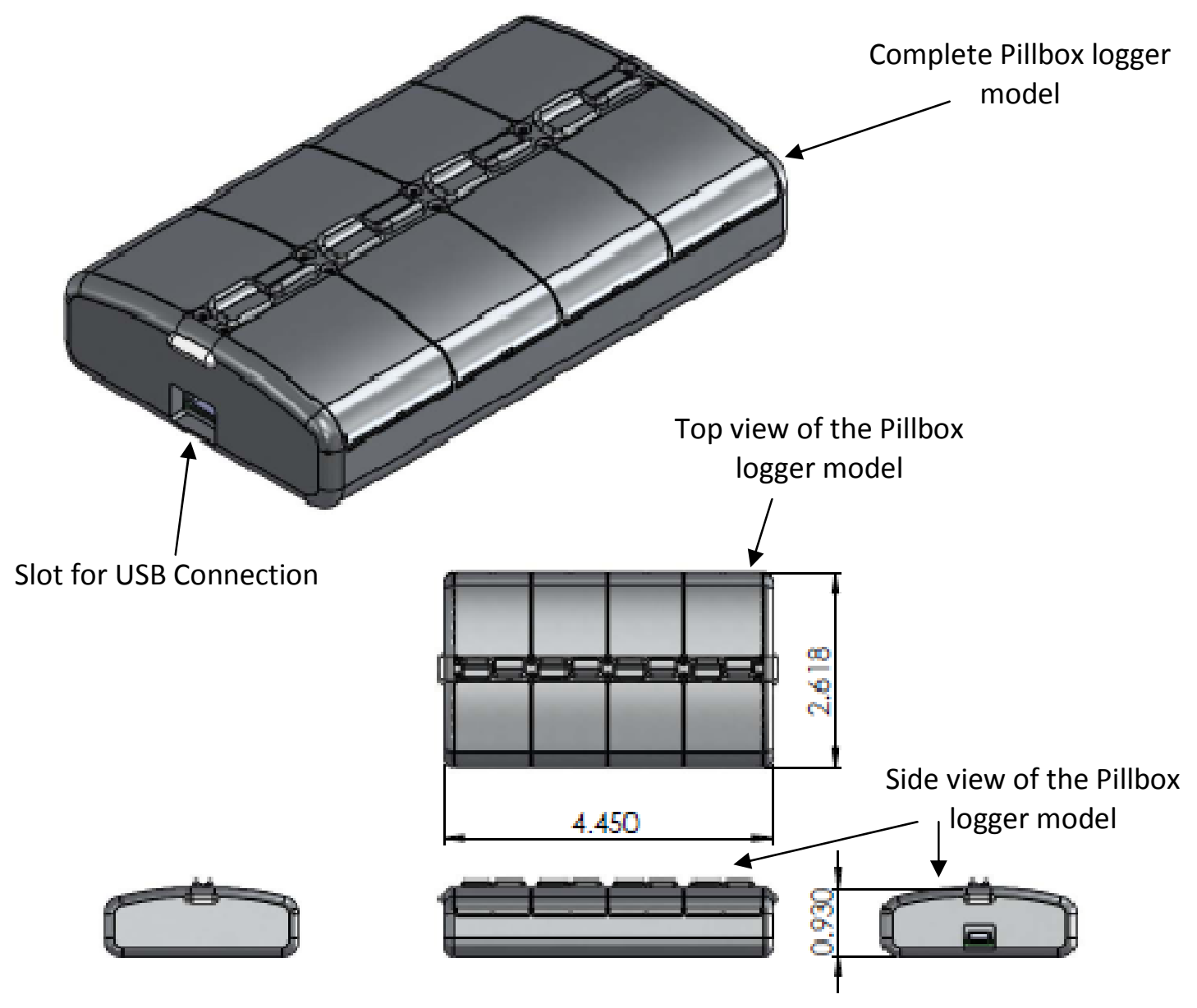

Bottom view of the Pillbox logger model
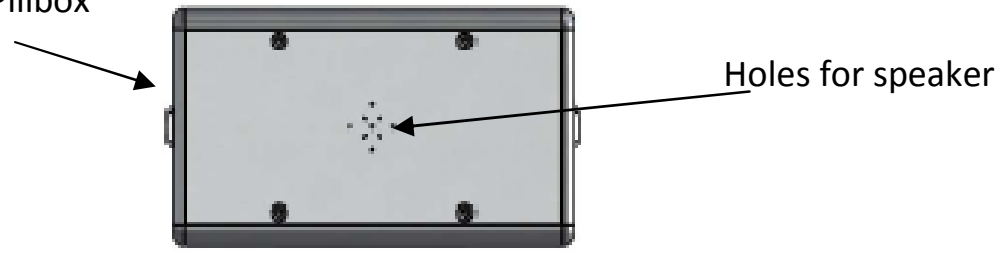

Fig. 4.20 Solid works model of the pillbox logger viewed from different angles (Image provided by Joshua Booren, dimensions in inches)

A plastic model for the pillbox logger was made using Dimensions Elite 3500 for testing, before a final metal model of the pillbox logger could be made [50]. The pieces 
of the plastic model were filed and reamed before they could be put together. Torsion springs and wire of $\approx 0.012 "$ thickness were used to attach the lids of the compartments to the body of the pillbox. Thin sheet metal was used to make the base of the compartments of the pillbox logger. $\approx 1 / 2 "$ thick food grade foam was then attached on the inside of each of the lids of the compartments using a double sided tape.

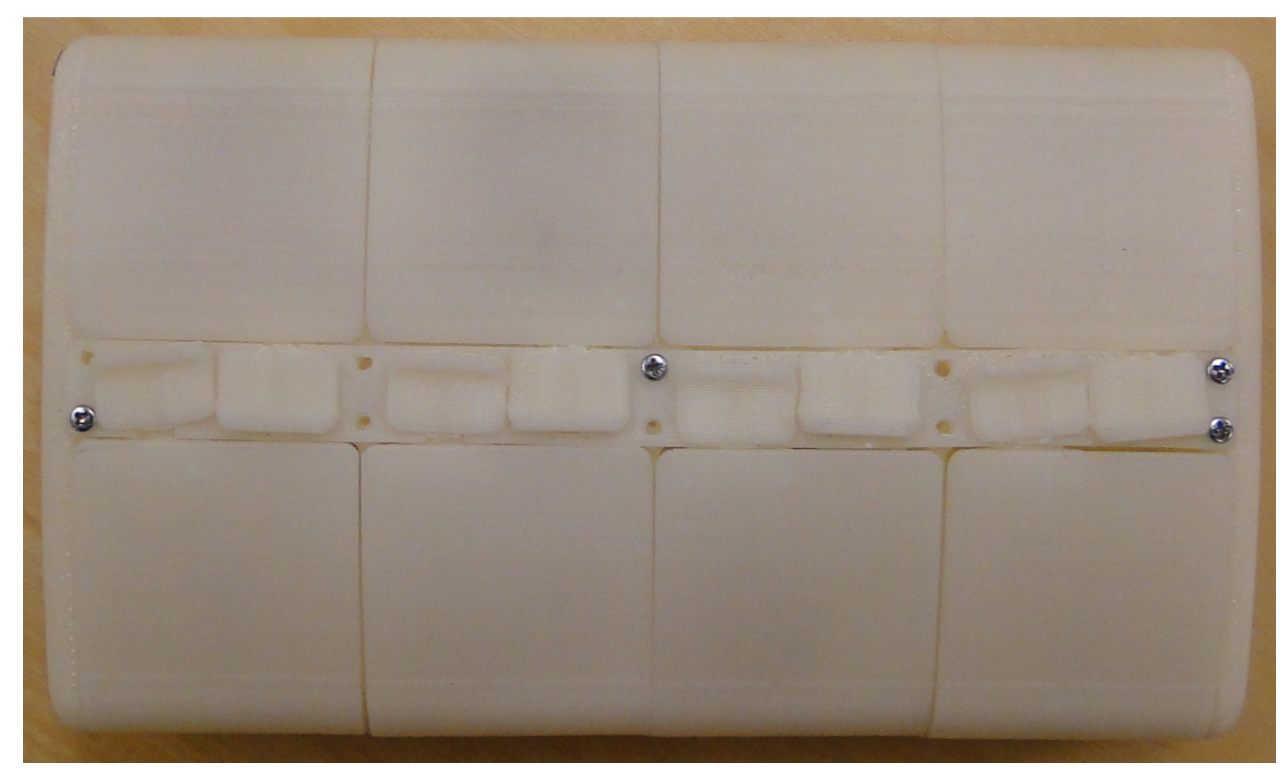

Fig. 4.21 Top View of the final plastic model of the pillbox (Image by Beenish Zia

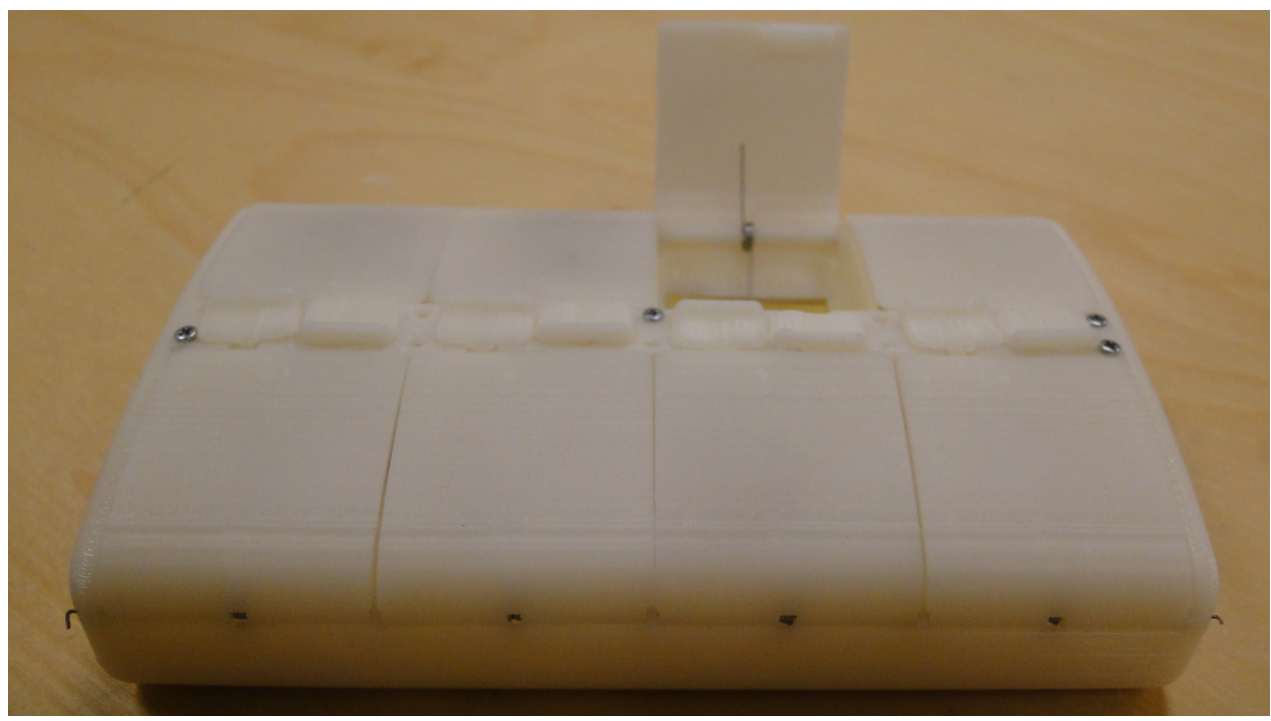

Fig. 4.22 Final plastic model of the pillbox (Image by Beenish Zia) 68 


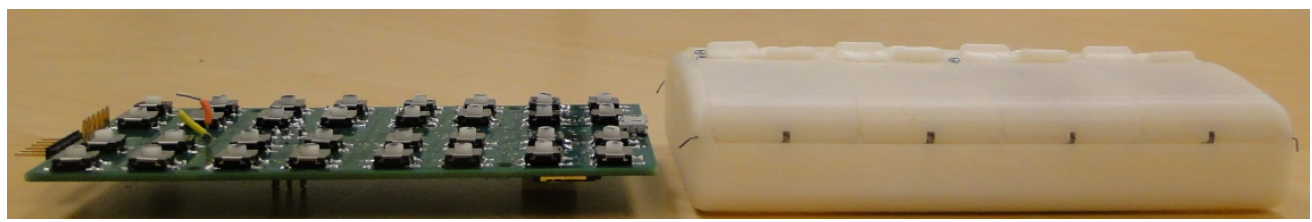

Fig. 4.23 Side View of the final plastic model of the pillbox and the PCB (Image by Beenish Zia) 


\section{Chapter 5}

\section{VALIDATION AND VERIFCATION}

This chapter describes the various tests that were done to validate the design and verify the functionality of the hardware and software section of the pillbox logger.

\subsection{Validation of Hardware}

\subsubsection{PCB Validation}

Test 1: The Eagle CAD tool provides design rule check (DRC) and electrical rule check (ERC) to verify the correctness of the layout and schematic respectively. The ERC covers aspects like overlap, intersecting wires, missing connection and wrong connections in the schematic of the design. The DRC covers issues like minimum width wire, minimum spacing between components on board, overlapping wires on a layer and layout matching between the schematic and the layout of the design. Before a designed PCB can be sent to board house for manufacturing it is crucial that the design passes both the ERC and DRC checks. The pillbox logger PCB was corrected until there were no ERC and DRC errors before being sent for manufacturing.

Test 2: Once the PCB was manufactured all the custom designed Eagle CAD library parts were tested by placing the actual components on the PCB. The first version of the pillbox logger PCB failed this test. It was found that the land patterns for the Maxim 14502 chip and the $8 \mathrm{MHz}$ crystal were incorrect. The designed TQFN package for the Maxim 14502 chip was bigger by $~ 1 \mathrm{~mm}$ than the actual package. Similarly, the pads in 
the SMD package for the $8 \mathrm{MHz}$ crystal were off from the center by $\sim 1 \mathrm{~mm}$. Both these mistakes resulted in failure of a working PCB.

Results: As a result of the wrong package on first version of PCB a second version of the PCB was manufactured with the errors in the first version fixed.

The second version of the manufactured also had a custom designed package problem for Max8881 chip which had the right size but wrong pin labeling. This problem was fixed by cutting few PCB traces and using mod wires to externally connect the right components.

Test 3: The manufactured PCB was matched against the mechanical section of the pillbox. The size, shape and location of components on PCB matched the mechanical design of model of the pillbox; however the holes for drilling in the support screws were found missing on the first version of the PCB.

Result: Drills were placed in the second version of the PCB.

Test 4: The second version of the manufactured PCB was tested in the same way as the first version of the PCB under Tests 1, 2 and 3.

Results: The second version of the designed PCB passed all the three major hardware tests. The design had no ERC or DRC. The manufactured PCB had the entire component packages correct except the Max8881 IC and the components soldered perfectly on the PCB. The second version of the PCB had drill holes on it and it fitted in the mechanical model of the pillbox perfectly.

Test 5: After soldering all the components on the PCB, the PCB was checked for any soldering mistakes, shorts and loose connections. It was also checked for any wrong component value which resulted in failure of the device. 
Results: The TQFN package for the Max14502 IC had a few dry soldering connections which were fixed. The USB connector was found to have an unsoldered connection, which was corrected.

The crystal oscillator driving the Max14502 IC was found to be of the wrong value. Instead of $19.2 \mathrm{MHz}$ the PCB was using a $12 \mathrm{MHz}$ crystal oscillator. This wrong value of crystal frequency had resulted in failure of device being able to acknowledge a USB connection. The wrong value crystal oscillator was replaced with the correct component to fix the error.

\subsubsection{Validation of Mechanical Model of the Pillbox Logger}

Test 1: After designing the model of pillbox logger in Solid Works, to validate the design, a prototype of the pillbox logger was made in plastic. Simulation tools for evaluating the design of Solid Works exist where a virtual environment can be set for testing the design. However, in the student's version of Solid Works such simulation environments are not supported so for testing the design a prototype was built using Dimension Elite 3D plastic printer [50]. After the plastic model of the pillbox logger was printed the manufactured PCB was matched against it for fitting, shape and size.

Results: The plastic prototype of the pillbox logger was sturdy. However the thinner walls were slightly thicker than their actual dimensions and the plastic model had to be filed by few millimeters to perfectly fit the PCB and all the parts together. The base of each of the compartments were custom made using a thin sheet of metal (aluminum) because they were too thin to be produced using a plastic printer. The lids of the 
compartments were reamed for slipping in wires at the edges of the lids to hold them together with the body of the pillbox.

All the parts of the plastic model were put together with the complete PCB and they fitted in well. This helped verify all the dimensions, shapes and location of the mechanical model of the pillbox logger design.

\subsection{Verification of Software}

\subsubsection{Bootloader Verification}

Before the AVR could be uploaded with the Arduino code for performing the functions of the pillbox logger, it was important to burn a bootloader onto the AVR. The bootloader for an Arduino Pro development board available on the Arduino website [49] was used. Correct burning of the bootloader on the Atmega328 IC helped in uploading the Arduino code onto the Atmega without any use of external programmer.

\subsubsection{Pillbox Logger Arduino Code Verification}

After soldering all the components on PCB and burning the AVR with bootloader the code for performing the flow of operations of the pillbox logger was uploaded on the AVR using a FTDI board. Before placing the built PCB inside the plastic model of the pillbox, two major software tests were conducted on the pillbox logger. A third final test of software and hardware verification, together, was conducted after placing the completely tested PCB into the plastic model of the pillbox logger. 
Test 1: Basic functionality test

The developed PCB was uploaded with a test code which allowed proper detection of state of the switches, recorded the state of switches on the micro SD card in a specified format and sent out reminder in form of vibration for pill intake at correct time. The switches on PCB were manually pressed and the state of the switches that were getting recorded on SD card was displayed on the serial monitor provided in the Arduino software.

Results: The result of running the test code showed that correct state of all switches were being recorded on micro SD card. It also demonstrated that the vibration alarm was sending out reminder at correct intervals of time. This showed that all the basic electrical connections on PCB were correct and that the PCB was correctly performing its basic operations.

Test 2: Test of USB read of micro SD card and charging of batteries

To the basic functionality test code another section for testing proper USB read was added. This added code allowed proper switch of the mode pin on Maxim 14502 chip after the ongoing writing operation on SD card was over. The new test code was uploaded to the PCB. The whole board was battery powered and the switches on the PCB were manually pressed. After some time the PCB was docked to a computer using a micro USB cable for SD card read using USB port.

Results: On the first trial the host computer was able to detect a USB connection but it was failing to receive any acknowledgment from the device. This problem was occurring because of the wrong crystal oscillator value attached to the Max14502 IC. After this hardware problem was corrected, the host computer was able to read the contents of the 
SD card on PCB board in a proper manner. This showed that the transition from SD write mode to SD read mode occurred smoothly. An LED connected to battery charging pin also indicated that the battery was getting charged while the PCB was docked to a computer. This test was repeated several number times and it was observed that each time the operation was executed perfectly.

However, though there was no problem with the actual read of SD card using USB port a problem of power cycling the SD card every time it changed from SPI mode communication with the AVR to the USB read of SD card was occurring. This error resulted in the addition of an external p-channel transistor controlled by the AVR to power cycle the SD card whenever it transitioned from the AVR writing to SD card to USB read of SD card.

Test 3: Integration of the Electronic and Mechanical sections

The PCB loaded with the test code from test 2, was placed in the plastic model of the pillbox logger. Commonly used PD pills were physically placed in each compartment of the pillbox logger, food grade foams were attached to the inside of each lid and the lids of the compartments were then closed. The test code was programmed in a way that it would send a reminder after every 2 hours till $10 \mathrm{pm}$ at night. When the reminder alarm was sounded pills were taken out from one of the compartments. Intentionally one time the pills were not taken out from a compartment when the reminder went off. Also, the pills were taken out of the pillbox logger at variable durations after the reminder went off. At the end of the day the pillbox logger was docked into a computer using a micro USB cable. 
Results: The test results showed that at the end of the day the SD card had stored all the information correctly at the correct time. The pillbox logger had precisely recorded the state of each compartment (empty/full) along with the time. This test was performed for few times and it was found that the pillbox logger correctly stored all the information each time, including sending out reminder at correct time. This ensured that the pillbox logger would perform correctly for longer duration of times. However, in most of the tests an external power supply was used instead of the batteries to avoid discharging the batteries for long. 


\subsection{Summary of the Validations and Verifications}

Table 5.1 briefly describes the different tests that were conducted to validate the pillbox logger design and verify its functionality.

\begin{tabular}{|c|c|c|c|c|}
\hline Tests & Hardware & Software & $\begin{array}{l}\text { No. of Failures } \\
\text { Corrected }\end{array}$ & $\begin{array}{l}\text { Overall } \\
\text { Product }\end{array}$ \\
\hline $\begin{array}{l}\text { Component } \\
\text { Package }\end{array}$ & $\sqrt{ }$ & & $\begin{array}{c}3 \text { (Max 14502, Max 8881, } \\
\text { 8Mhz Crystal) }\end{array}$ & $\sqrt{ }$ \\
\hline Components & $\sqrt{ }$ & & 1 (Crystal Oscillator) & $\sqrt{ }$ \\
\hline Soldering & $\sqrt{ }$ & & 2 (Max 14502, USB) & $\sqrt{ }$ \\
\hline Connections & $\sqrt{ }$ & & & $\sqrt{ }$ \\
\hline USB Detection & $\sqrt{ }$ & & $\begin{array}{c}1 \text { (Failed } \\
\text { Acknowledgment) }\end{array}$ & $\sqrt{ }$ \\
\hline $\begin{array}{l}\text { Correct signals } \\
\text { switching }\end{array}$ & & $\sqrt{ }$ & $\begin{array}{c}1 \text { (Diode direction for } \\
\text { alarm) }\end{array}$ & $\sqrt{ }$ \\
\hline $\begin{array}{l}\text { Data read/write of } \\
\text { SD card }\end{array}$ & & $\sqrt{ }$ & 1 (USB read of SD card) & $\sqrt{ }$ \\
\hline $\begin{array}{c}\text { Time } \\
\text { Initialization }\end{array}$ & & $\sqrt{ }$ & & $\sqrt{ }$ \\
\hline Sequential Flow & & $\sqrt{ }$ & & $\sqrt{ }$ \\
\hline
\end{tabular}

Table 5.1: Summary table for different validation and verification tests 


\subsection{Discussion}

The results of this chapter give supporting evidence that the pillbox logger prototype functions as designed. The designed pillbox logger can be used to keep track of the daily medication intake of a PD subject. It is small, portable, sends a vibration alarm reminder and has an easy method of reading the information stored in it. The three test methods indicated that the designed pillbox logger is capable of performing its functions correctly, without any problem. The thorough tests and their successful results suggest that the designed pillbox logger can be handed to PD subjects in future and be used for medication monitoring. 


\section{Chapter 6}

\section{CONCLUSIONS}

The main objective of this work was to successfully design and implement a pillbox logger aimed at people afflicted with Parkinson's Disease. The pillbox logger was designed to be a pocket-sized, compartmented device capable of keeping a log of the time of pill consumption by a subject by detecting the presence/absence of pills in the pillbox logger. The device was also designed to include vibration and audio alarm system for reminding the subjects to take their dose at correct time of the day.

The pillbox logger described in this work is expected to help subjects adhere to their medications, thereby reducing the chances of medications failing to have any effect on the symptoms of PD by irregular pill intake. The pillbox logger complements the need of a device that can be used with wearable sensors being developed for continuously recording impaired movement of PD subjects. The use of pillbox logger along with such wearable sensors would allow direct measure of response to oral medications and hence help clinicians optimize the therapy.

This thesis covers in detail the design and implementation of the electronic pillbox

logger. The thorough testing of the final device verifies the correct working of the overall product. The work describes the successful completion of the electronic pillbox logger which can be commercialized and be used to aid people suffering from PD. 


\subsection{Future Work}

This is the first generation of a pillbox logger. There are several things that can be done in future to improve the current design of pillbox logger.

- A metallic body of pillbox logger can be made, which is sturdier. Such a pillbox logger can be handed to PD subjects for few months and then the data collected from the pillbox logger be compared to the data collected from previous similar works [1]. Also, feedback from subjects on the first generation pillbox logger can be used to improve the next generation pillbox logger.

- Feature for snoozing the reminder alarm can be added as well as an external button for turning off and resetting the alarm can be added to next generation of pillbox loggers.

- Wireless transmission of recorded data can be added as another feature of pillbox logger instead of only having a USB cable wired data transmission.

- A display showing the time for next pill and other required information may be added to the device without increasing the size and weight of the design.

- Power saving features should be added to increase battery life.

- Graphical user interface can be added on the host side for easier time initialization of the pillbox logger. Hardware and software can be added to the device to give more control over setting date and time and scheduling alarm.

There is a wide scope for adding more electronic features to the next generation pillbox logger. The features and design of pillbox logger however can be modified best after getting feedback from PD subjects who would use the pillbox logger. Also, results 
of using pillbox logger in conjunction with using wearable sensors would provide useful results for clinicians and may help them optimize PD treatments. 


\section{References}

[1] Hayes, T. L., J. M. Nutt, A. Adami and J. A. Kaye. “An Electronic Pillbox for Continuous Monitoring of Medication Adherence". Proceeding of the $28^{\text {th }}$ Annual International Conference of the IEEE Engineering in Medicine and Biology Society, 2006; 6400-6403.

[2] Claxton, A. J., J. Cramer and C. Pierce, "A Systematic Review of Associations Between Dose Regimens and Medication Compliance". Clinical Therapeutics, Vol. 23, Issue 8, August 2001; 1296-1310.

[3] Kalichman, S. C., D. Cain, C. Cherry, M. Kalichman and H. Pope, "Pillboxes and Antiretroviral Adherence: Prevalence of Use, Perceived Benefits, and Implications for Electronic Medication Monitoring Devices". AIDS Patient Care and STDs, Vol. 19, No. 12, 2005; 833-839.

[4] Bedell, S. E., S. Jabbour, R. Goldberg, H. Glaser, S. Gobble, Y. Young-Xu, T. B. Graboys, and S. Ravid, "Discrepancies in the use of medications: their extent and predictors in an outpatient practice," Arch Intern Med, 2000; 160: 2129-34,

[5] Fishkin, K., M. Wang, and G. Borriello, "A ubiquitous system for medication monitoring," presented at Pervasive, April 18-23, Vienna, Austria, 2004.

[6] Gorkin, L., M. G. Goldstein, M. J. Follick, and R. C. Lefrbvre, "Strategies for enhancing adherence in clinical trials.," in Handbook of Health Behavior Change, J. K. Ockene, Ed. New York: Springer, 1990; 361-375.

[7] Hermann, M. M., and Diestelhorst M., "Microprocessor controlled compliance monitor for eye drop medication". British Journal of Ophthalmology, 2006; 90: 830-832. 
[8] Thinking Outside the Pill box, A system wide approach to improving patient medication adherence for chronic disease. A NEHI Research Brief, 2009.

[9] Raven, M. R. “Alarm Pill Box”. US Patent 5020037, May 28, 1991.

[10] Halbich, F. "Plastic Pillbox”. US Patent 4084695, April 18, 1978.

[11] Oas, D. “Pillbox with Insert”. US Patent D517799S, March 28, 2006.

[12] Stugelmeyer, M. “Automatically timed locking pillbox”. US Patent D541039S, April 24, 2007.

[13] Smith, G. R. "Pocket Pill box”. US Patent 3817372, June 18, 1974.

[14] Sterns, A. A. "Pill box". US Patent 7337899, March 4, 2008.

[15] Petersen, M. L., Y. Wang, M. J. Van der Laan, D. Guzman, E. Riley and D. R. Bangsberg "Pillbox Organizers are associated with Improved adherence to HIV antiretroviral therapy and viral suppression: A marginal structural model analysis", Clinical Infectious Diseases, 2007; 45: 908-915

[16] Waterhouse, D. M., K. A. Calzone, C. Mele and D. E. Brenner, “Adherence to oral tamoxifen: A comparison of patient self-report, pill counts and electronic monitoring". Journal of Clin Oncology. 1993; 11: 1189-1197.

[17] Mallion, J. M., C. Dutrey-Dupange, L. Vaur, et.al. "Benefits of electronic pillboxes in evaluating treatment compliance of patients with mild to moderate hypertension”. Journal of Hypertens. 1996; 14:137-144.

[18] Aardex Group. "MEMS products, Electronic monitoring of adherence”. Online page for Pharmaceutical company March 2011. www.aardexgroup.com/ aardex_index.php? group $=$ aardex\&id=85> 
[19] MedSignals. Online product information. 2010. Feb. 2010.

https://www.medsignals.com/ HowItWorks.aspx

[20] Patrick, M. “Parkinson's Disease”, About.com. Online Guide. 2009.March 2011. parkinsons.about.com/od/parkinsonsdiseasebasics/a/what_is_PD.htm

[21] GigaNano. "Top 10 e-pill devices", e-pill Medication reminders. Online providers for medication compliance devices. 2010. October 2010. www.epill.com/bestseller.htm

[22] GigaNano. "Monitored automatic medication dispenser", e-pill medication reminders. Online providers for medication compliance devices. 2010. October 2010. www.epill.com/md2.html

[23] Drugs.com. "Carbidopa and levodopa images”. Online drug information. 2011. March 2011. www.drugs.com/carbidopa-levodopa-images.html

[24] Sparkfun Electronics. "Product Info, Arduino Pro 328-5V/16MHz". Online product information and seller. 2011. November 2010. www.sparkfun.com/products/9219

[25] Arduino. “Arduino Pro”. Online product information. 2011. November 2010. www.arduino.cc/en/Main/ArduinoBoardPro

[26] Arduino. "Arduino Duemilanove". Online product information. 2011. November 2010. www.arduino.cc/en/Main/ArduinoBoardDuemilanove

[27] LadyAda. “Arduino tutorials". Online tutorial lessons. 2011. October 2010. www.ladyada.net/learn/arduino/lesson5.html

[28] Nick. Arduino Playground. "Writing data to USB memory stick". Publicly editable wiki about Arduino. October 2010. www.arduino.cc/playground/Main/UsbMemory 
[29] Agent_orange. Arduino:Forum. "SD card read/write with Arduino". Online Arduino forum. 2011. October 2010. www.arduino.cc/cgibin/yabb2/YABB.pl?num=1206874649/8

[30] Blushingboy. "SD_uFAT". Online library to handle SD cards from Arduino compatible platforms. 2008. September 2010. blushingboy.net/p/SDuFAT

[31] Libelium Communicaciones Distribuidas. "Cooking hacks: MicroSD 2GB module for Arduino". Virtual store. October $2010 . \quad$ www.cookinghacks.com/index.php/shop/arduino/microsd-2gb-module-for arduino.html

[32] Libelium Communicaciones Distribuidas. "Cooking hacks: Documentation:Arduino Micro SD tutorial". Online product documentation. October 2010.www.cookinghacks.com/index.php/documentation/tutorials/arduinomicro-sd

[33] Sparkfun Electronics. "Product Info: ATmega328 -TQFP”. Online product information. December 20101. www.sparkfun.com/products/9261

[34] GigaNano. "Automatic Pill dispenser", e-pill medication reminders. Online website for medical device company. 2010. February 2011. www.epill.com/dispenser.html

[35] Andrew, D. InventorSpot. "uBox for Life: New Pillbox is lifesaver". February 2011.inventorspot.com/articles/ubox_life_new_pillbox_lifesaver_11119

[36] Arduino Playground. "Arduino time library". Publicly editable wiki about Arduino. October 2010. www.arduino.cc/playground/Code/Time

[37] Jason, rpcelectronics. Youtube. "Cadsoft Eagle Cad Tutorial". Online video for public. Nov. 2009. February 2011. www.youtube.com/ watch? $v=c B 5 Z \_$fRpLrE\&feature $=$related 
[38] Maxim. "Max 14502, High speed USB-to-SD card Readers with bypass". Online production information. 2010. November 2010. www.maximic.com/datasheet/index.mvp/id/6226

[39] Maxim. "Charging Batteries using USB Power". Online design support. June 2004. February 2011. www.maxim-ic.com/app-notes/index.mvp/id/3241

[40] Maxim. "Package land pattern". Online technical support. February 2011. pdfserver.maxim-ic.com/land_patterns/90-0055.PDF

[41] Craig, P. Beyond Logic. "USB in a Nut Shell". Online product information. September 2010. February. www.beyondlogic.org/usbnutshell/usb1.shtml.

[42] Markus, K. "A summary of the International standard date and time notation." Online article. December 2004. April 2011. http://www.cl.cam.ac.uk/ mgk25/isotime.html

[43] Ladyada. "PIC vs AVR". Online forum. March 2011. March 2011. http://www.ladyada.net/library/picvsavr.html

[44] Shalansky, S. J., A. R. Levy, and A. P. Ignaszewski, "Self-reported Morisky score for identifying nonadherence with cardiovascular medications," Ann Pharmacother, 2004; 38: 1363-8.

[45] Keram, S. and M. E. Williams, "Quantifying the ease or difficulty older persons experience in opening medication containers," J Am Geriatr Soc, 1988; 36: 198201

[46] Viartis. "Prevalence of Parkinson's Disease". Online site for information on Parkinson's disease.2010. March 2011. http://viartis.net/parkinsons.disease/prevalence.htm 
[47] Fauci, A. S. Harrison's Principle of Internal Medicine, 17e. (Eugene Braunwald, Dennis L. Kasper, Stephen L. Hauser, Dan L. Longo, J. Larry Jameson, and Joseph Loscalzo, Eds.) United States. The McGraw-Hill Companies, Inc. 2008.

[48] Sharp, M. and Dhome Limited. "Sinemet”. September 2007. October 2010. http://www.medsafe.govt.nz/profs/datasheet/s/Sinemettab.pdf

[49] Arduino. "Bootloader Development". Online product information. April 2011. http://arduino.cclen/Hacking/Bootloader

[50] Nystrom, P. “Nystrom Engineering: Packaging”. Nystrom Company Website. May 2011. http://www.nystromengineering.com/packaging.html

[51] Pregis. "Microfoam XFS". Food grade foam information online. May 2011. http://www.pregis.com/PregisHome/ProtectivePackaging/Microfoamsheetfoam/Mi crofoamXFSFoamFoodPackaging/FoamFoodPackaging/tabid/308/languagelenUS/Default.aspx 


\section{Appendix}

Components used on the PCB and their corresponding functions

\begin{tabular}{|c|c|c|}
\hline S.No. & $\begin{array}{l}\text { Component } \\
\text { on PCB }\end{array}$ & Function of component \\
\hline 1. & $\begin{array}{l}\text { Atmega328 } \\
\text { (U1) }\end{array}$ & Host microcontroller (AVR) \\
\hline 2. & Maxim 14502 & $\begin{array}{l}\text { High Speed USB to SD card reader with bypass. Bypass } \\
\text { chip that allows SD write by AVR in pass thru mode and } \\
\text { allows USB to read SD card in card read mode }\end{array}$ \\
\hline 3. & Max 8881 & $\begin{array}{l}\text { Low drop linear regulator capable of delivering } 200 \mathrm{~mA} \text {. } \\
\text { Used for reverse battery protection and longer battery life } \\
\text { because of its ultra low supply current }(3.5 \mu \mathrm{A})\end{array}$ \\
\hline 4. & $\begin{array}{l}\text { Max } 1555 \\
(\mathrm{IC} 1)\end{array}$ & $\begin{array}{l}\text { Dual input, USB/AC adapter charging chip. Used for } \\
\text { USB charging of the Li ion polymer batteries }\end{array}$ \\
\hline 5. & $\begin{array}{l}8 \mathrm{x} 1 \\
\text { Mux/Demux } \\
(\mathrm{IC} 2)\end{array}$ & $\begin{array}{l}\text { Uses } 3 \text { select lines to choose one of the } 8 \text { inputs and send } \\
\text { one output. The } 3 \text { select lines are connected to AVR and } \\
\text { the } 8 \text { input lines are connected to the switches. The AVR } \\
\text { selects inputs sequentially and the state of the switches } \\
\text { connected to the input lines are sent to the output which in } \\
\text { read by the AVR }\end{array}$ \\
\hline 6. & $8 \mathrm{MHz}$ Crystal & $\begin{array}{l}\text { Used for clocking the Atmega } 328 . \text { Value of } 8 \mathrm{MHz} \\
\text { chosen because the whole board uses a power supply of } \\
3.3 \mathrm{~V}\end{array}$ \\
\hline 7. & $\begin{array}{l}19.2 \mathrm{MHz} \\
\text { Crystal } \\
\text { oscillator (Q1) }\end{array}$ & Used for clocking the Maxim 14502 IC \\
\hline 8. & $\begin{array}{l}\text { P-channel } \\
\text { MOSFETs } \\
(\mathrm{P} 1 \text { \& P2) }\end{array}$ & $\begin{array}{l}\text { Act as a switch to pull up the lines connected to vibration } \\
\text { motor and buzzer to } 3.3 \mathrm{~V} \text {. Gates connected to AVR } \\
\text { which controls the switching of the MOSFETs }\end{array}$ \\
\hline 9. & $\begin{array}{l}\text { USB-micro B } \\
\text { connector } \\
(\mathrm{CF} 2)\end{array}$ & Connector for connecting a USB cable to the PCB \\
\hline 10. & $\begin{array}{l}\text { Resistor R1 } \\
(6.2 \mathrm{k} \Omega)\end{array}$ & $\begin{array}{l}\text { Bias resistor from the Reference resistor (RREF) pin on } \\
\text { Max } 14502 \text { IC to ground. Value taken from datasheet of } \\
\text { Max14502 IC }\end{array}$ \\
\hline
\end{tabular}




\begin{tabular}{|c|c|c|}
\hline 11. & $\begin{array}{l}\text { Resistor R2 } \\
(10 \mathrm{k} \Omega)\end{array}$ & $\begin{array}{l}\text { Pull up resistor connected to the RESET pin on AVR. } \\
\text { Keeps the reset pin high pulled high unless the reset } \\
\text { switch is closed }\end{array}$ \\
\hline 12. & $\begin{array}{l}\text { Resistor R3 } \\
(330 \Omega)\end{array}$ & $\begin{array}{l}\text { Protection resistor connected between the BERR! pin and } \\
\text { LED }\end{array}$ \\
\hline 13. & $\begin{array}{l}\text { Resistor R4 } \\
(330 \Omega)\end{array}$ & $\begin{array}{l}\text { Protection resistor connected between the BUSY! pin and } \\
\text { LED }\end{array}$ \\
\hline 14. & $\begin{array}{l}\text { Resistor R5 } \\
(47 \mathrm{k} \Omega)\end{array}$ & $\begin{array}{l}\text { Pull up resistor connected to the gate of PMOS (P1). The } \\
\text { resistors keeps the gate high unless the gate is written low } \\
\text { by the AVR }\end{array}$ \\
\hline 15. & $\begin{array}{l}\text { Resistor R6 } \\
(100 \mathrm{k} \Omega)\end{array}$ & $\begin{array}{l}\text { Pull up resistor connected to CHG! pin on Max1555 IC. } \\
\text { The resistor keeps the pin pulled high unless the AVR } \\
\text { writes a low. Value taken from Max } 1555 \text { datasheet }\end{array}$ \\
\hline 16. & $\begin{array}{l}\text { Resistor R7 } \\
(100 \mathrm{k} \Omega)\end{array}$ & $\begin{array}{l}\text { Pull up resistor connected to the output pin of } \\
\text { multiplexer. Keeps the line pulled up high by default } \\
\text { unless it is pulled down by the input selected }\end{array}$ \\
\hline 17. & $\begin{array}{l}\text { Resistor R8 } \\
(47 \mathrm{k} \Omega)\end{array}$ & $\begin{array}{l}\text { Pull down resistor connected to the output enable (OE) } \\
\text { pin of crystal oscillator. It keeps the enable pin pulled low } \\
\text { unless the AVR writes a high to it. This was used to save } \\
\text { power consumption by turning the crystal oscillator only } \\
\text { when needed }\end{array}$ \\
\hline 18. & $\begin{array}{l}\text { Resistor R11 } \\
(1 \mathrm{k} \Omega)\end{array}$ & $\begin{array}{l}\text { Voltage divider resistor connected to the power pin of } \\
\text { USB connector }\end{array}$ \\
\hline 19 & $\begin{array}{l}\text { Resistor R13 } \\
(10 \mathrm{k} \Omega)\end{array}$ & $\begin{array}{l}\text { Pull up resistor connected between HCRD_PRST pin on } \\
\text { Max } 14502 \text { IC and pin } 28 \text { (PC5) on AVR. The AVR } \\
\text { writes a high to it pulling that pin high }\end{array}$ \\
\hline 20. & $\begin{array}{l}\text { Resistor R14 } \\
(330 \Omega)\end{array}$ & $\begin{array}{l}\text { Pull down resistor connected to USB bus power supply } \\
\text { detection (KVBUS) pin on Max14502 IC }\end{array}$ \\
\hline 21. & $\begin{array}{l}\text { Resistor R15 } \\
(1 \mathrm{k} \Omega)\end{array}$ & $\begin{array}{l}\text { Voltage divider resistor connected to the power pin of } \\
\text { USB connector }\end{array}$ \\
\hline 22. & $\begin{array}{l}\text { Resistor R16 } \\
(47 \mathrm{k} \Omega)\end{array}$ & Pull down resistor connected to HDAT pin on Max 14502 \\
\hline 23. & $\begin{array}{l}\text { Resistor R17 } \\
(47 \mathrm{k} \Omega)\end{array}$ & Pull down resistor connected to HDAT pin on Max 14502 \\
\hline 24. & $\begin{array}{l}\text { Resistor R18 } \\
(47 \mathrm{k} \Omega)\end{array}$ & $\begin{array}{l}\text { Pull up resistor connected to the gate of PMOS (P2). The } \\
\text { resistors keeps the gate high unless the gate is written low } \\
\text { by the AVR }\end{array}$ \\
\hline 25. & $\begin{array}{l}\text { Resistor R20 } \\
(330 \Omega)\end{array}$ & $\begin{array}{l}\text { Voltage divider resistor between USB and KVBUS line } \\
\text { on Max } 14502\end{array}$ \\
\hline 26. & $\begin{array}{l}\text { Capacitor C1 } \\
(0.1 \mu \mathrm{F})\end{array}$ & $\begin{array}{l}\text { Bypass capacitor connected between AREF pin on AVR } \\
\text { and ground }\end{array}$ \\
\hline 27. & $\begin{array}{l}\text { Capacitor C2 } \\
(0.1 \mu \mathrm{F})\end{array}$ & $\begin{array}{l}\text { Bypass capacitor connected between the Reset pin on the } \\
\text { VAR and the DTR pin on FTDI pin connector. Value } \\
\text { taken from Arduino Pro board eagle files }\end{array}$ \\
\hline
\end{tabular}




\begin{tabular}{|c|c|c|}
\hline 28. & $\begin{array}{l}\text { Capacitor C3 } \\
(0.1 \mu \mathrm{F})\end{array}$ & $\begin{array}{l}\text { Bypass capacitor between power pins on AVR and } \\
\text { ground }\end{array}$ \\
\hline 29. & $\begin{array}{l}\text { Capacitor C4 } \\
(18 \mathrm{p} \mathrm{F})\end{array}$ & $\begin{array}{l}\text { Shunt capacitor between the } 8 \mathrm{Mhz} \text { crystal connected to } \\
\text { XTAL pin on AVR and ground }\end{array}$ \\
\hline 30. & $\begin{array}{l}\text { Capacitor C5 } \\
(0.1 \mu \mathrm{F})\end{array}$ & $\begin{array}{l}\text { Bypass capacitor connected between VTM (USB Analog } \\
\text { switch and Transceiver power supply) pin on Max14502 } \\
\text { IC and ground. Value taken from Max14502 datasheet }\end{array}$ \\
\hline 31. & $\begin{array}{l}\text { Capacitor C6 } \\
(1 \mu \mathrm{F})\end{array}$ & $\begin{array}{l}\text { Bypass capacitor for internal 1.8V LDO. Value taken } \\
\text { from Max } 14502 \text { datasheet }\end{array}$ \\
\hline 32. & $\begin{array}{l}\text { Capacitor C7 } \\
(1 \mathrm{n} \mathrm{F})\end{array}$ & $\begin{array}{l}\text { Bypass capacitor connected between the power supply pin } \\
\text { on USB connect and AVR pin } 24 \text { (PC1) and ground. }\end{array}$ \\
\hline 33. & $\begin{array}{l}\text { Capacitor C8 } \\
(1 \mu \mathrm{F})\end{array}$ & $\begin{array}{l}\text { Bypass capacitor to ground connected to the BAT pin on } \\
\text { Max } 1555 \text { and IN pin on Max } 8881 \text {. Value taken from } \\
\text { Maxim documents for battery charging circuits }\end{array}$ \\
\hline 34. & $\begin{array}{l}\text { Capacitor C9 } \\
(4.7 \mu \mathrm{F})\end{array}$ & $\begin{array}{l}\text { Bypass capacitor ground connected on the OUT and FB } \\
\text { pin of Max } 8881 \text {. Value taken from Maxim battery } \\
\text { charging circuits document }\end{array}$ \\
\hline 35. & $\begin{array}{l}\text { Capacitor C10 } \\
(0.1 \mu \mathrm{F})\end{array}$ & $\begin{array}{l}\text { Bypass capacitor to ground connected to the power pins } \\
\text { invoked on Mux IC }\end{array}$ \\
\hline 36. & $\begin{array}{l}\text { Capacitor C11 } \\
(0.1 \mu \mathrm{F})\end{array}$ & $\begin{array}{l}\text { Bypass capacitor to ground connected on the power pin of } \\
\text { USB connector and the CCRD_PRST (Card present } \\
\text { detection) pin on Max14502 IC }\end{array}$ \\
\hline 37. & $\begin{array}{l}\text { Capacitor } \mathrm{C} 12 \\
(1 \mu \mathrm{F})\end{array}$ & $\begin{array}{l}\text { Bypass capacitor to ground on the SD card voltage (VSD) } \\
\text { pin of Max14502 IC. Value taken from Max } 14502 \\
\text { datasheet }\end{array}$ \\
\hline 38. & $\begin{array}{l}\text { Capacitor C13 } \\
(18 \mathrm{p} \mathrm{F})\end{array}$ & $\begin{array}{l}\text { Shunt capacitor between the 8Mhz crystal connected to } \\
\text { XTAL pin on AVR and ground }\end{array}$ \\
\hline 39. & $\begin{array}{l}\text { Capacitor } \mathrm{C} 14 \\
(1 \mu \mathrm{F})\end{array}$ & $\begin{array}{l}\text { Bypass capacitor to ground on the digital supply voltage } \\
\text { (VCC) pin of Max } 14502 \text { IC. Value taken from Max } 14502 \\
\text { datasheet }\end{array}$ \\
\hline 40. & $\begin{array}{l}\text { Capacitor C15 } \\
(10 \mu \mathrm{F})\end{array}$ & $\begin{array}{l}\text { Bypass capacitor to ground connected to the power pin on } \\
\text { SD card socket }\end{array}$ \\
\hline 41. & $\begin{array}{l}\text { Capacitor C16 } \\
(0.1 \mu \mathrm{F})\end{array}$ & $\begin{array}{l}\text { Bypass capacitor to ground connected to the reset input } \\
\text { (RST!) pin and I/O logic level transistor voltage (VIO) } \\
\text { pin on Max } 14502 \text { IC. Value taken from Max } 14502 \\
\text { datasheet }\end{array}$ \\
\hline 42. & $\begin{array}{l}\text { Capacitor C17 } \\
(0.1 \mu \mathrm{F})\end{array}$ & $\begin{array}{l}\text { Bypass capacitor to ground connected to the power pin of } \\
\text { the } 19.2 \mathrm{MHz} \text { crystal oscillator }\end{array}$ \\
\hline 43. & $\begin{array}{l}\text { Capacitor C18 } \\
(0.1 \mu \mathrm{F})\end{array}$ & $\begin{array}{l}\text { Bypass capacitor to ground connected on the invoked pins } \\
\text { of the USB connector }\end{array}$ \\
\hline 44. & $\begin{array}{l}\text { Vibration } \\
\text { Motor }\end{array}$ & $\begin{array}{l}\text { Connected to the digital pin } 7 \text { on AVR, vibration motor } \\
\text { was used to act as vibrating alarm reminder }\end{array}$ \\
\hline 45. & Magnetic & Connected to digital pin 6 (PWM) on AVR, buzzer was \\
\hline
\end{tabular}




\begin{tabular}{|c|c|c|}
\hline & Buzzer & used to act as audio alarm reminder \\
\hline 46. & 50 gf switches & $\begin{array}{l}\text { A total of } 32 \text { switches, with a set of four under each } \\
\text { compartment was placed to detect the physical presence } \\
\text { of pills in each compartment }\end{array}$ \\
\hline 47 & $\begin{array}{l}\text { Hirose Micro } \\
\text { SD card } \\
\text { socket }\end{array}$ & $\begin{array}{l}\text { Used for holding the SD card in place and for making the } \\
\text { right connections to the AVR and Maxim } 14502 \text { IC }\end{array}$ \\
\hline 48. & Green LEDs & $\begin{array}{l}\text { LEDs connected to BERR! and BUSY! pins on } \\
\text { Max } 14502 \text { to indicate whether there is an error in card } \\
\text { read mode and whether the Max } 14502 \text { IC is busy or not. } \\
\text { The LEDs goes high in either of the case. }\end{array}$ \\
\hline 49. & $\begin{array}{l}\text { Li ion } \\
\text { Polymer } \\
\text { rechargeable } \\
\text { batteries }\end{array}$ & $\begin{array}{l}\text { Two } 3.7 \mathrm{~V}, 40 \mathrm{mAh} \mathrm{Li}+\text { polymer rechargeable batteries } \\
\text { were connected in between the Max } 1555 \text { and Max } 8881 \\
\text { ICs to provide a constant } 3.3 \mathrm{~V} \text { supply to the PCB }\end{array}$ \\
\hline 50. & $\begin{array}{l}\text { Diodes } \\
\text { (D1,D2) }\end{array}$ & $\begin{array}{l}\text { Unidirectional diodes were connected to the motor and } \\
\text { buzzer for reverse current protection }\end{array}$ \\
\hline
\end{tabular}

